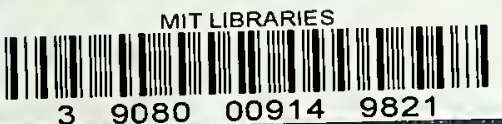




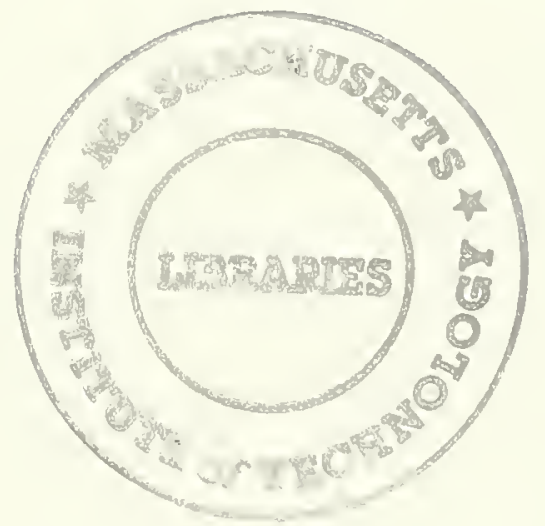





\section{Digitized by the Internet Archive in 2011 with funding from}

Boston Library Consortium Member Libraries 


\section{working paper department \\ of economics}

VERTICAL INTEGRATION AND MARKET FORECLOSURE

$$
\begin{aligned}
& \text { Oliver Hart } \\
& \text { Jean Tirole }
\end{aligned}
$$

No. 548

$$
\text { April } 1990
$$

\section{massachusetts institule of technology}

50 memorial drive cambridge, mass. 02139 


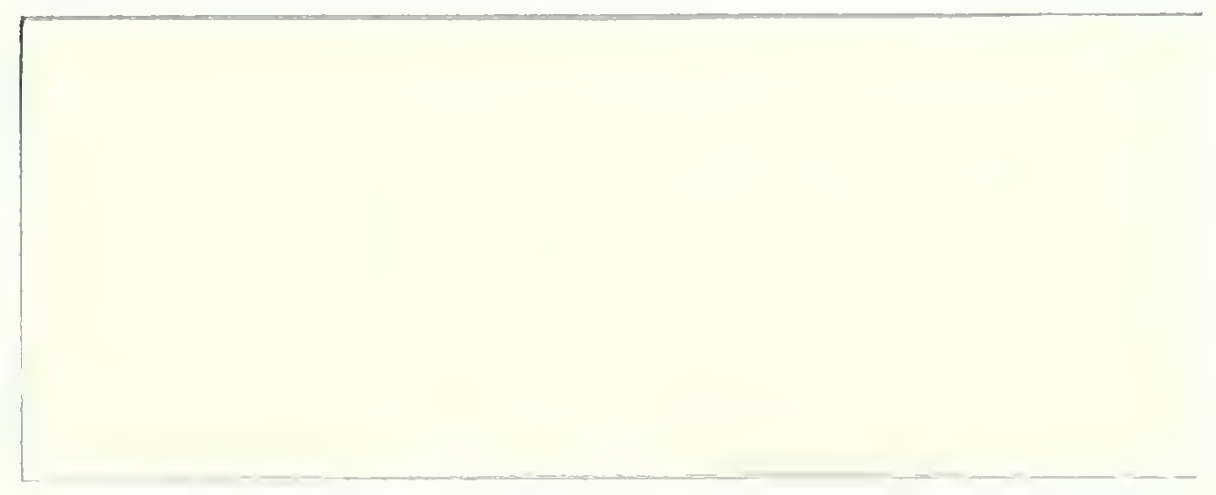


VERTICAL INTEGRATION AND MARKET FORECLOSURE

Oliver Hart

Jean Tirole

No. 548

April 1990 


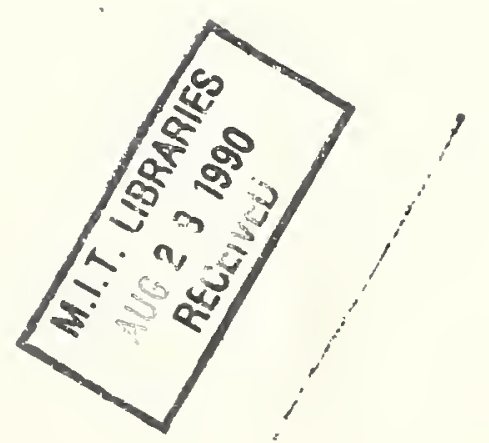




\title{
VERTICAL INTEGRATION AND \\ MARKET FORECLOSURE
}

\author{
By OLIVER HART \\ AND \\ JEAN TIROLE
}

APRIL 1990

No. 548 



\section{VERTICAL INTEGRATION AND MARKET FORECLOSURE ${ }^{1}$}

BY

OLIVER HART

AND

JEAN TIROLE

[DECEMBER 1989, REVISED APRIL 1990]

1. Introduction.

Few people would disagree with the proposition that horizontal mergers have the potential to restrict output and raise consumer prices. In contrast, there is much less agreement about the anti-competitive effects of vertical mergers. Some commentators have argued that a purely vertical merger will not affect a firm's monopoly power, since a merger of an upstream and a downstream firm, each of which controls, say, 10 of its respective market, does not change market shares: other firms continue to possess 90 s of each market after the merger just as before. ${ }^{2}$ others have responded by developing models in which vertical integration can lead to the foreclosure of competition in upstream or downstream markets. These models, however,

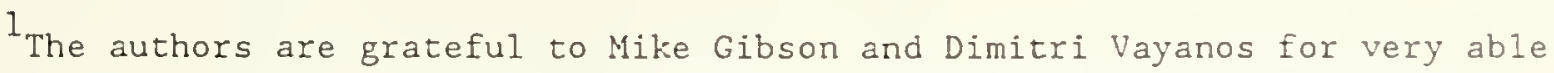
research assistance; and to Steve Salop, Mike Whinston, Richard Zeckhauser and the discussants for helpful comments, and to the MIT Energy Lab, the Guggenheim Foundation, the Olin Foundation, the National Science Foundation, the Taussig Visiting Professorship at Harvard and the Marvin Bower Fellowship at Harvard Business School, for financial support for the period over which this research was conducted.

${ }^{2}$ See, in particular, Bork (1978).
} 
rely on particular assumptions about contractual arrangements between

nonintegrated firms (e.g. that pricing must be linear), or about the ability of integrated firms to make commitments (e.g. that an integrated supplier can commit not to undercut a rival). Thus at this stage the debate about the conditions under which vertical mergers are anti-competitive is far from settled.

The purpose of this paper is to develop a theoretical model showing how vertical integration changes the nature of competition in upstream and downstream markets and identifying conditions under which market foreclosure will be a consequence and/or a purpose of such integration. In contrast to much of the literature, we do not restrict upstream and downstream firms to particular contractual arrangements, but instead allow firms to choose from a full set of contractual arrangements both when integrated and when not (so, for example, two part tariffs are permitted). ${ }^{3}$ We also allow non-integrated firms to respond optimally to the integration decisions of other firms, either by remaining nonintegrated, exiting the industry or integrating too (i.e. bandwagoning). In Section 7 we use our analysis to shed some light on a number of prominent vertical merger cases, involving computer reservation systems for airlines, the cement industry, and the St. Louis Terminal Railroad.

We follow the recent literature on ownership and residual control rights in the way we formalize vertical integration. We assume that the upstream and downstream firms do not know ex-ante which type of intermediate

\footnotetext{
3 This means that the elimination of the double marginalization of prices is not a motive for integration in our model. For a discussion of this issue, see Tirole [1988].
} 
good will be the appropriate one to trade in the future and that the large number of potential types makes it too costly to write contingent forward contracts ex-ante. As a result, the only way to influence ex-post behavior is through the allocation of residual rights of control over assets (as in Grossman-Hart (1986)). ${ }^{4}$ Moreover, we take the point of view that the shift in residual control rights that occurs under integration permits profitsharing between upstream and downstream units and that as a consequence all conflicts of interest about prices and trading policies are removed. In this respect, vertical integration does not differ formally from a profit-sharing scheme between independent contractors. Profit-sharing may be difficult to implement in the absence of integration, however, because independent units can divert money and misrepresent profits. In contrast, the owner of a subordinate unit, because he has residual righis of control over the unit's assets, may be able to prevent diversion and enforce profit-sharing. 5

${ }^{4}$ For discussions of how this approach compares with others on integration, see Hart [1989] and Holmström-Tirole [1989a].

${ }^{5}$ On this, see Williamson [1985], and, for formal models, hart [1988]. Hölmstrom-Tirole [1989a] and Riordan [1989]. As an (extreme) example, consider an independent unit A that has signed a profit-sharing agreement with another firm B. One way A can misrepresent and divert its profits is by purchasing a (possibly useless) input at an inflated price from another company in which A's owners have an interest. It may be hard for B to write an enforceable contract ex-ante to prevent such a diversion, even though $B$ may be well aware of the practice ex-post (the information that the input is over-priced is observable, but not verifiable). On the other hand, if $A$ and $B$ are integrated, $B$ can ex-post refuse $A^{\prime} s$ managers permission to spend company resources on the expensive input, thus effectively blocking the transaction. (This is because $B$ now possesses residual rights of control over company $A^{\prime} s$ resources by virtue of integration.)

Of course, diversion problems are not completely eliminated by integration. In particular, if $B$ owns $A, B$ can use its residual control rights to divert money from $A$. Note, however, that as long as $B$ diverts on a proportionate basis from both units $A$ and $B$.. and as long as this diversion is less than 1008 -. A's subordinate manager can be given a compensation package which is some iraction of $A$ and $B^{\prime} s$ joint profit. Given this, $A^{\prime} s$ 
Although integration removes conflicts of interest over pricing and trading policies, it is accompanied by costs. First, after integration, a subordinate manager may have lower ex-ante incentives to come up with productive ideas to reduce production costs or to raise quality because this investment is expropriated ex-post by the owner of the firm. 6 Second, there may be a loss in information about the subordinate's performance, and therefore lower incentives to make ex-ante or ex-post improvements, because vertical integration reduces or eliminates the fluidity of the market for the stock of the now subordinate unit. 7 Third, there may be legal costs associated with the merger. We do not explicitly formalize these costs of integration, although it is easy to do so. Instead for our purposes it will be enough to represent them by a fixed amount $\mathrm{E}$.

subordinate manager will have an incentive to choose pricing and trading policies that are in the interest of the company as a whole.

Note that another argument can be given as to why a merger reduces conflicts of interest over prices and trading policies. Under integration, a subordinate manager will act in the interest of the parent company since otherwise he or she will be dismissed. In contrast the pressure on the manager of an independent unit to act in the interest of another independent contractor is less since the only sanction available to the independent contractor is to sever the whole relationship with the unit (i.e. the contractor can't fire the unit's manager alone). On this, see Hart and Moore (1988).

${ }^{6}$ See Grossman-Hart [1986] or Hart-Moore [1988]. We assume that effort costs cannot be reimbursed as part of a profit-sharing scheme.

7

See Holmström-Tirole [1989b]. 
1a. Description of the Model

Our basic model consists of two potential suppliers or upstream firms $\left(\mathrm{U}_{1}\right.$ and $\mathrm{U}_{2}$ ) and two potential buyers or downstream firms $\left(\mathrm{D}_{1}\right.$ and $\left.\mathrm{D}_{2}\right)$. $^{8}$ The downstream firms compete on the product market and sell perfect substitutes. The upstream firms produce the same intermediate good at constant (although possibly different) marginal costs, $c_{1}, c_{2}$, subject possibly to a capacity constraint.

We will in fact develop three variants of the basic model, each of which illustrates a different motive for integration. Variant one (which we call Ex-Post Monopolization) focusses on the incentive of a relatively efficient upstream firm to merge with a downstream firm in order to restrict output in the downstream market. To understand the idea, consider the special case where one of the upstream firms, $U_{2}$ say, has infinite marginal cost. It is sometimes claimed that in this case $U_{1}$ would never have an incentive to merge with a downstream firm, $D_{1}$ say, since $U_{1}$ is already a monopolist in the upstream market. "We argue that this claim is false unless (enforceable) exclusive dealing contracts are feasible (or unless $U_{1}$ 's offers to $\mathrm{D}_{1}$ and $\mathrm{D}_{2}$ are public). In particular, in the absence of exclusive dealing contracts, $U_{1}$ has an incentive to supply both $D_{1}$ and $D_{2}$ and, in so doing, to produce more than the monopoly output level. For example, suppose $U_{1}$ tries to monopolize the downstream market by selling the monopoly output $q^{m}$ to $D_{1}$

\footnotetext{
8 The model could easily be generalized to the case of more than two upstream or downstream firms, however.

${ }^{9}$ For example, as Posner and Easterbrook (1981, p.870) have written: "[T]here is only one monopoly profit to be made in a chain of production".
} 
for a lump-sum fee equal to monopoly profit. It is not an equilibrium for D 1 to accept such an offer since $D_{1}$ knows that $U_{1}$ has an incentive to sell an additional amount to $D_{2}$, thus causing $D_{1}$ to make a loss. On the other hand, suppose $U_{1}$ tries to monopolize the downstream market by offering $\frac{1}{2} q^{m}$ to each of $D_{1}, D_{2}$ at a fee equal to half of monopoly profit. It is not an equilibrium for $U_{1}$ to make and $D_{1}, D_{2}$ to accept these offers either, because if $D_{1}$, say, is expected to accept, $\mathrm{U}_{1}$ has an incentive to increase its supply to $\mathrm{D}_{2}$ above $\frac{1}{2} q^{m}$, and $D_{1}$ again makes a loss.

Integration can be a way round the inability of $U_{1}$ to restrict output. If $\mathrm{U}_{1}$ and $\mathrm{D}_{1}$ merge, $\mathrm{U}_{1}$ has no incentive to supply $\mathrm{D}_{2}$ anymore. The reason is that under integration $\mathrm{U}_{1}$ and $\mathrm{D}_{1}$ 's profits are shared and every unit sold to $\mathrm{D}_{2}$ reduces $\mathrm{U}_{1}-\mathrm{D}_{1}^{\prime}$ 's combined profit by depressing price. Thus the unique equilibrium now is for $U_{1}$ to supply $q^{m}$ to $D_{1}$ and zero to $D_{2}$.

One might ask why $\mathrm{U}_{1}$ could not achieve the same outcome by writing an exclusive dealing contract with $D_{1}$. There are several answers to this. First, exclusive dealing may be unenforceable for informational reasons. In particular, it may be difficult for $D_{1}$ to monitor and/or control shipments by $\mathrm{U}_{1}$ to other parties without having residual rights of control over $\mathrm{U}_{1}$ 's assets (including buildings, trucks, inventories). And even if shipments can be monitored, if there are third parties outside the industry with whom $U_{1}$ can realize gains from trade and who could bootleg $U_{1}$ 's product to $D_{2}$, then a strict enforcement of exclusive dealing requires not trading with these third parties, which may prove costly. Second, exclusive dealing may be unenforceable for legal reasons: the courts have taken a harsh stance on those exclusive dealing contracts they think may result in foreclosure. 
In addition, we shall see that exclusive dealing, even if it is

feasible, is not generally a perfect substitute for integration. 10 In particular, if $\mathrm{U}_{2}$ 's supply costs are finite rather than infinite, then it is no longer optimal for an integrated $U_{1}-D_{1}$ pair not to supply $D_{2}$ at all. Instead $U_{1}-D_{1}$ will want to offer $D_{2}$ the same amount that $U_{2}$ would offer $D_{2}$, but at a slightly lower price (see Section 3). An exclusive dealing contract will not achieve this. Moreover, a contract that limits the anount that $U_{1}$ can sell $D_{2}$ may be very difficult to enforce: given that $U_{1}$ is supplying $D_{2}$ anyway, it may be hard for $D_{1}$ to verify that supplies equal 100, say, rather than 200. 11 Integration avoids this problem: profit-sharing between $U_{1}$ and $D_{1}$ means that $U_{1}$ automatically finds it in its interest to supply the profit-maximizing level (and quality of service) to $D_{2}$.

In extensions of this first variant, we consider the possibility that it is not known in advance whether $U_{1}$ or $U_{2}$ is the more efficient supplier, and that the upstream and downstream fixms must make ex-ante industxy-specific investments prior to trading ex-post. We show that the more efficient (in a stochastic sense) upstream firm will have a greater incentive to merge to monopolize the market ex-post. Also, if $U_{1}-D_{1}$ merge, $D_{2}$ 's profits will typically fall since if $U_{1}$ turns out to be the more efficient firm ex-post, $U_{1}$ will channel supplies towards $D_{1}$ at the expense of $\mathrm{D}_{2}$. This fall in $\mathrm{D}_{2}$ 's profits may cause it to stop investing (or exit the industry). To the extent that exit by $\mathrm{D}_{2}$ reduces $\mathrm{U}_{2}$ 's profit by lowering the total demand for its product, $\mathrm{U}_{2}$ may have an incentive to rescue $\mathrm{D}_{2}$ by

\footnotetext{
${ }^{10}$ An analysis of exclusive dealing contracts is contained in Appendix 3.

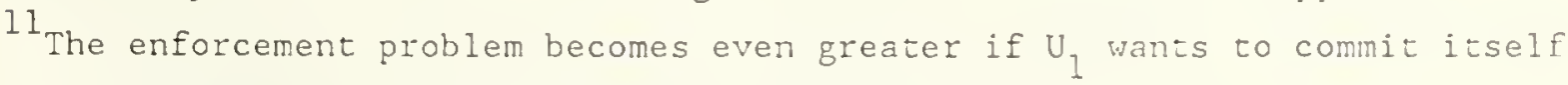
not to supply $\mathrm{D}_{2}$ with quality of service above $\mathrm{U}_{2}$ 's.
} 
merging with it and paying part of its investment cost (via profii-sharing). In other words, bandwagoning may occur.

This first variant assumes that upstream firms engage in Bertrand competition in the price/quantity offers they make to downstream firms. Our second variant (which we call Scarce Needs) supposes instead that upstream and downstream firms bargain over the gains from trade in such a way that each upstream firm obtains on average a positive share of these gains. In addition we now assume for simplicity that $c_{1}=c_{2}$ : the upstream firms are equally efficient.

Under these conditions, there is a new motive for integration: an upstream firm may merge with a downstream firm to ensure that the downstream firm purchases its supplies from this upstream firm rather than from others. In particular, if $U_{1}-D_{1}$ merge, then, rather than $D_{1}$ sometimes buying input from $U_{1}$ and sometimes from $U_{2}$ as under nonintegration, $D_{1}$ will now buy all its input all the time from its partner $U_{1}$. Thus $U_{1}$ gains a valuable trading opportunity and $\mathrm{U}_{2}$ loses one. ("Scarce Needs" refers to the fact that $\mathrm{D}_{1}$ and $\mathrm{D}_{2}$ have limited input reouirements.)

If $\mathrm{U}_{2}$ remains in the industry (continues to invest), the only effect of the merger is to increase $\mathrm{U}_{1}-\mathrm{D}_{1}^{\prime}$ 's share of industry profit and reduce $\mathrm{U}_{2}-$ $D_{2}^{\prime}$ s. In particular, there is no ex-post monopolization effect in this second variant: given that $U_{2}$ is as efficient as $U_{1}$, there is no reason for $\mathrm{U}_{1}$ to restrict its supplies to $\mathrm{D}_{2}$ since $\mathrm{U}_{2}$ will make up the difference anyway. However, if the reduction in $\mathrm{U}_{2}$ 's profit causes $\mathrm{U}_{2}$ to quit the industry, this leaves $U_{1}$ as the only supplier (we refer to this as ex-ante monopolization) and, given that it is merged with $D_{1}, U_{1}$ will be able to use this power to completely monopolize the market ex-post (as part of a merged 
firm it has no incentive to supply $\mathrm{D}_{2}$ ). Thus total quantity supplied will

fall and the price consumers pay will rise.

Bandwagon does not occur in equilibrium in this second variant.

However, $\mathrm{U}_{2}-\mathrm{D}_{2}$ may try to pre-empt $\mathrm{U}_{1}-\mathrm{D}_{1}$ by merging first. We show that in real time the lower investment cost upstream firm will win this pre-emption game by merging prematurely.

Our last variant reverses the role of upstream and downstream firms (and goes under the heading of Scarce Supplies). Now we suppose that the upstream firms are capacity-constrained relative to downstream firms' needs, with upstream and downstream firms again bargaining over the terms of trade. Under these conditions, a third incentive to integrate arises: a downstream firm and an upstream firm may merge to ensure that the upstream firm channels its scarce supplies to its downstream partner rather than to other downstream firms.

- If $\mathrm{U}_{1}-\mathrm{D}_{1}$ merge, $\mathrm{D}_{2}$ suffers, since under nonintegration $\mathrm{D}_{2}$ obtains some profit from being able to purchase $U_{I}$ 's supplies, whereas under integration $U_{1}$ channels all its supplies to $D_{1}$. The fall in $D_{2}$ 's profit may cause $\mathrm{D}_{2}$ to quit the industry. In this case, $\mathrm{U}_{2}$ 's profit will also fall since $U_{2}$ faces only one purchaser for its output: $D_{1}$. Hence $U_{2}$ may in turn cease to invest. If this happens, capacity will be eliminated from the market, consumer price will rise, and the effect of the $U_{1}-D_{1}$ merger will have been to monopolize the market ex-ante.

In order to avoid exit by $\mathrm{D}_{2}, \mathrm{U}_{2}$ may merge with it. Thus, as in the first variant, bandwagon is a possible outcome. Also $\mathrm{U}_{2}-\mathrm{D}_{2}$ may try to pre-empt $U_{1}-D_{1}$ by merging first. We show that pre-emption game will lead to premature merger by $U_{1}-D_{1}$ or $U_{2}-D_{2}$. 
A sumnary of our three variants is given in Chart 1:

\begin{tabular}{|c|c|c|c|}
\hline & $\begin{array}{c}\text { Ex-post } \\
\text { Monopolization }\end{array}$ & Scarce Needs & Scarce Supplies \\
\hline $\begin{array}{l}\text { Output contraction } \\
\text { Bargaining effect }\end{array}$ & $\sqrt{ }$ & $\checkmark$ & $\sqrt{ }$ \\
\hline $\begin{array}{l}\text { Possible } \\
\text { circumstances }\end{array}$ & $\begin{array}{l}\text { No capacity con- } \\
\text { straints upstream } \\
\text { and downstream }\end{array}$ & $\begin{array}{l}\text { Downturn in } \mathrm{D} \\
\text { industry, or ex- } \\
\text { cess capacity in } \\
U \text { industry }\end{array}$ & $\begin{array}{l}\text { Downturn in } U \\
\text { industry, or ex- } \\
\text { cess capacity in D } \\
\text { industry }\end{array}$ \\
\hline $\begin{array}{l}\text { Direct victim of } \\
\text { vertical integra- } \\
\text { tion }\end{array}$ & Unintegrated D & Unintegrated $\mathrm{U}$ & Unintegrated D \\
\hline $\begin{array}{l}\text { Indirect victim } \\
\text { (if direct victim } \\
\text { exits) }\end{array}$ & $\begin{array}{l}\text { Unintegrated U } \\
\text { (under certain } \\
\text { conditions) }\end{array}$ & Unintegrated D & Unintegrated U \\
\hline $\begin{array}{l}\text { Trade between in- } \\
\text { tegrated unit and } \\
\text { unintegrated } \\
\text { direct victim? }\end{array}$ & $\begin{array}{l}\text { Yes (but price } \\
\text { squeeze) }\end{array}$ & $\mathrm{No}^{a}{ }^{\mathrm{l}}$ & $\mathrm{No}^{\mathrm{b}}{ }^{\mathrm{f}}$ \\
\hline $\begin{array}{l}\text { Incentive to inte- } \\
\text { grate larger for: }\end{array}$ & $\begin{array}{l}\text { More efficient U } \\
\text { firm }\end{array}$ & $\begin{array}{l}\text { More efficient D } \\
\text { firm }\end{array}$ & Larger U firm \\
\hline $\begin{array}{l}\text { Possible industry } \\
\text { structures }\end{array}$ & $\begin{array}{l}\text { Non integration; } \\
\text { partial integra- } \\
\text { tion; bandwagon; } \\
\text { integration and } \\
\text { exit (downstream } \\
\text { or downstream and } \\
\text { upstream) }\end{array}$ & $\begin{array}{l}\text { Non integration; } \\
\text { integration and } \\
\text { exit (upstream, } \\
\text { or upstream and } \\
\text { downstream) }\end{array}$ & $\begin{array}{l}\text { Non integration; } \\
\text { partial integra- } \\
\text { tion; bandwagon; } \\
\text { integration and } \\
\text { exit (downstream } \\
\text { or downstream and } \\
\text { upstream) }\end{array}$ \\
\hline
\end{tabular}

a) As long as integrated $U$ does not operate at full capacity. Otherwise the integrated $D$ may still buy some supplies from unintegrated $U$.

b) As long as integrated D does not operate at full capacity. Otherwise, the integrated $U$ may sell some of $i$ is supplies to a nonintegrated $D$.

c) If the downstream firms have the same demands. If they have different demands, say, because they have different storage or marketing facilities, then the same industry structures as in the scarce supplies case may emerge. 
Our theory has a number of implications for the welfare analysis of vertical mergers. In our model, there are three sources of social loss from mergers and two sources of social gain. First, in variant one, a merger by $U_{1}$ - $D_{1}$ raises consumer prices to the extent that it allows $U_{1}-D_{1}$ to monopolize the market ex-post. This reduces the sum of consumer and producer surplus for the usual reasons. Second, in all three variants of the model, a merger by $U_{1}$ - $D_{1}$ may cause exit by either $U_{2}, D_{2}$ or both. This ex-ante monopolization effect again gives $U_{1}-D_{1}$ greater market power ex-post, causing consumer prices to rise and consumer plus producer surplus to fall. Third, mergers involve incentive and legal costs, which we have represented by a fixed amount E.

Offsetting these losses are two potential gains from mergers. First, a merger by $\mathrm{U}_{1}-\mathrm{D}_{1}$ that causes exit by $\mathrm{U}_{2}$ and/or $\mathrm{D}_{2}$ leads to a saving in investment costs. To the extent that these costs were incurred by $\mathrm{U}_{2}$ and $\mathrm{D}_{2}$ to increase their aggregate profic at the expense of $U_{1}-D_{1}$, with no price effects, this represents a social gain. In other words, a merger-induced exit can be beneficial to the extent that it leads to a reduction in rent-seeking behavior.

Second, there may be pure efficiency gains from mergers. In all three variants of the model, upstream and downstream firms make ex-ante investments. Although these investments are taken to be industry-specific, given that the industry is imperfectly competitive, they have many of the characteristics of the relationship-specific investments emphasized by 
Williamson (1975, 1985) and Klein, Crawford and Alchian (1978) (see also Grossman and Hart (1986)). In particular, an upstream firm, say, might be unwilling to invest given that the absence of a perfectly competitive market for its product can cause it to be held up. Thus one motive for a merger between an upstream and downstream firm may be to encourage investments by reducing such hold-up problems. A merger carried out for these reasons will increase competition and reduce consumer prices. (For simplicity, our formal model supposes that firms are prepared to invest under nonintegration and so hold-up problems are not a notive for merger; it would be easy to relax this assumption however.)

Given these conflicting welfare effects, it is hard to come up with clear-cut prescriptions for anti-trust policy towards vertical mergers. Any industry in which investments are industry-specific rather than relationship-specific (the various cases we consider in Section 7 all fit into this category) is either competitive - - in which case neither hold-up nor foreclosure effects should be important and vertical mergers should be irrelevant; or imperfectly competitive - - in which case both hold-up and foreclosure effects are potentially important and it is hard to distinguish between the two. Our theory can, however, give some guidance as to when the foreclosure effects are likely to be significant and the onus should be on the merging firms to show that there are substantial efficiency gains offsetting the anti-competitive effects. According to our models, restriction of competition is most likely to be a factor when the merging firms are efficient (have low marginal costs or investment costs) or are large (have high capacities) relative to non-merging firms. Since there is no strong reason to think that hold-up problems will be more serious for efficient or large firms, 
the theory suggests that vertical mergers involving efficient or large firms should be subject to particular scrutiny by the anti-trust authorities.

In addition, the theory suggests that the anti-trust authorities should only be suspicious of vertical mergers that significantly harm rivals (possibly causing exit). Thus a merger between an upstream and a downsteam firm that have had substantial dealings with outside firms is potentially more damaging than one between firms that have primarily traded with each other since, in the latter case, the foreclosure effect on rivals will be sma11.

The paper is organized as follows. The model is described in Section 2. The first variant is explored in Sections 3 and 4, the second in Section 5 and the third in Section 6. (Section 4 is considerably more involved than the other sections and the reader may well wish to skip this on first reading.) Section 7 applies the analysis to various industries and section 8 relates our work to the literature - - in particular to the paper of Ordover, Saloner and Salop [OSS, 1990]. We argue that their model is concerned more vith the use of different types of exclusive dealing contracts to restrict competition than with vertical integration per se. In addition our predictions about which mergers will occur differ from OSS's in a number of important ways. Finally, the appendices contain technical material and an analysis of exclusive dealing contracts.

2. The model.

There are two potential suppliers or upstream firms ( $U_{1}$ and $U_{2}$ ) and two potential buyers or downstream firms $\left(D_{1}\right.$ and $\left.D_{2}\right)$. The downstream firms 
compete on the product market and sell perfect substitutes. The demand function for the final good is $Q=D(p)$ with concave demand $p=P(Q)$. The upstream firms produce the same intermediate good at constant marginal cost ${ }_{i}$ $(i=1,2)$. In Section 6 , we will introduce capacity constraints for the upstream firms, but in Sections 3, 4 and 5, no such constraint exists. The intermediate good is transformed into the final good by the downstream firms on a one-for-one basis at zero marginal cost (the downstream firms are thus symmetric).

We will assume that the upstream marginal costs $c_{i}$ are sufficiently high relative to the downstream marginal cost (zero) that if the downstream firms $D_{1}$ and $D_{2}$ have purchased quantities $Q_{1}$ and $Q_{2}$ in the "viable range, the Nash equilibrium in prices in the downstream market has both firms charge the market clearing price $P(Q)$ where $Q=Q_{1}+Q_{2}$ (see Tirole [1988, chapter 5] for more detail). For this reason the Cournot revenue functions, profit functions and reaction curves are relevant. Define:

$$
\begin{aligned}
& r(q, \hat{q}) \equiv P(q+\hat{q}) q, \\
& \pi^{i}(\hat{q}, \hat{q}) \equiv\left(P(\hat{q}+\hat{q})-c_{i}\right) q
\end{aligned}
$$

and

$$
R_{i}(\hat{q}) \equiv \underset{q}{\arg \max \pi^{i}(q, \hat{q})}
$$

We assume that $\pi^{i}$ is strictly concave in $q$ and twice differentiable. $R_{i}(\hat{q})$ is then unique and differentiable. As is well-known, the slope of a reaction curve is between minus one and zero:

$$
-1<\frac{\mathrm{dR}_{\mathrm{i}}}{\mathrm{dq}}<0 .
$$


We assume that for any costs $\left(c_{1}, c_{2}\right)$, the reaction curves $R_{1}$ and $R_{2}$ have a unique intersection $\left(q_{1}^{*}\left(c_{1}, c_{2}\right), q_{2}^{*}\left(c_{1}, c_{2}\right)\right) ;$ i.e. the Cournot equilibriun is unique. We also introduce the monopoly output $q^{m}(c)$ and monopoly profit $\pi^{m}$ (c) $\equiv \max \{(P(Q)-c) Q\}=\left(P\left(q^{m}(c)\right)-c\right) q^{m}(c)$ at cost $c$. Last, for technical Q convenience, we assume that firm i's marginal revenue is convex in firm j's output (as is the case for instance for linear demand curves); this assumption is needed only in the first variant and is a sufficient condition for contracts that induce random behavior by downstream firms not to be optimal for upstream firms.

The industry evolves in two stages: ex-ante and ex-post. The ex-ante stage includes the decisions before uncertainty resolves: vertical integration and industry-specific investments.

The uncertainty is two-dimensional. First, the firms do not know ex-ante which intermediate good will be the appropriate one to trade ex-post. We adopt the Grossman-Hart [1986] methodology of presuming that the lalge number of potential technologies or products ex-ante make it too costly to write complete contracts and that the only way to influence ex-post behavior is through the allocation of residual rights of control over assets. Second, the firms may not know which marginal cost structure $\left(c_{1}, c_{2}\right)$ to supply the relevant product will prevail. Rather, they have a prior or cumulative distribution functions $F_{1}\left(c_{1}\right)$ and $F_{2}\left(c_{2}\right)$ on $[c, \bar{c}]$; for simplicicy $c_{1}$ and $c_{2}$ are drawn from independent distributions.

The timing is as follows: 
Step 1 (vertical integration). First, firms decide whether to integrate vertically. Antitrust statutes prevent any merger with a horizontal element. They thus allow only mergers between a $U$ and $a D$, as a firm cannot include the two upstream units or the two downstream units. Assuming that the four parties are still active after the investment/exit stage (see step 2), four industry structures may emerge:

- NI (non-integration): A1l four parties are separately run.

- $\quad \mathrm{PI}_{1}\left(\mathrm{U}_{1}-\mathrm{D}_{1}\right.$ integrated $)$ firms $\mathrm{U}_{1}$ and $\mathrm{D}_{1}$ have merged, firms $\mathrm{U}_{2}$ and $\mathrm{D}_{2}$ remain independent (without loss of generality we can assume that $U_{i}$ merges with $D_{i}$ as the two downstream firms are symmetric).

- $\mathrm{PI}_{2}\left(\mathrm{U}_{2}-\mathrm{D}_{2}\right.$ integrated $)$ only firms $\mathrm{U}_{2}$ and $\mathrm{D}_{2}$ have merged.

- FI (full integration): $\mathrm{U}_{1}$ and $\mathrm{D}_{1}$ have merged and so have $\mathrm{U}_{2}$ and $\mathrm{D}_{2}$. We will later say that the industry has experienced "bandwagon."

We also want to study the possibility of ex-ante monopolization in which vertical integration by $a U$ and a $D$ triggers exit by the other $D$, the other $U$ or by both. We will denote these industry structures by $\mathrm{M}_{\mathrm{d}}^{\mathrm{i}}, \mathrm{M}_{\mathrm{u}}^{\mathrm{i}}$, and $\mathrm{M}_{\mathrm{ud}}^{\mathrm{i}}$ respectively; for instance $M_{d}^{i}$ means that the integration of $U_{i}$ and $D_{i}$ has triggered exit of $\mathrm{D}_{j}$ and thus the (ex-ante) monopolization of the downstream market (but not of the upstream market).

Step 2 (investment/exit). After choosing whether to integrate, the $U$ and $D$ units commit industry-specific investments: 0 or I for upstream units, 0 or 
$\mathrm{J}$ for downstream units. Investing 0 implies that the unit is not able to trade in the ex-post stage and thus exits. A unit that invests is able to trade ex-post. Investments are non-contractible and are thus private costs to the parties that commit them, in the tradition of the bilateral monopoly paradigms of Williamson [1975, 1985] and Grossman-Hart [1986] (with the particularity that investments are industry-specific rather than firm-specific). Under integration, however, an implication of our profit-sharing assumption $A l$ below is that these investment costs can be internalized between the merging parties. At the end of step 2, the industry structure is one of $\left\{N I, \mathrm{PI}_{1}, \mathrm{PI}_{2}, \mathrm{FI}\right\}$ (if all units have invested) or $\left\{\mathrm{M}^{i}\right.$, $\mathrm{M}_{\mathrm{d}}^{\mathrm{i}}$, $\mathrm{M}_{\text {ud }}^{\mathrm{i}}$ ) (if integration between $U_{i}$ and $\mathrm{D}_{i}$ has triggered exit of $U_{j}$, $D_{j}$ or both - - the other configurations will be irrelevant under our assumptions).

\section{EX-POST STAGE}

Step 3 (resolution of uncertainty). At the beginning of the ex-post stage, all parties learn the relevant product to trade. They also learn the upstream marginal costs $\left(c_{1}, c_{2}\right)$ to produce this product. There is no asymmetry of information (all parties know the marginal costs as well as the demand curve).

$\underline{\text { Steps }} 4$ and 5 (Contract offers and acceptances). The upstream and downstream firms contract about how much of the intermediate good to trade. The variant of Sections 3 and 4 and those of Sections 5 and 6 differ in the nature of competition between the $U$. The first variant presumes Bertrand competition while the other two allow a more even distribution of bargaining power between the upstream and downstream firms. 
Step 6 (production and payments): Outputs of intermediate good specified by contracts as well as internal orders are produced and delivered. Payments are made by the downstream firms to the upstream firms.

Step I (final product market competition): $D_{1}$ and $D_{2}$ transform the intermediate good into final product (at zero marginal cost) and sell their outputs $\mathrm{Q}_{1}$ and $\mathrm{Q}_{2}$ at price $\mathrm{P}\left(\mathrm{Q}_{1}+\mathrm{Q}_{2}\right)$. [As noted above, it is optimal for them to do so assuming that they learn each other's output before choosing their prices and $c_{1}$ and $c_{2}$ are sufficiently large.]

Let us return to the ex-ante stage.

We make the following assumptions about the consequences of vertical integration, a justification for which was given in the Introduction.

A. Integration between $a U$ and a $D$ results in their sharing profits ex-post (this is the benefit of integration). This leads to the removal of all conflicts of interest about prices and trading policies (however, conflicts over effort may remain; see A2). 12

${ }^{12}$ A subtlety implicit in (Al) should be noted. What is actually being assumed is that under integration profits of the parent and subsidiary are comingled in such a way that profit-sharing is inevitable. In other words, the previous arrangement whereby the manager of the subsidiary (resp. the parent) is paid according to the subsidiary's (resp. parent's) profit, is no longer feasible. (A1) is, of course extreme, but it does seem reasonable to suppose that it is harder to identify the performances of the parent and subsidiary under integration than under nonintegration. Note that most of our results seem likely to generalize to the case where conflicts of interest over prices and trading policies are reduced even if not eliminated under integration.

An implication of (Al) is that it does not matter which is the parent company and which is the subordinate company in a merger (i.e. it doesn't 
A2. Integration between a $U$ and a $D$ involves a loss in efficiency equal to at fixed number $E \geq 0$ (this is the cost of integration). 13

We also make the following assumptions on the merger game:

A3: $U_{i}$ can merge with $D_{i}$ only.

Assumption $\mathrm{A} 3$ is made for convenience. Allowing an upstream firm, say, to bargain with several downstream firms raises some thorny issues related to antitrust. What would happen under the antitrust statutes if both downstream firms agreed to merge with the same upstream firm? If we assume that an upstream firm can negotiate with a single downstream firm, A3 involves no loss of generality because the downstream firms are symmetric. ${ }^{14}$ We will further assume that $U_{i}-D_{i}$ take the optimal merger decision for them. The

matter whether the upstream firm buys the downstream firm or vice versa). This simple view of mergers suffices for the analysis presented here, but we should emphasize that the identity of the owning party does matter under more general conditions. See Grossman-Hart [1986] or Hart-Moore [1988] for a discussion.

${ }^{13}$ As noted in the introduction, one component of the cost of integration is the loss due to a subordinate manager's dulled incentives. One case consistent with our hypothesis that $E$ is a fixed number independent of the rest of the model is where the subordinate's dulled incentives concern activities having to do with the reduction of fixed (as opposed to marginal) production costs and the supply of goods to third parties (firms outside the industry).

14 Assumption A3 does have one important implication, however: it rules out the possibility of extortion by the upstream firms. For instance, it might be the case that the sum of $U_{1}$ and $D_{1}$ 's profit falls if they integrate, and yet $D_{1}$ accepts a low offer from $U_{1}$ to merge because of $U_{1}$ 's threat to merge with $D_{2}$ and foreclose $\mathrm{D}_{1}$ at the ex-post stage. 
distribution of the gains from merging between them depends on their relative bargaining power, and will not be investigated here as it does not affect industry structure and performance. ${ }^{15}$

A4: Integration is irreversible.

Divestiture is ruled out by assumption A4. In practice, divestiture is costly, because some of the integration costs are sunk and because new costs are incurred. However, assumption $\mathrm{A} 4$ would be unduly restrictive in industries in which demand and cost conditions change dramatically over time. Allowing integration and disintegration to study the industry integration cycle is an important item on the research agenda, for which our model is amenable, but it is outside the scope of this paper.

A5: If $\mathrm{U}_{i}$ and $\mathrm{D}_{i}$ integrate, $\mathrm{U}_{j}$ and $\mathrm{D}_{j}$ can follow suit before step 2 (immediate response).

${ }^{15}$ As we shall see, a merger between $U_{i}$ and $D_{i}$ will often hurt $U_{j}$ and/or $D_{j}$. One possibility we do not allow is that $U_{j}$ or $D_{j}$ bribe $U_{i}-D_{i}$ not to merge. There are two justifications for ignoring this. First, such a bribe might be viewed with suspicion by the anti-trust authorities. Second, there may be round-about ways in which $U_{i}$ and $D_{i}$ can merge (e.g. by forming a holding company that owns both $U_{i}$ and $D_{i}$ ) so as to evade a contract committing them not to combine. Note that this position is not inconsistent with the view that the anti-trust authorities can prohibit mergers. There might be enough evidence that the formation of a holding company, say, amounted to a merger for a court to rule against such a holding company in an antitrust case, but not enough evidence for a court to make such a ruling in a breach of contract case. 
This assumption deserves some clarification. It states that fims can react quickly to their rivals' integration decision. Formally, A5 corresponds to the following "reduced form merger Eame" within step 1: Fixst, the $U_{i}$ simultaneously decide whether to integrate. Second, if $U_{i}$ has integrated and $U_{j}$ has not, $U_{j}$ gets a chance to respond (but the firms cannot integrate in this "second period of step 1 " if none has integrated in the "first period"). The reduced form merger game is not rich enough to depict some interesting situations. Suppose for instance that if one of the U merges, the unintegrated D exits; it may be the case that the reduced form merger game has two equilibria: "U $U_{1}$ integrates, $U_{2}$ does not" and " $U_{2}$ integrates, $U_{1}$ does not." Both to select between the two equilibria and to give a more realistic picture of merger dynamics, we also develop a continuous-time. version of the merger game. Suppose that time is continuous, and that at each instant there is a new trading dimension ("product" in our model) to contract on. Contacting must be done just before trading. Similarly investment must be committed continuously in order for the firms to keep abreast of industry developments (i.e., to avoid exit: we suppose that once a unit has stopped investing it cannot come back). The profits mentioned in the paper are then flow profits; $E$ is the present discounted value of the integration cost (it can be though of as being equal to $E_{0}+\frac{E_{1}}{r}$ where $E_{0}$ is the upfront integration cost (legal fees, say), $E_{1}$ is the flow loss of incentives and $r$ is the rate of interest). In this continuous time framework, the strategic variable is the date of integration. The loss for $U_{i}$ to integrating just after $U_{j}$ compared to integrating simultaneously is negligible, because the loss in flow profit is small (infinitesimal) relative to present values of profits. We adopt the convention that the market 
"opens" at date 0. That is, the flow investment is incurred and the flow profits are received at each instant from date 0 on. However, we let firms incur the integration cost before date 0 if they so wish, in order to allow preemption.

Besides giving an interpretation of the immediate response postulate of Assumption A5, this continuous time model selects among multiple equilibria and yields the date at which integration occurs. In those cases in which the reduced form game has a urique equilibrium, the continuous time model predicts the same integration pattern, which then occurs at date 0 .

3. Ex-post Monopolization: The Case of Perfect Certainty and No Investment

We now develop the first variant of our model in which the U compete $\dot{a}$ la Bertrand in step 4. In this section, we consider the case in which the upstream firms' marginal costs are certain and investment costs are zero; in the next section, we extend the analysis to uncertain marginal costs and positive investments. In sections 5 and 6 , we consider the case where upstream and downstream firms bargain over the terms of trade.

Under Bertrand competition, Step 4 is described as follows:

$\underline{\text { Step }} 4$ (contract offers). Both $U$ make simultaneous and secret contract offers to each unintegrated D. ${ }^{16}$ In a vertically integrated firm, given the

\footnotetext{
${ }^{16}$ The secrecy assumption reflects the possibility of hidden or side contracting. It allows us to abstract from the possibility of contracts commiting the downstream firms to adopt certain behaviors in the final product market (see Fershtman-Judd [1987] and Katz [1987]). In addition it rules out the possibility that an upstream firm can commit itself to limit its sales to some downstream firm by making an appropriate public offer to that firm.
} 
profit sharing assumption, this offer is a willingness to supply any level of output at an internal marginal transfer price equal to the marginal cost $c_{\text {i }}$ of the upstream unit.

We will not put any restriction on the contracts that can be signed between a $U$ and a $D$ given the information structure. ${ }^{17}$ A simple contract between $U_{i}$ and $D_{j}$ specifies a transfer $t_{i j}$ from $D_{j}$ to $U_{i}$ that depends on the quantity purchased by $D_{j}$ from $U_{i}: t_{i j}\left(q_{i j}\right)$ (for instance, a two-part tariff is an affine function of $\mathrm{q}_{i j}$ ). We will actually allow a finer information structure and accordingly a larger class of feasible contracts. lie suppose that $\mathrm{D}_{j}$ can show to $\mathrm{U}_{i}$ any amount of the good (or exhibit receipts for the sales on the final good market) as long as it does not exceed the total amount of the good bought by $D_{j}$ from $U_{i}$ and $U_{j}$. Thus, if $Q_{j}=q_{1 j}+q_{2 j}$ is the quantity purchased by $D_{j}, D_{j}$ can demonstrate any $\hat{Q}_{i j} \leq Q_{j}$ to $U_{i}$. Accordingly we allow "conditional contracts" $t_{i j}\left(q_{i j}, \hat{Q}_{i j}\right) .18$

17 Unlike most papers in the literature, we are not conferring an exogenous advantage to the integrated firms by having the internal transfer price be equal to marginal cost while external transfer prices differ from marginal cost because two-part tariffs are ruled out. We will allow general contracts (including two-part tariffs) for external transactions.

18

The reason for introducing conditional contracts is technical. Conditional contracts turn out to be irrelevant in six of the seven possible industry structures, and the reader might as well think in terms of simple contracts. In the seventh industry structure (partial integration in which the higher cost upstream firm is integrated), no equilibrium exists that involves simple contracts only (uniess $c_{1}=c_{2}$ or $\left|c_{2}-c_{1}\right|$ is large); there exists an equilibrium in conditional contracts offers in which the downstream firms end up choosing simple contracts (so that conditional clauses, although offered, are not selected on the equilibrium path). Furthermore, we argue that this equilibrium yields the reasonable outcome of a richer contract offer game in which only simple contracts are enforceable: See footnote 20. 
Step 5 (acceptance/rejection of contracts). The unintegrated downstrean

firm(s) simultaneously accept or reject the contracts offered in step 4 . If $D_{j}$ accepts $U_{i}$ 's offer, it selects an input level $q_{i j}$ and (in the case of a conditional contract) announces a quantity $\hat{Q}_{i j}$ to be exhibited later to $U_{i}$, such that $\hat{Q}_{i j} \leq Q_{j} \equiv q_{I j}+q_{2 j}$.

Assume, without loss of generality, that $c_{1} \leq c_{2}$. We describe equilibrium in the four industry structures that are possible given that no firm exits, and relegate the study of uniqueness to Appendix 2.

\section{Nonintegration.}

The outcome under nonintegration is given in Proposition 1.

Proposition 1: Assume $c_{1} \leq c_{2}$. Under nonintegration, $D_{1}$ and $D_{2}$ each buy $q^{*}$ $=q^{*}\left(c_{1}\right)$ from $U_{1}$ and 0 from $U_{2}$, where $q^{*}$ is the Cournot level corresponding to marginal cost $c_{1}: q^{\star *}=R_{1}\left(q^{*}\right)$. They each pay a transfer $t^{*}$ to $U_{1}$ and 0 to $U_{2}$, where

$$
r\left(q^{*}, q^{*}\right)-t^{*}=r\left(R_{2}\left(q^{*}\right), q^{*}\right)-c_{2} R_{2}\left(q^{*}\right)
$$

Total output is $2 \mathrm{q}^{*}$ and profits are:

$$
\begin{aligned}
& U_{1}: \quad U^{N I}\left(c_{1}, c_{2}\right)=2\left(r\left(q^{*}, q^{*}\right)-c_{1} q^{*}\right)-2\left(r\left(R_{2}\left(q^{*}\right), q^{*}\right)-c_{2} R_{2}\left(q^{*}\right)\right) \\
& U_{2}: \quad U^{N I}\left(c_{2}, c_{1}\right)=0 \\
& D_{j}: \quad D^{N I}\left(c_{1}, c_{2}\right)=r\left(R_{2}\left(q^{*}\right), q^{*}\right)-c_{2} R_{2}\left(q^{*}\right) \quad \text { for } j=1,2 .
\end{aligned}
$$


The intuition behind proposition 1 is as follows. In foquilibrium (rich i) anticipates that its rival buys the Cournot output from the low-cost firm. Given this it can do no better than buying $q^{*}$ from the low-cost firm too. The transfer price given by (3.1) is such that each D is indifferent between accepting $U_{1}^{\prime}$ s offer to sell $\mathrm{q}^{*}$ at $t^{*}$ and buying the best reaction to $\mathrm{q}^{*}$ given marginal cost $c_{2}$, at a cost of $c_{2}$ per unit (from $U_{2}$ ). $U_{1}$ 's profit is equal to industry profit minus the downstream firms' profit. Note that, from Bertrand competition, $U^{N I}(c, c)=0$ for all $c$.

The proof of Proposition 1, as well as of other propositions in this section, is to be found in Appendix 1.

Partial integration $\mathrm{PI}_{1}$. Suppose now that $U_{1}$ and $\mathrm{D}_{1}$ are integlated and $\mathrm{U}_{2}$ and $\mathrm{D}_{2}$ have remained independent. We index profits by "PI". In particular, we let $\mathrm{D}^{\mathrm{PI}}\left(c, c^{\prime}\right)$ denote the nonintegrated downstream firm's profit when the integrated supplier has cost $c$ and the nonintegrated one has cost $c^{\prime}$.

Proposition 2. Assume $c_{1} \leq c_{2}$. Let $\left(q_{1}^{*}, q_{2}^{*}\right)=\left(q_{1}^{*}\left(c_{1}, c_{2}\right), q_{2}^{*}\left(c_{1}, c_{2}\right)\right)$ be given

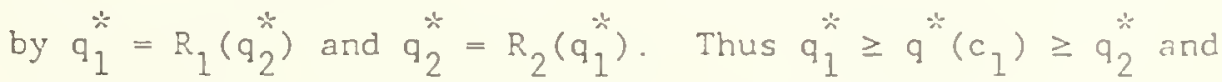
$\mathrm{q}_{1}^{*}+\mathrm{q}_{2}^{\ddot{*}} \leq 2 \mathrm{q}^{*}\left(c_{1}\right)$. Under PI, $\mathrm{U}_{1}$ produces $\mathrm{q}_{1}^{\ddot{*}}$ for the intirnal buyer $\mathrm{D}_{1}$ and selis $\mathrm{q}_{2}^{*}$ at price $t_{2}^{*}$ to $\mathrm{D}_{2}$ where

$$
\tau_{2}^{*}=c_{2} q_{2}^{*} \text {. }
$$

$\mathrm{U}_{2}$ does not se11. Total industry output is $\left(\mathrm{q}_{1}^{\ddot{2}}+\mathrm{q}_{2}^{\ddot{*}}\right)$ and profits are:

$$
\begin{aligned}
\left(U_{1}-D_{1}\right): & V^{P I}\left(c_{1}, c_{2}\right)-E \text {, where } \\
& V^{P I}\left(c_{1}, c_{2}\right)=r\left(q_{1}^{*}, q_{2}^{*}\right)-c_{1} q_{1}^{\ddot{*}}+\left(c_{2}-c_{1}\right) q_{2}^{*}
\end{aligned}
$$




$$
\begin{gathered}
\geq U^{N I}\left(c_{1}, c_{2}\right)+D^{N I}\left(c_{1}, c_{2}\right) \\
U_{2}: \quad U^{P I}\left(c_{2}, c_{1}\right)=0=U^{N I}\left(c_{2}, c_{1}\right) \\
D_{2}: \quad D^{P I}\left(c_{1}, c_{2}\right)=r\left(q_{2}^{*}, q_{1}^{*}\right)-c_{2} q_{2}^{*} \leq D^{N I}\left(c_{1}, c_{2}\right) .
\end{gathered}
$$

All inequalities in this proposition are strict if and only if $c_{1}<c_{2}$.

In words, the equilibrium is the Cournot equilibrium between two firms with marginal costs $c_{1}$ and $c_{2}$ except that production efficiency holds. The low cost, integrated upstream firm supplies $\mathrm{q}_{2}^{*}$ to the external buyer at profit $\left(c_{2}-c_{1}\right) q_{2}^{*}$. The comparison with the non-integrated case is depicted in Figure 1 .

\section{Figure $\underline{1}$ Here}

The difference from nonintegration stems from the fact that an integrated $U_{1}-D_{1}$, because of profit-sharing, has an incentive to restrict supplies to $\mathrm{D}_{2}$ as much as possible. However, since it cannot stop $U_{2}$ from supplying $\mathrm{R}_{2}\left(\mathrm{q}_{1}^{*}\right)$, its best strategy is to undercut $\mathrm{U}_{2}$ slightly and supply $\mathrm{R}_{2}\left(\mathrm{q}_{1}\right)$ itself. $\mathrm{D}_{2}$ is partially foreclosed and is hurt by vertical integration, while the profit of the integrated firm rises. Ex-post monopolization $\left(\mathrm{q}_{1}^{*}+\mathrm{q}_{2}^{*}<2 \mathrm{q}^{*}\right.$ if $\left.\mathrm{c}_{1}<\mathrm{c}_{2}\right)$ results from the facts that $-1<\frac{\mathrm{dR}_{1}}{\mathrm{dq}_{2}}$ $<0$ and $\left(q_{1}^{*}, q_{2}^{*}\right)$ and $\left(q^{*}, q^{*}\right)$ are both on the $q_{1}=R_{1}\left(q_{2}\right)$ reaction curve. Note that social welfare is reduced, and that (gross of the integration cost E) industry profit has increased. 


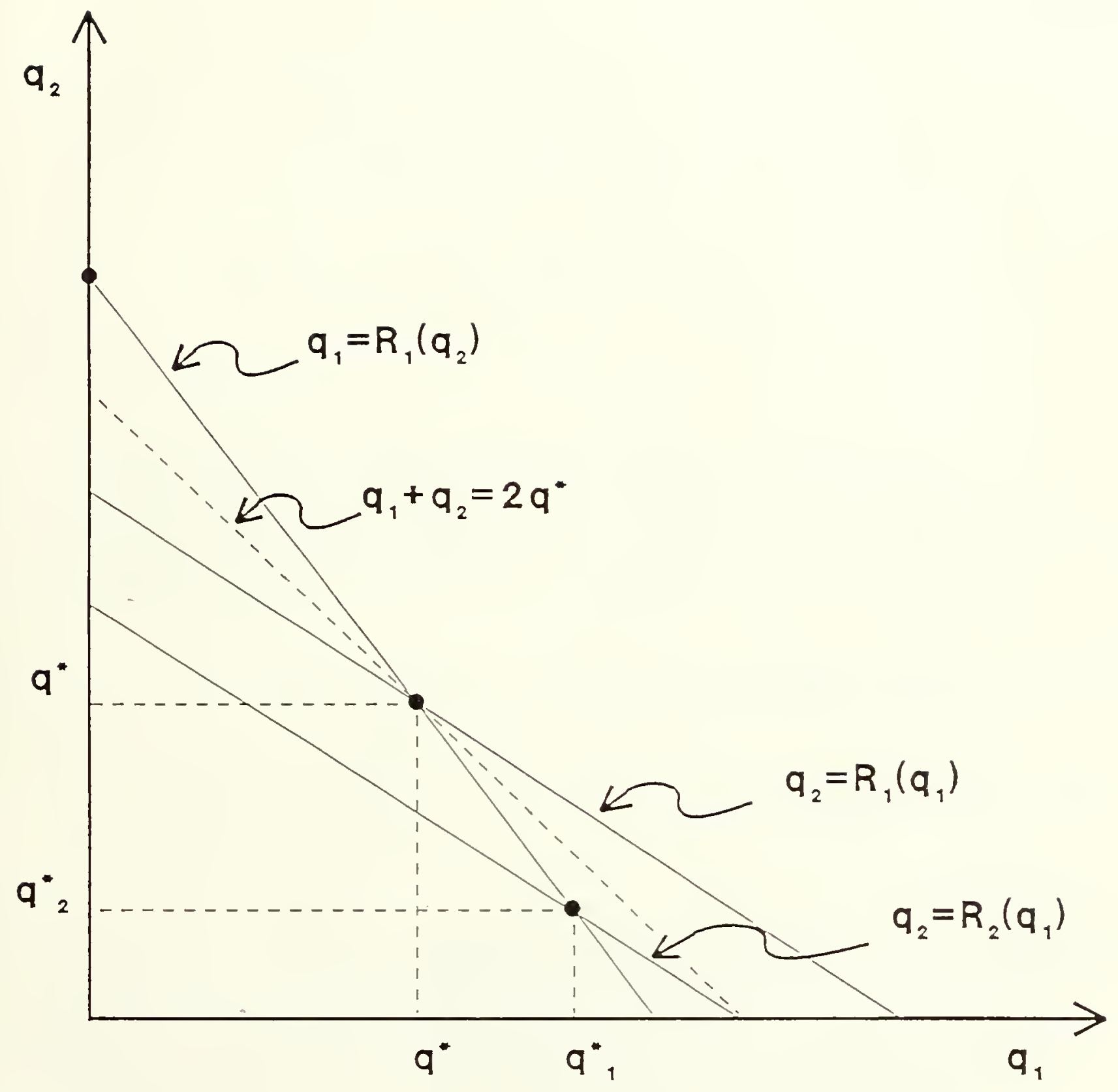

Figure 1 
Ful1 integration. Suppose now that $\left(\mathrm{U}_{1}-\mathrm{D}_{1}\right)$ and $\left(\mathrm{U}_{2}-\mathrm{D}_{2}\right)$ are integraied.

Proposition 3 : Under full integration and $c_{1} \leq c_{2}$, the allocation is the same as under $\mathrm{PI}_{1}$ except that the integrated firm $\left(\mathrm{U}_{2}-\mathrm{D}_{2}\right)$ also incurs efficiency loss $E$. That is, $\mathrm{U}_{1}$ supplies $\mathrm{q}_{1}^{*}$ to $\mathrm{D}_{1}$ and $\mathrm{q}_{2}^{*}$ to $\mathrm{D}_{2}$ and $\mathrm{U}_{2}$ does not supply. The profits are thus:

$$
\begin{aligned}
& \left(\mathrm{U}_{1}-\mathrm{D}_{1}\right): \mathrm{V}^{\mathrm{FI}}\left(\mathrm{c}_{1}, \mathrm{c}_{2}\right)-\mathrm{E} \text {, where } \mathrm{v}^{\mathrm{FI}}\left(\mathrm{c}_{1}, \mathrm{c}_{2}\right)=\mathrm{v}^{\mathrm{PI}}\left(\mathrm{c}_{1}, \mathrm{c}_{2}\right) \\
& \left(\mathrm{U}_{2}-\mathrm{D}_{2}\right): \mathrm{V}^{\mathrm{FI}}\left(\mathrm{c}_{2}, \mathrm{c}_{1}\right)-\mathrm{E} \text {, where } \mathrm{V}^{\mathrm{FI}}\left(\mathrm{c}_{2}, \mathrm{c}_{1}\right)=\mathrm{D}^{\mathrm{PI}}\left(\mathrm{c}_{1}, \mathrm{c}_{2}\right) .
\end{aligned}
$$

Thus, vertical integration by the high-cost supplier has no other effect than the efficiency 1oss. The reason is that $\mathrm{U}_{2}$ did not supply $\mathrm{D}_{1}, \mathrm{D}_{2}$ anyway. In particular $\left(\mathrm{U}_{2}-\mathrm{D}_{2}\right)$ do not have an incentive to integrate in the deterministic case if $\left(U_{1}-D_{1}\right)$ have integrated. We will see in contrast that with uncertain costs, bandwagoning may occur.

a $\mathrm{PI}_{2}$ : Last, suppose that only $\left(\mathrm{U}_{2}-\mathrm{D}_{2}\right)$ are integrated and that $\mathrm{c}_{1} \leq \mathrm{c}_{2}$.

Proposition 4: Under $\mathrm{PI}_{2}$ and $c_{1} \leq c_{2}$, the allocation is the same as under NI, except that $\left(\mathrm{U}_{2}-\mathrm{D}_{2}\right)$ incurs the efficiency loss $\mathrm{E}$. $\mathrm{U}_{1}$ supplies $\mathrm{q}^{*}=\mathrm{q}^{*}\left(\mathrm{c}_{1}\right)$ to both $\mathrm{D}_{1}$ and $\mathrm{D}_{2}$ and $\mathrm{U}_{2}$ does not supply. Industry output is $2 \mathrm{q}^{*}$ and profits are:

$$
\begin{aligned}
& U_{1}: U^{P I}\left(c_{1}, c_{2}\right)=U^{N I}\left(c_{1}, c_{2}\right) \\
& D_{1}: \quad D^{P I}\left(c_{2}, c_{1}\right)=D^{N I}\left(c_{1}, c_{2}\right)
\end{aligned}
$$




$$
\left(\mathrm{U}_{2}-\mathrm{D}_{2}\right): \quad \mathrm{V}^{\mathrm{PI}}\left(\mathrm{c}_{2}, \mathrm{c}_{1}\right)-\mathrm{E} \text {, where } \mathrm{V}^{\mathrm{PI}}\left(\mathrm{c}_{2}, \mathrm{c}_{1}\right)=\mathrm{D}^{\mathrm{NI}}\left(\mathrm{c}_{1}, \mathrm{c}_{2}\right)
$$

As in Proposition 3, vertical integration by the high-cost supplin has no other effect than the efficiency loss. 19,20

We turn next to the ex-ante stage. This is trivial when $c_{1}, c_{2}$ are deterministic and investment costs are zero. We have seen that $U_{2}-D_{2}$ have no incentive to integrate, whether or not $\mathrm{U}_{1}-\mathrm{D}_{1}$ have. Thus the possible equilibrium industry structures are nonintegration and partial integration by $\mathrm{U}_{1}-\mathrm{D}_{1}$. The latter will occur if and only if $U_{1}-D_{1}$ 's profit is higher

${ }^{19}$ Some readers have questioned how our analysis would change if $D_{1}, D_{2}$ competed à la Bertrand instead of à la Cournot in the downstream market. Note that this would involve a radical change in the timing of production and sales. Given our assumption that upstream firms must first ship the intermediate good to downstream firms, and that downstream firms then transform this good into final output, the downtream market game is played by firms with capacity constraints, and as noted previously, the outcome vill inevitably be Cournot if $c_{1}, c_{2}$ are high enough.

${ }^{20}$ It is worth giving the flavor of the argument as to why there may exist no pure strategy equilibrium in simple contracts under $\mathrm{PI}_{2}$ (see footnoie 18 ). $\mathrm{U}_{2}$ can try to reduce industry output by offering $\mathrm{q}_{21}<\mathrm{q}^{\star *}$ to $\mathrm{D}_{1}$ at the money-losing price $t_{21}<c_{2} q_{21}$ such that $D_{1}$ makes more profit accepting $U_{2}^{\prime}$ s offer than $U_{1}$ 's. While such a strategy would be too costly in terms of production cost for $U_{2}$ if $c_{2}$ is much larger than $c_{1}$, it may become optimal for $U_{2}$ if $c_{2}$ is close to $c_{1}$. We fird such a strategy unlikely to succeed in practice. Basically, $U_{2}$ bribes $D_{1}$ to purchase a low output. But $D_{1}$ would always go back to $U_{1}$ to buy more output and brings itself to the reaction curve $R_{1}$. If such recontracting is feasible, $U_{2}$ 's counterstrategy does not succeed in bringing industry output below $2 q^{*}$. The possibility of $D_{1}$ 's getting more from $U_{1}$ is formalized in the equilibrium of our one-shot contracting game by $\mathrm{U}_{1}$ 's sleeping clause allowing $\mathrm{D}_{1}$ to complement to $q^{*}$ its purchases from $\mathrm{U}_{2}$. 
under partial integration than nonintegration, i.e.

$$
v^{P I}\left(c_{1}, c_{2}\right)-\left(U^{N I}\left(c_{1}, c_{2}\right)+D^{N I}\left(c_{1}, c_{2}\right)\right)-E>0 .
$$

This completes our analysis of the deterministic-marginal-cost, zeroinvestment-cost case. In the next section we consider uncertain marginal cost and positive investment cost. Since Section 4 is more involved, the reader may well wish to skip to Section 5 on first reading.

\section{Ex-post monopolization: Uncertainty and positive investments}

We now look at the general ex-post monopolization variant with uncertainty and investments. $c_{1}$ and $c_{2}$ are uncertain ex-ante but are known ex-post. In the certainty case with $c_{1} \leq c_{2}, U_{2}$ had no incentive at all to remain in the industry and so with $I>0$, it would have exited. This feature disappears once $c_{1}$ and $c_{2}$ are stochastic. Because $c_{2}<c_{1}$ with some probability, $\mathrm{U}_{2}$ has an incentive to stay to take advantage of realizations in which it is the more efficient firm, as long as I is small. We start by considering the case in which investments costs $I$ and $J$ are small enough that none of the four parties has an incentive to exit.

\subsection{The ex-ante stage when investment costs are small.}

In order to analyze the case where $c_{1}$ and $c_{2}$ are uncertain, we make use of the following corollary of Propositions 1 through $4: \quad\left(U_{i}-D_{i}\right)^{\prime}$ s gain from integration is independent of whether $U_{j}$ and $D_{j}$ merge. (This is not to say they are indifferent as to $\mathrm{U}_{j}$ and $\mathrm{D}_{j}$ 's integration decision; rather, integration by $U_{j}$ and $D_{j}$ implies the same decrease in the aggregate profit of 
$U_{i}$ and $D_{i}$ whether $U_{i}$ and $D_{i}$ are integrated or not.)

For $c_{i} \leq c_{j}$, define the ex-post gain from integration for $U_{i}$ and $D_{i}$ :

$$
\begin{aligned}
g\left(c_{i}, c_{j}\right) & \equiv V^{P I}\left(c_{i}, c_{j}\right)-\left(U^{N I}\left(c_{i}, c_{j}\right)+D^{N I}\left(c_{i}, c_{j}\right)\right) \\
& =V^{F I}\left(c_{i}, c_{j}\right)-\left(U^{P I}\left(c_{i}, c_{j}\right)+D^{P I}\left(c_{j}, c_{i}\right)\right) .
\end{aligned}
$$

Note that $g(c, c)=0$ for all $c$. For $c_{i} \geq c_{j}$ the ex-post gain from integration $g\left(c_{i}, c_{j}\right)=0$. The ex-ante or expected gain from integration for $\left(U_{i}-D_{i}\right)$ is thus

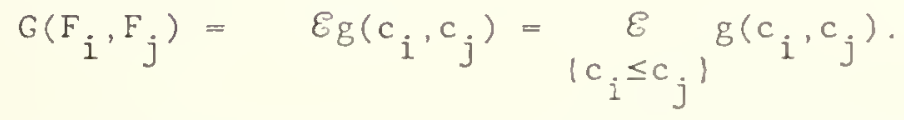

The deterministic case suggests that the efficient firm gains more from integration than the inefficient one (which does not gain anything). We now show that the same holds in the uncertainty case. The natural definition of efficiency refers to first-order stochastic dominance.

Definition: $\quad U_{I}$ is more efficient than $U_{2}$ if $F_{1}(c) \geq F_{2}(c)$ for all $c$ (with at least some strict inequality).

Proposition 5: Suppose that $U_{1}$ is more efficient than $U_{2}$ and that either (i) $[\underline{c}, \bar{c}]$ is sufficiently small where $[\underline{c}, \bar{c}]$ is the support of $F_{1}$ and $F_{2}$ (small uncertainty),

or (ii) $c_{i}=c$ with probability $\alpha_{i}$ and $=+\infty$ with probability $\left(1-\alpha_{i}\right)$ where $\alpha_{1}>\alpha_{2}$ (large uncertainty).

Then $U_{1}$ has more incentive to integrate than $U_{2}$ :

$$
G\left(E_{1}, E_{2}\right)>G\left(E_{2}, E_{1}\right)
$$


The proof of Proposition 5 is in Appendix 4.

Next, we study the loss $L\left(F_{i}, F_{j}\right)$ incurred by $U_{i}$ and $D_{i}$ when $U_{j}$ and $D_{j}$ merge. Propositions 1 through 4 imply that this loss is independent of whether $U_{i}$ and $D_{i}$ are integrated or not. Define for $c_{i}>c_{j}$

$$
\begin{aligned}
\ell\left(c_{i}, c_{j}\right) & \equiv D^{N I}\left(c_{i}, c_{j}\right)-D^{P I}\left(c_{j}, c_{i}\right) \\
& \equiv V^{P I}\left(c_{i}, c_{j}\right)-V^{F I}\left(c_{i}, c_{j}\right) ;
\end{aligned}
$$

and for $c_{i} \leq c_{j}, \ell\left(c_{i}, c_{j}\right) \equiv 0$. Last define

$$
L\left(F_{i}, F_{j}\right) \equiv \quad \mathcal{R}\left(c_{i}, c_{j}\right)=\underset{\left\{c_{i} \geq c_{j}\right\}}{E} \ell\left(c_{i}, c_{j}\right) .
$$

Proposition 6: Suppose that $\mathrm{U}_{1}$ is more efficient than $\mathrm{U}_{2}$ and that one of the two assumptions of Proposition 5 (small uncertainty, large uncertainty) holds. Then $\mathrm{U}_{1}$ and $\mathrm{D}_{1}$ lose less from $\mathrm{U}_{2}$ and $\mathrm{D}_{2}$ integrating than $\mathrm{U}_{2}$ and $\mathrm{D}_{2}$ lose when $\mathrm{U}_{1}$ and $\mathrm{D}_{1}$ integrate: $L\left(F_{1}, F_{2}\right) \leq L\left(F_{2}, F_{1}\right)$

Proposition 6 is proved in Appendix 5. Under the assumptions of Propositions 5-6, it is straightforward to solve the merger game. Let $G_{i} \equiv$ $G\left(F_{i}, F_{j}\right)$ and $L_{i} \equiv L\left(F_{i}, F_{j}\right)$, where by Propositions $5-6, G_{1} \geq G_{2}$ and $L_{1} \leq L_{2}$.

- Case 1: $G_{1}<E$ (which implies $G_{2}<E$ ). In this case, $U_{1}$ and $U_{2}$ have a dominant strategy not to integrate. The industry structure is nonintegration. 
- Case 2: $\mathrm{G}_{1}-\mathrm{L}_{1}>\mathrm{E}$. In this case, it is a dominant strategy for $\mathrm{U}_{1}$ to integrate. There are two subcases:

If $G_{2}<E$, the outcome is $\mathrm{PI}_{1}$.

If $G_{2}>E$, the outcome is FI. We can further distinguish between eager bandwagon, which arises when $U_{2}-D_{2}$ prefer a fully integrated industry to a nonintegrated industry $\left(G_{2}-L_{2}>E\right)$, and reluctant bandwagon, which arises when $\mathrm{U}_{2}-\mathrm{D}_{2}$ follow suit, but would have preferred the industry to remain nonintegrated $\left(G_{2}-L_{2}<E\right)$.

- Case 3: $\mathrm{G}_{1}-\mathrm{L}_{1}<E<G_{1}$. In this case, $\mathrm{U}_{1}$ wants to integlate only if $U_{2}$ does not jump on the bandwagon. Thus

If $G_{2}<E, U_{1}$ integrates and the industry structure is $\mathrm{PI}_{1}$.

If $G_{2}>E, U_{1}$ refrain from integrating because this would trigger full integration. The industry structure is NI.

The stochastic cost case is summarized in Proposition 7.

Proposition 7. Suppose that $U_{1}$ is more efficient than $U_{2}$ and that small uncertainty or large uncertainty holds.

Then:

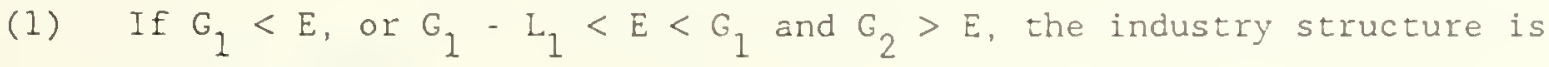
nonintegration.

(2) If $G_{1}-L_{1}>E$ and $G_{2}<E$, or $G_{1}-L_{1}<E<G_{1}$ and $G_{2}<E$, the industry structure is partial integration by $U_{1}-D_{1}$.

(3) If $G_{1}-L_{1}>E, G_{2}>E$, the industry structure is full integration. 
A welfare comparison of the different industry structures is simple in the case where I, J are sufficiently small that none of the four parties ever exits.

Welfare: The notion of welfare is the sum of consumer and producer surplus.

Proposition 8: In the absence of exit, any industry structure involving vertical integration $\left(\mathrm{PI}_{1}, \mathrm{PI}_{2}, \mathrm{FI}\right)$ is socially dominated by the nonintegrated industry structure (NI).

Proof: Vertical integration implies two welfare losses: the efficiency loss (E under $\mathrm{PI}_{1}$ and $\mathrm{PI}_{2}$, and $2 \mathrm{E}$ under $\mathrm{FI}$ ) and output contraction $\left(q_{1}^{*}\left(c_{1}, c_{2}\right)+q_{2}^{*}\left(c_{1}, c_{2}\right)<q^{*}\left(c_{i}\right)\right.$ if $c_{i}<c_{j}$ and either regime PI or FI holds see Propositions 2 through 4 ).

$$
Q . E . D .
$$

We now consider general investment costs $I$ and $J$. Because we must now allow for the possibility of exit, we start by solving the ex-post stage when exit has occured (Subsection 4.2). We then solve the merger game (Subsections 4.3 and 4.4 and Appendix 7).

4.2 The ex-post stage after ex-ante monopolization. Assume without loss of generality that $U_{1}$ and $D_{1}$ have integrated. We consider the case where integration by $U_{1}-D_{1}$ causes $D_{2}$ or $U_{2}$ or both to exit, leading to ex-ante 
monopolization. We will denote the three cases by $M_{\text {ud }}$ (both $U_{2}$ and $\mathrm{D}_{\text {? }}$ ? have exited), $M_{d}$ (only $D_{2}$ has exited) and $M_{u}$ (only $U_{2}$ has exited).

Upstream and downstream monopolization ( $\left.\mathrm{M}_{\mathrm{ud}}\right)$ or upstream monopolization $\left(M_{d}\right)$.

If $U_{1}$ and $D_{1}$, who have integrated, are monopolists in their respective industry segments, and $U_{1}$ has marginal cost $c_{1}$, then $\left(U_{1} \cdot D_{1}\right.$ )'s profit is $\mathrm{V}^{\mathrm{M}}{ }^{\mathrm{ud}}\left(c_{1}\right)-\mathrm{E}$, where $\mathrm{V}^{\mathrm{M}}\left(\mathrm{c}_{1}\right)=\pi^{\mathrm{m}}\left(\mathrm{c}_{1}\right)$. The same holds if $\mathrm{U}_{2}$ only has exited as $u_{1}$ supplies only its internal unit $D_{1}$; hence $v^{M}\left(c_{1}\right)=v^{M^{2}}{ }^{u}\left(c_{1}\right)$.

- Downstream monopolization $\left(M_{d}\right)$. Suppose that only $D_{2}$ has exited.

If $c_{1} \leq c_{2}$, then $D_{1}$ procures internally and $\left(U_{1}-D_{1}\right)$ 's profit is $\mathrm{v}^{M} \mathrm{~d}\left(c_{1}, c_{2}\right)-E$, where $\mathrm{v}^{M}\left(c_{1}, c_{2}\right)=\pi^{m}\left(c_{1}\right)$ while $u_{2}$ 's profit, $U^{M} d\left(c_{2}, c_{1}\right)$, is equal, to zero.

If $c_{1}>c_{2}$, then $U_{2}$ makes an offer to supply $q^{m}\left(c_{2}\right)$ to $D_{1}$ at price $\tau_{21}=$ $P\left(q^{m}\left(c_{2}\right)\right) q^{m}\left(c_{2}\right)-\pi^{m}\left(c_{1}\right)$. Hence the profics are: for $\left(U_{1}-D_{1}\right): V^{M}\left(c_{1}, c_{2}\right)-E$, where $v^{M}\left(c_{1}, c_{2}\right)=\pi^{m}\left(c_{1}\right)$; and for $U_{2}$ : $u^{M}\left(c_{2}, c_{1}\right)=\pi^{m}\left(c_{2}\right)-\pi^{m}\left(c_{1}\right)$.

4.3. I "small", I "large" (possibility of ex-ante downstream monopolization).

Next we assume that downstream firms' investment is large in the sense that $J>E^{P I}\left(c_{1}, c_{2}\right)$, where $\mathcal{E}$ is the expectation with respect to $c_{1}, c_{2}$; while the upstream firms' investment remains small. Throughout Section 4 , we assume that none of the fixms exits in step 2 under nonintegration: 
A6 (viability under nonintegration): For all $i$ and $j, \varepsilon U^{N I}\left(c_{i}, c_{j}\right) \geq I$ and $E D^{N I}\left(c_{i}, c_{j}\right) \geq J$.

We first analyze when a $U$ wants to rescue a failing $D$ by merging with it; this may happen sometimes even though $U$ and $D$ would not want to merge if D) were viable (we will call this forced bandwagon). We relegate the investigation of the merger game to Appendix 7.

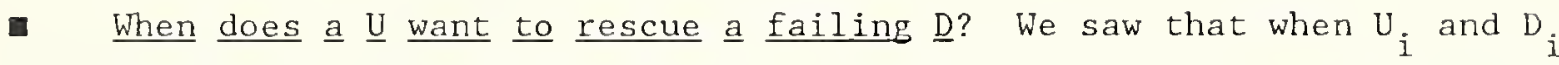
integrate, only $D_{j}$ suffers directly. Its loss is equal to $\mathrm{L}_{j}$. This may lead $D_{j}$ to exit if its new expected profit falls under $J$ and $U_{j}$ does not come to its rescue by accepting a merger with $D_{j}$. A merger gives $D_{j}$ an incentive to invest since, given profit sharing, investment costs can be split between $D_{j}$ and $U_{j}$. [ $U_{j}$ cannot come to $D_{j}$ 's rescue by subsidizing its investment cost because investment is not contractible. The only thing it can do is to merge at a reasonable price.]

As we will see, a crucial factor for knowing whether $U_{j}$ and $D_{j}$ merge when $\mathrm{U}_{i}$ and $\mathrm{D}_{i}$ have merged is whether $\mathrm{U}_{\mathrm{j}_{\mathrm{M}}}$ is made better off by $\mathrm{D}_{j}$ 's exit. Let us simplify the notation a bit: Let $U_{j}{ }^{M} \equiv E U^{M}{ }^{M}\left(c_{j}, c_{i}\right)$ denote $U_{j}$ 's expected profit when $D_{j}$ exits; $U_{j}^{P I} \equiv E U^{P I}\left(c_{j}, c_{i}\right)$ be $U_{j}^{\prime} s$ expected profit under partial integration and no ex-ante monopolization; $V_{j}^{F I}=E V^{F I}\left(c_{j}, c_{i}\right)$ be $\left(U_{j}-D_{j}\right)^{\prime} s$ expected profit under full integration; $D_{j}^{P I}=E D^{P I}\left(c_{i}, c_{j}\right)$ be $D_{j} s_{\text {expected }}$ profit under partial integration if it stays. (Note that these expected profits are computed assuming that $\left(U_{i}-D_{i}\right)$ are integrated.) 


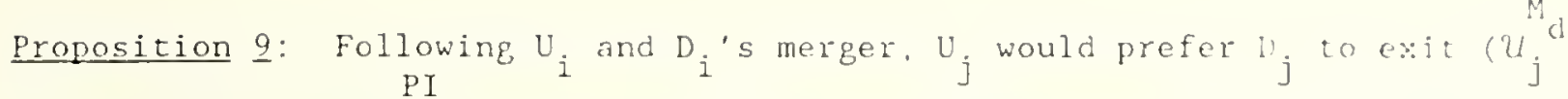
$>u_{j}$ ) in the case of large uncertainty. $U_{j}$ would prefer $D_{j}$ to stay $\left(u_{j}{ }^{M}<u_{j}{ }^{P I}\right)$ in the case of small uncertainty.

Proposition 9 (proved in Appendix 6) indicates when $U_{j}$ would like to keep an industrial base downstream. The intuition is that when $U_{j}$ has a large cost advantage over $U_{i}$ (which may arise in the large uncertainty case), $U_{j}$ is able to obtain the monopoly profit if it deals with a single downstream firm (in the absence of the bargaining effect emphasized in Sections 5 and 6), while it cannot commit not to supply both downstream firms if $D_{j}$ stays around. We call this the comitment effect. In contrast, Bertrand competition between the upstream firms implies that if $U_{j}$ has only a small cost advantage over $U_{i}$, $U_{j}$ 's profit is approximately $2 q^{*}\left(c_{j}\right)\left(c_{i}-c_{j}\right)$ when both downstream firms are around, where $q^{*}\left(c_{j}\right)$ is the symmetric Cournot output for cost $c_{j}$; and $q^{m}\left(c_{j}\right)\left(c_{i}-c_{j}\right)$ when only $D_{i}$ is around, where $q^{m}\left(c_{j}\right)$ is the monopoly output at cost $c_{j}$. Because the Cournot industry output exceeds the monopoly output, $U_{j}$ is better off facing two downstream units. We call this the demand effect.

Forced bandwagon: Next suppose that $U_{i}$ and $D_{i}$ have merged. We say that forced bandwagon by $U_{j}$ and $D_{j}$ occurs if the following three conditions hold:

(a) $J>D_{j}^{P I}\left(D_{j}\right.$ is no longer viable by itself).

(b) $v_{j}^{F I}-E-J>u_{j}^{M}\left(U_{j}\right.$ and $D_{j}$ are better off integrating than letting $D_{j}$ exit).

(c) $U_{j}^{P I}+D_{j}^{P I}-J>V_{j}^{F I}-E-J\left(U_{j}\right.$ and $D_{j}$ would not want to merge if $D_{j}$ were viable). 
We now investigate the conditions under which forced bandwagon can follow $U_{i}-D_{i}^{\prime}$ s merger.

Proposition 10: $\quad$ Suppose $U_{i}$ and $D_{i}$ have merged.

(i) A necessary condition for forced bandwagon is that $U_{j}$ would prefer $D_{j}$ not to exit: $u_{j}^{P I}>u_{j}^{M}$. (ii) Conversely, if $u_{j}^{P I}>u_{j}{ }^{M}$, there exists (E,J) such that forced bandwagon occurs.

Proof: (i) Add (a), (b), and (c).

(ii) Straightforward. Q.E.D.

Propositions 9 and 10 together say that forced bandwagon cannot occur for large uncertainty, but may occur for small uncertainty because the nonintegrated upstream supplier is concerned about keeping an industrial base.

- The merger game. The merger game with large downstream investments involves many cases, including pre-emption and war of attrition games. See Appendix 7 .

4.4 I "large" J "large" (possibility of ex-ante upstream and downstream monopolization).

We do not treat the case of general investments upstream and downstream. We content ourselves with the following observation: When $U_{i}$ and $D_{i}$ merge, $U_{j}$ may suffer indirectly through the exit of $\mathrm{D}_{j}$ (see Proposition 9), and may exit 
itself. Given that $D_{j}$ exits, the exit of $U_{j}$ can only hurt the integrated firm $\left(U_{i}-D_{i}\right)$ as $\left(U_{i}-D_{i}\right)$ can always refuse to trade with $U_{j}$. It is thereforo conceivable that $U_{i}$ and $D_{i}$ might refrain from integrating because this would trigger a chain of exits and reduce the industrial base upstream. In the model of this section, however, this phenomenon does not arise because we assumed that the upstream firms set prices. Hence, when $\mathrm{U}_{j}$ is more efficient than $U_{i}$, it makes an offer to $\left(U_{i}-D_{i}\right)$ that makes $\left(U_{i}-D_{i}\right)$ indifferent between accepting the offer and using the internal technology. Thus ( $\left.U_{i}-D_{i}\right)$ does not benefit from $U_{j}$ 's not exiting. But if the bargaining power were more evenly distributed, the phenomenon could occur; we return to these ideas in Section 6.

5. Bargaining Effects (Scarce Needs).

In the previous sections, we focussed on the idea that an upstream firm and a-downstream firm might integrate in order to reduce their willingness to supply a rival downstream firm, thus enabling them to monopolize (at least partially) the downstream market. In this and the next section we analyze a different mechanism by which foreclosure can occur: via bargaining effects. In particular, we argue that an upstream firm and a downstream firm may merge in order to ensure that they trade with each other, i.e. that the upstream firm channels scarce supplies to its downstream partner rather than to a downstream competitor and that the downstream firm satisfies its scarce needs by purchasing from its upstream partner rather than an upstream competitor. This can benefit the merging firms in two ways. First, to the extent that rival firms were obtaining some profit from trading with the merging partners previously, the merger, by eliminating this profit, will increase the merging 
firms' share of total profit. Second, the profits of rival firms may fall below the critical level at which they are covering their costs and hence they may exit the market. As a result the merging firms may succeed in monopolizing the market ex-ante.

We will present two models that capture these ideas. The first, in this section, focusses on a downstream firm with scarce needs favoring its upstream partner. The second, in Section 6 , focusses on an upstream firm with scarce supplies favoring its downstream partner. We separate these effects both because they have somewhat different implications and also to avoid making the analysis too burdensome. Obviously in many real situations one would expect to find both effects.

The Case of Scarce Needs.

The framework is similar to that of section 3. As there, we suppose two upstream firms and two downstream firms. In the present variant, downstream firms are not directly hurt by vertical integration and we can assume without loss of generality that their investment is equal to zero. Denote the investment cost of upstream firm $U_{i}$ by $I_{i}(i=1,2)$, where, without loss of generality, $I_{1} \leq I_{2}$. In order to abstract from the ex-post monopolization issues discussed in the last section, we suppose that $U_{1}$ and $\mathrm{U}_{2}$ have the same constant marginal cost $c$. (In this case, the model of Section 3 predicted that nonintegration would be the outcome.) However, we now drop the assumption that the upstream firms make independent and simultaneous take-it-or-leave-it offers to the downstream firms, supposing instead that contracts are bargained over. To be more specific, we assume that each (nonintegrated) upstream firm negotiates with each downstream firm 
to be its supplier. Moreover, the bargaining of an independent $U_{i}$ with $D_{1}$ is independent of the bargaining of $U_{i}$ with $D_{2} \cdot{ }^{21}$ Finally, the competition of the upstream firms is not so fierce that their profits are completely

eliminated; instead we suppose that a constant fraction $\beta$ of the surplus from supplying a downstream firm accrues to each upstream firm, where $0<\beta<\frac{1}{2}$ (so the fraction of surplus accruing to the downstream firm is $(1-2 \beta)$ ). ${ }^{22}$ We will also sometimes need to consider the case where there is only one upstream firm in the market. In this case we assume that this upstream firm captures a fraction $\beta^{\prime}$ of the surplus from supplying a downstream firm, where $\beta^{\prime}>2 \beta$ (so a downstream firm does strictly worse bargaining with one upstream firm than with two).

Remark. The scarce Needs variant can be reinterpreted as applying to a situation where the upstream firms supply a piece of machinery or a technology that-allows the downstream firms to produce at marginal cost c. Each downstream firm has a unit demand for the machinery or the technology. In this reinterpretation, the sense in which needs are scarce is particularly clear.

${ }^{2} I_{\text {If }} U_{i}$ and $D_{i}$ are integrated, bargaining between them over price is irrelevant given our assumption that managers of $\mathrm{U}_{i}$ and $\mathrm{D}_{i}$ both get a fraction of total profit. As we shall see, in this case, $U_{i}-D_{i}$ will still want co compete with $U_{j}$ to supply $D_{j}$ (assuming $U_{j}$ has not exited).

${ }^{22}$ Here $\beta$ should be understood as the expected share of the surplus that $U_{i}$ obtains rather than the actual share. For example, one interpretation is that each upstream firm wins the competition to supply a particular downstream firm with probability $1 / 2$, the winner receives a share $2 \beta$ of profit and the loser receives nothing. 
Nonintegration.

Suppose for the moment that both upstream firms invest under nonintegration. Since $U_{1}, U_{2}$ have the same marginal cost, the reaction curves $R_{1}, R_{2}$ defined in the last section are the same: $R_{1}(q)=R_{2}(q)=R(q)$, say. The equilibrium under nonintegration is described in the next proposition.

Proposition 11: Under nonintegration, $D_{1}$ and $D_{2}$ each buy $q^{*}$ from the upstream firms, where $\mathrm{q}^{*}$ is the cournot level corresponding to marginal cost $\mathrm{c}$ : $\mathrm{q}^{*}=\mathrm{R}\left(\mathrm{q}^{*}\right)$. The surplus to be shared between each downstream firm $D_{i}$ and $U_{1}$ and $U_{2}$, given that the rival downstream firm chooses $q^{*}$, is $P\left(2 q^{*}\right) q^{*}-c q^{*} \equiv \pi^{d}$, and this is divided in the proportions $(1-2 \beta), \beta$ and $\beta$ respectively. Total output is $2 \mathrm{q} *$ and profits are:

$$
\begin{gathered}
U_{i}: \quad U^{N I}=\beta \pi^{d}+\beta \pi^{d}=2 \beta \pi^{d} \\
D_{i}: \quad D^{N I}=(1-2 \beta) \pi^{d} .
\end{gathered}
$$

The proof of this proposition is very straightforward. Let $q_{1}, q_{2}$ be the amounts that $D_{1}$ and $D_{2}$ are expected to purchase in equilibrium. Then $D_{1}$ in combination with either (or both) of $\mathrm{U}_{1}$ or $\mathrm{U}_{2}$ can, taking $\mathrm{q}_{2}$ as given, achieve a total surplus of $\underset{q}{\operatorname{Max}}\left[\mathrm{P}\left(\mathrm{q}+\mathrm{q}_{2}\right) \mathrm{q}-\mathrm{cq}\right]$. The solution to this maximization problem is $\mathrm{q}_{1}=\mathrm{R}\left(\mathrm{q}_{2}\right)$. By a similar argument, $\mathrm{q}_{2}=\mathrm{R}\left(\mathrm{q}_{1}\right)$. It follows that $q_{1}=q_{2}=q *$. The remainder of Proposition 11 follows from our assumptions about bargaining and the division of surplus. 
Eull Integration.

Consider next full integration, maintaining for the moment the assumption that $\mathrm{U}_{1}$ and $\mathrm{U}_{2}$ both invest. Then the only change caused by full integration is that $\mathrm{D}_{1}$ will obtain all its supplies from its partner U, and similarly $\mathrm{D}_{2}$ will obtain all its supplies from $\mathrm{U}_{2}$ (there is no reason to buy externally given that internal production is as cheap). This does not change equilibrium output levels since the best reaction for $U_{i}-D_{i}$ to an expected purchase of $q_{j}$ by $D_{j}$ is $R\left(q_{j}\right)$. Hence $q_{l}=R\left(q_{2}\right)$ and $q_{2}=R_{l}\left(q_{l}\right)$, i.e. $q_{l}=$ $\mathrm{q}_{2}=\mathrm{q} * \mathrm{U}_{1}$ and $\mathrm{D}_{1}$ will together share the profit $\pi$, and similarly so will $\mathrm{U}_{2}$ and $\mathrm{D}_{2}$. From these profits must be subtracted the integration costs $E$. The outcome is summarized in Proposition 12.

Proposition 12. Under full integration, $D_{i}$ buys q* from upstream firm $U_{i}$ $(i=1,2)$, where $q^{*}=R\left(q^{*}\right)$. Total output is $2 q^{*}$ and profits are:

$$
\begin{aligned}
& \left(U_{1}-D_{1}\right): \quad V^{F I}=\pi^{d}-E \\
& \left(U_{2}-D_{2}\right): \quad V^{F I}=\pi^{d}-E .
\end{aligned}
$$

Note that the combined profits of $U_{i}-D_{i}$ are the same under full integration as under nonintegration, except for the integration cost.

\section{Partial Integration.}

Suppose next that $U_{i}$ and $D_{i}$ integrate, $U_{j}$ and $D_{j}$ remain separate, and $U_{i}, U_{j}$ both continue to invest. $U_{i}$ will now supply all of $D_{i}$ s needs, putting $\mathrm{D}_{i}$ on its reaction curve $\mathrm{R}\left(\mathrm{q}_{j}\right)$; but, as in the case of nonintegration, $U_{i}$ and 
$U_{j}$ will compete for $D_{j}$ 's custom. The latter conclusion follows from the fact that, given that $U_{i}$ and $U_{j}$ have the same marginal costs, $U_{i} \operatorname{cannot}$ gain ex-post from refusing to deal with $D_{j}$ or restricting its supplies to $D_{j}: U_{j}$ alone will agree to put $D_{j}$ on its reaction curve $R\left(q_{i}\right)$, which is the same outcome that occurs if $\mathrm{U}_{i}$ and $\mathrm{U}_{j}$ are both willing to supply $\mathrm{D}_{j}$.

This argument shows that $q_{i}=R\left(q_{j}\right), q_{j}=R\left(q_{i}\right), i \cdot e \cdot q_{i}=q_{j}=q *$.

Although partial integration does not change output levels, however, it does affect the division of surplus. $U_{j}$ will lose the $\beta \pi^{d}$ it earned from supplying $D_{i}$ under nonintegration (i.e. $U_{i}-D_{i}$ will now divide $\pi^{d}$ between them); while the gains from trade that $D_{j}$ can realize in combination with $U_{i}$ and/or $\mathrm{U}_{j}$ will be shared in the proportions $1-2 \beta, \beta, \beta$, respectively.

Proposition 13: Under partial integration, $D_{i}$ buys $q^{*}$ from $U_{i}$ and $D_{j}$ buys $q *$ from $U_{i}$ and/or $U_{j}$, where $q *=R(q *)$. Total output is $2 q *$ and profits are:

$$
\begin{aligned}
& U_{i}-D_{i}: V^{P I}=(1+\beta) \pi^{d}-E . \\
& U_{j}: \quad U^{P I}=\beta \pi^{d} . \\
& D_{j}: \quad D^{P I}=(1-2 \beta) \pi^{d} .
\end{aligned}
$$

$U_{i}-D_{i}^{\prime}$ 's combined profits are higher by $\beta \pi^{d}$ - E under partial integration than under nonintegration. On the other hand, $U_{j}-D_{j}$ s profits are lower by $\beta \pi^{\mathrm{d}}$. 
Ex-ante Monopolization.

So far we have supposed that $U_{1}, U_{2}$ both invest under both integration and nonintegration. The final structure we consider is where $\mathrm{U}_{1}$ and ${ }_{1}$ integrate and this causes $U_{2}$ not to invest (to exit). (The mirror image case in which the higher-investment cost firm $U_{2}$ merges with $D_{2}$ and $U_{1}$ exits will turn out to be irrelevant.) This case leaves the single supplier $\mathrm{U}_{1}$ facing two upstream firms $D_{1}, D_{2}$, one of which is its partner. We can apply Proposition 1 of the previous section to learn the outcome: $U_{1}$ will supply only $D_{1}$ and will monopolize the market, i.e. $U_{1}-D_{1}$ will choose the output level $q^{m}$ that maximizes $P(q) q-c q$.

Denote monopoly profit, $P\left(q^{m}\right) q^{m}-c q^{m}$ by $\pi^{m}$.

Proposition 14: Under ex-ante monopolization (integration by $U_{1}-D_{1}$ and exit by $\left.\mathrm{U}_{2}\right), \mathrm{D}_{1}$ buys $\mathrm{q}^{\mathrm{m}}$ from $\mathrm{U}_{1}$ where $\mathrm{q}^{\mathrm{m}}$ maximizes $\mathrm{P}(\mathrm{q}) \mathrm{q}-\mathrm{cq}$, and $\mathrm{D}_{2}$ buys nothing. Total output is $\mathrm{q}^{\mathrm{m}}$ and profits are:

$$
\begin{gathered}
U_{1}-D_{1}: v^{M u}=\pi^{m}-E, \\
U_{2}: \text { zero, } \\
D_{2}: \text { zero. }
\end{gathered}
$$

We will assume in what follows that $U_{1}-D_{1}$ 's profits are higher if they can monopolize the market ex-ante than under nonintegration. That is:

$$
v^{M} u=\pi^{m}-E>\pi^{d}
$$


If this were not the case, integration would not be profitable under any conditions in the model of this section. 23

The Investment Decision.

Let's reconsider our assumption that upstream firms invest. Under nonintegration, $U_{1}$ and $U_{2}$ cover their costs and invest as long as

$$
2 \beta \pi^{\mathrm{d}}>\mathrm{I}_{2}
$$

We assume (5.2) in what follows.

Consider next full integration. Here investment is less of an issue for the following reason. Full integration plus exit by $U_{i}$, say, could never be a correctly anticipated equilibrium outcome, since, given that $\mathrm{D}_{i}$ will not be supplied by $U_{j}$ and will make zero profits, $U_{i}-D_{i}$ could do better by staying separate and saving their merger costs $E$.

Consider finally partial integration - - in particular the case where $U_{1}$ and $D_{1}$ merge but $U_{2}$ and $D_{2}$ stay separate (the logic in the reverse case is similar). Under these conditions, as we have already noted, $U_{2}$ may or may not invest. It is easily seen, however, that $U_{1}$ invests. In particular, suppose the contrary: $U_{1}$ does not invest, but $U_{2}$ does. (If $U_{2}$ does not invest, $U_{1}-D_{1}^{\prime}$ s profits are automatically zero if $U_{1}$ does not invest and hence in this case it is better for $U_{1}$ to invest.) Then ex-post a single nonintegrated firm $U_{2}$ will face two downstream firms $D_{1}, D_{2}$. Applying the same logic as in Proposition 1, we see that $\mathrm{U}_{2}$ will supply $\mathrm{q}$ t to each of $\mathrm{D}_{1}$,

\footnotetext{
${ }^{23}$ In particular, $V^{\mathrm{M}} \leq \pi^{\mathrm{d}} \Rightarrow \beta \pi^{\mathrm{d}}<\mathrm{E}$, since $\pi^{\mathrm{m}}>2 \pi^{\mathrm{d}}$. That is, the net gain to $U_{i}-D_{i}$ from integrating when $U_{j}-D_{j}$ stay separate is negative.
} 
$D_{2}$. Moreover, given our assumption about one-on-one bargaining, $D_{1}$ and $D_{2}$ will obtain a share $\left(1-\beta^{\prime}\right)$ of the surplus $\pi^{d}$, and $U_{2}$ will obtain the remainder. Thus $\mathrm{U}_{1} \cdot \mathrm{D}_{1}^{\prime}$ 's profits will be $\left(1-\beta^{\prime}\right) \pi^{\mathrm{d}}-\mathrm{E}$. But $\mathrm{I}_{1} \leq \mathrm{I}_{2}, \beta^{\prime}>\beta$ and (5.2) imply that

$$
\left(1-\beta^{\prime}\right) \pi^{\mathrm{d}}<(1+\beta) \pi^{\mathrm{d}}-\mathrm{I}_{1} \text {, }
$$

which ensures that $U_{1}-D_{1}$ can do better by investing (see Proposition 13 ). Thus it is never profitable for $\mathrm{U}_{1}-\mathrm{D}_{1}$ to merge and $\mathrm{U}_{1}$ not to invest.

The Merger Game.

We treat the merger game as in the ex-post monopolization variant. In particular, we suppose that the merger is irreversible and that if $U_{i}$ and $D_{i}$ merge, $U_{j}$ and $D_{j}$ can respond instantaneously by merging too. Under these assumptions it is easy to see that in the present model full integration will never be an equilibrium outcome. This is because neither $U_{1}-D_{1}$ nor $U_{2}-D_{2}$ will merge if the other follows suit since by Propositions 11-12, the final profit of each $U_{i}-D_{i}$ pair will be less than the combined profits of $U_{i}$ and $D_{i}$ under nonintegration.

Partial integration without exit is also not a possible outcome. The reason is that, as in the ex-post monopolization variant the gain from $U_{j}-D_{j}$ merging is the same whether $U_{i}, D_{i}$ are integrated or not; and is given by $\beta \pi^{d}$ - E. If this gain is positive, then $U_{j}-D_{j}$ will follow suit if $U_{i}-D_{i}$ merge. On the other hand, if it is negative, then $U_{j}-D_{j}$ will not follow suit, but $U_{i}-D_{i}$ will also prefer nonintegration to partial integration.

Hence the only reason for $U_{i}$ and $D_{i}$ to merge is if the response of $U_{j}$ is to exit. In other words, the final outcome of the merger game will be either 
nonintegration or ex-ante monopolization.

Proposition 15 tells us which of these outcomes will actually occur. In the formal statement of the proposition we suppose that $U_{1}-D_{1}$ merge if any merger occurs at all. It turns out that in subcase 2 of the proposition, there can be another equilibrium in which $U_{2}-D_{2}$ merge and $U_{1}$ exits. We will argue, however, that this equilibrium is not compelling because in the continuous time model described in Section 2, $\mathrm{U}_{1}-\mathrm{D}_{1}$ would pre-empt $\mathrm{U}_{2}-\mathrm{D}_{2}$ by merging prior to date 0 .

Proposition 15: Assume (5.1)-(5.2). Suppose also that $\mathrm{U}_{1}-\mathrm{D}_{1}$ decide first whether to merge, and if and only if they merge, $U_{2}-D_{2}$ can respond by merging too. Then:

(1) The merger game will result in nonintegration if either

(a) $\beta \pi^{\mathrm{d}}>\mathrm{E}$ and $\pi^{\mathrm{d}}-\mathrm{E}>\mathrm{I}_{2}$; or

(b) $\beta \pi^{\mathrm{d}}<\mathrm{E}$, and $\pi^{\mathrm{d}}-\mathrm{E}>\mathrm{I}_{2}$.

(c) $\beta \pi^{\mathrm{d}}<\mathrm{E}, \beta \pi^{\mathrm{d}}>\mathrm{I}_{2}$.

(2) The merger game will result in a merger of $U_{1}-D_{1}$ and exit of $U_{2}$ if either

(a) $\beta \pi^{\mathrm{d}}>\mathrm{E}, \pi^{\mathrm{d}}-\mathrm{E}<\mathrm{I}_{2}$; or

(b) $\beta \pi^{\mathrm{d}}<\mathrm{E}, \pi^{\mathrm{d}}-\mathrm{E}<\mathrm{I}_{2}$ and $\beta \pi^{\mathrm{d}}<\mathrm{I}_{2}$.

Note that as long as we rule out "probability zero" cases of equality $\left(\beta \pi^{\mathrm{d}}=\mathrm{E}\right.$, etc.), these cases are exhaustive. 
The proof of Proposition 15 is straightforward. In Case 1(a), $\beta \pi^{d}>E$ implies that $U_{2}-D_{2}$ will find it profitable to bandragon if $U_{1}-D_{1}$ merge. unless $U_{2}$ exits. Since full integration is unprofitable for $U_{1}-D_{1}$, this means that $U_{1}-D_{1}$ merge only if $U_{2}$ exits (i.e. only if $\pi^{d}-E<I_{2}$ ). In l(b), $\mathrm{U}_{2}-\mathrm{D}_{2}$ 's profits are positive under full integration $\left(\pi^{\mathrm{d}}-\mathrm{E}>\mathrm{I}_{2}\right)$, and hence $U_{1}-D_{1}$ cannot force exit by $U_{2}$. Therefore $U_{1}-D_{1}$ prefer not to integrate. In $1(c), U_{1}-D_{1}$ can again not force exit by $U_{2}$ since, if $U_{1}-D_{1}$ merge, $U_{2}$ can cover its investment costs by staying independent. Again $U_{1}-$ $D_{1}$ choose not to integrate.

Case 2 consists of the complementary region in parameter space to Case 1 , i.e. it consists of those subcases where a merger by $U_{1}-D_{1}$ will cause $U_{2}$ to exit. Under these conditions, integration is profitable for $U_{1}-D_{1}$ (by) (5.1)).

In Case 2 the model may be consistent with another outcome: $U_{2}-D_{2}$ merge and $U_{1}$ exits. In the continuous time version of the model described in Section 2, however, this would lead to a preemption game that $U_{I}-D_{I}$ would win by merging at date (-T) where $T$ satisfies:

$$
-E+e^{-r T}\left[\frac{\pi^{m}-I_{2}}{r}\right]=0
$$

(Note that the discounted profit of $U_{I}-D_{1}$ at date 0 in this equilibrium is $\left.\left\{\left(I_{2}-I_{1}\right) / r\right\}.\right)$ For this reason we have ignored the possibility that $U_{2}-D_{2}$ merge and force exit of $\mathrm{U}_{1}$ in the above.

Remark. We have noted that in this "scarce needs" model, partial integration (without exit) and bandwagon (full integration) are not possible outcomes. 
However, there is another version of the "scarce needs" model where these outcomes can occur. In particular, suppose that there are limits on how much $D_{1}$ and $D_{2}$ can purchase from the upstream firms, e.g. because they have limited storage. Then if $D_{1}$ has larger storage than $D_{2}, U_{1}$ may merge with $D_{1}$ in order to cut $\mathrm{U}_{2}$ out of the gains from trading with $\mathrm{D}_{1}$. Moreover, this can be profitable even if $U_{2}-D_{2}$ respond by merging, in order to cut $U_{1}$ out of the gains from trading with $\mathrm{D}_{2}$.

Rather than analyze a model of this type, we turn in Section 6 to a symmetric version of it in which the upstream firms have scarce capacities. This model goes under the heading of Scarce Supplies.

\section{Welfare.}

The welfare effects of merger are straightforward in this variant. Merger followed by exit leads to lower output ( $\mathrm{q}^{\mathrm{m}}$ vs. $2 \mathrm{q}{ }^{*}$ ) and higher prices for consumers. So consumer surplus falls. Producer surplus, however, rises and in some cases total surplus may also rise as a result of the saring in the exiting firm's investment cost. 24

${ }^{24}$ For example, let $p=a-b Q, \beta \simeq \frac{1}{2}$. Then $q=\frac{a-c}{2 b}, q *=\frac{a-c}{3 b}$. Total surplus if $U_{1}-D_{1}$ merge and $U_{2}$ exits, $W_{m}=\frac{3}{8} \frac{(a-c)^{2}}{b}-I_{1}-E$. Total surplus under duopoly, $W_{d}=\frac{4}{9} \frac{(a-c)^{2}}{b}-I_{1}-I_{2}$. If $E$ is small and $\pi^{d}-E<I_{2}$, it is easy to check that (1) $U_{1}-D$ will merge and $U_{2}$ will exit; (2) $W_{m}>W_{d}$. Also these conditions are consistent with $2 \beta \pi^{\mathrm{d}}>I_{2}$, i.e. with both firms investing under nonintegration. 
6. Bargaining Effects (Scarce Supplies).

We turn now to the case where the upstream firms are

capacity-constrained and integration occurs to ensure that an upstream firm channels its scarce supplies to its downstream partner. To capture this idea, we suppose that the two upstream firms $U_{1}, U_{2}$ have exogenously given capacities $\bar{q}_{1}, \bar{q}_{2}$, respectively. We assume that $u_{1}$ is bigger than $U_{2}: \bar{q}_{1}>$ $\bar{q}_{2}$. To simplify, we suppose that $U_{i}^{\prime}$ 's marginal cost of production is zero up to its capacity constraint $\bar{q}_{i}(i=1,2)$ and that

$$
\overline{\mathrm{Q}}=\overline{\mathrm{q}}_{1}+\overline{\mathrm{q}}_{2} \leq \mathrm{q}^{\mathrm{m}}=\operatorname{argmax} \mathrm{P}(\mathrm{q}) \mathrm{q} .
$$

(6.1) ensures that there is no motive to monopolize the market ex-post by restricting output. To be more precise, even if there were only one downstream firm, given (6.1), it would wish to purchase, and sell on the downstream market, all the output that $U_{1}$ and $U_{2}$ have available.

(6.1) is a simplifying assumption, which will fail to be satisfied in many markets. 25 In the absence of (6.1), aspects of the models of both previous variants come into play $\left(\bar{q}_{i}=\infty, \bar{q}_{j}=0\right.$ arises in the large uncertainty case of the ex-post monopolization model and $\bar{q}_{i}=\bar{q}_{j}=\infty$ in the Scarce Needs model). Also a new possibility must be dealt with: a downstream firm may try to purchase more supplies than it needs and destroy some of them, in order to keep them out of the hands of a rival (in principle, each firm would like to destroy $\bar{Q}-q^{m}$ if it can buy all the supplies). If (6.1) holds, such a strategy is never optimal. We should also stress that we are confident that our results will continue to be relevant when (6.1) does not hold.

\footnotetext{
${ }^{25}$ We expect (6.1) to hold if the cost of building capacity is large.
} 
Note that, while $D_{1}$ and $D_{2}$ compete for supplies, they do not really compete on the product market. As long as no upstream firm exits, each unit of the intermediate good has a fixed value, $P(\bar{Q})$, for the downstream firms. Thus, if upstream investment costs are small enough and ex-ante monopolization is not an issue, the scarce supplies model applies to industries in which the downstream firms are in separate product markets.

Because in this model, only the nonintegrated downstream firms are hurt by integration, it is natural to assume that only $D_{i}$ has to invest in order to operate (but see Remark 1 after Proposition 20, where we discuss upstream investments). We denote $\mathrm{D}_{i}$ 's investment cost by $\mathrm{J}$ (assumed to be independent of i).

We model bargaining in a similar way to section 5, with the roles of the upstream and downstream firms reversed. We assume that the downstream firms negotiate with each independent upstream firm to purchase its supplies, where the bargaining of $\mathrm{D}_{i}$ with $\mathrm{U}_{1}$ is independent of the bargaining of $\mathrm{D}_{i}$ with $\mathrm{U}_{2}$. By analogy to Section 5, we suppose that a fraction $\beta$ of the surplus from $U_{i}$ supplying $D_{1}$ or $D_{2}$ accrues to each of $D_{1}, D_{2}$ and the remaining fraction $(1-2 \beta)$ accrues to $U_{i}$. We will also sometimes want to consider the case where a single downstream firm bargains with $U_{i}$. Under these conditions, again by analogy to Section 5, the downstream firm receives a fraction $\beta^{\prime}$ of the surplus and $U_{i}$ receives $1-\beta^{\prime}$, where $\beta^{\prime}>2 \beta$.

\section{Nonintegration.}

Suppose for the moment that both downstream firms invest under nonintegration. The following proposition which characterizes equilibrium in this case is immediate. 
Proposition 16: Under nonintegration, the downstream firms buy the total available capacity $\bar{Q}$ from the upstream firms. The surplus to be shared between each upstream firm $U_{i}$ and $D_{1}$ and $D_{2}$ is $P(\bar{Q}) \bar{q}_{i}$ and this is divided in the proportions $(1-2 \beta), \beta$ and $\beta$ respectively. Profits are:

$$
\begin{aligned}
& U_{i}: \quad U_{i}^{N I}=(1-2 \beta) P(\bar{Q}) \bar{q}_{i} \\
& D_{i}: \quad D^{N I}=\beta p(\bar{Q})\left(\bar{q}_{1}+\bar{q}_{2}\right)=\beta p(\bar{Q}) \bar{Q}
\end{aligned}
$$

We turn next to full integration and partial integration, maintaining for the moment the assumption that $D_{1}, D_{2}$ invest. If $U_{i}-D_{i}$ and $U_{j}-D_{j}$ both merge, $U_{i}$ will sell all its supplies to $D_{i}$ and $U_{j}$ all its supplies to $D_{j}$. On the other hand, if $U_{i}-D_{i}$ merge and $U_{j}$ and $D_{j}$ do not, $U_{i}$ will sell all its supplies to $D_{i}$, and $D_{i}$ and $D_{j}$ will compete for $U_{j}$ s supplies.

The outcomes in these cases are summarized in Propositions 17-18.

proposition 17: Under full integration, $D_{i}$ buys $\bar{q}_{i}$ from $U_{i}(i=1,2)$ and profits are:

$$
\left(U_{i}-D_{i}\right): \quad v_{i}^{F I}=P(\bar{Q}) \dot{q}_{i}-E . \quad(i=1,2) .
$$

Proposition 18: Under partial integration ( $U_{i}-D_{i}$ merge, $U_{j}-D_{j}$ do not), $D_{i}$ buys $\bar{q}_{i}$ from $U_{i}, D_{i}$ and $D_{j}$ compete to buy $U_{j}$ 's supplies $\bar{q}_{j}$ ' sharing the surplus from this transaction in the proportions $\beta, \beta$ and $(1-2 \beta)$ respectively. Profits are: 


$$
\begin{gathered}
\left(U_{i}-D_{i}\right): \quad V_{i}^{F I}-P(\bar{Q})\left(\bar{q}_{i}+\beta \bar{q}_{j}\right)-E, \\
U_{j}: \quad U_{j}^{P I}=(1-2 \beta) P(\bar{Q}) \bar{q}_{j}, \\
D_{j}: \quad D_{j}^{P I}=\beta P(\bar{Q}) \bar{q}_{j} .
\end{gathered}
$$

Propositions 16 through 18 tell us that the gain to $U_{1}-D_{1}$ from integrating while its rival $\mathrm{U}_{2}-\mathrm{D}_{2}$ does not is $\beta \mathrm{P}(\overline{\mathrm{Q}}) \overline{\mathrm{q}}_{1}-\mathrm{E}$ (this is the share of surplus that $\mathrm{D}_{2}$ used to get from buying $\mathrm{U}_{1}$ 's supplies, but which is now divided between $U_{1}$ and $D_{1}$ ); and that the gain to $U_{2}-D_{2}$ of jumping on the bandwagon is $\beta \mathrm{P}(\overline{\mathrm{Q}}) \overline{\mathrm{q}}_{2}$ - E. In other words, as in the previous two variants, the benefits to $U_{i}-D_{i}$ of integrating are independent of whether $U_{j}-D_{j}$ integrate (this ignores the possibility that integration by $U_{i}-D_{i}$ causes $D_{j}$ to exit). In contrast to Section 5, however, $U_{1}-D_{1}$ may gain from integrating even if $\mathrm{U}_{2}-\mathrm{D}_{2}$ follow suit since $\mathrm{V}_{i}^{\mathrm{FI}}-\left(\mathrm{U}_{i}^{\mathrm{NI}}+\mathrm{D}^{\mathrm{NI}}\right)=\beta \mathrm{P}(\overline{\mathrm{Q}})\left(\overline{\mathrm{q}}_{i}-\right.$ $\bar{q}_{j}$ ) - E, which may be positive if $\bar{q}_{1}$ is sufficiently larger than $\bar{q}_{2}$ (however, the same formula shows that $\mathrm{U}_{2}-\mathrm{D}_{2}$ cannot gain from integrating if $\mathrm{U}_{1}-\mathrm{D}_{1}$ follow suit, given $\bar{q}_{2}<\bar{q}_{1}$ ).

Propositions 16 through 18 also tell us that a merger by $\mathrm{U}_{1}-\mathrm{D}_{1}$ reduces $\mathrm{D}_{2}$ 's profits, but does not have a direct effect on $\mathrm{U}_{2}$ 's profits (compare $\mathrm{U}_{2}^{\mathrm{PI}}$ and $\mathrm{U}_{2}^{\mathrm{NI}}$ ). The reduction in $\mathrm{D}_{2}$ 's profit may cause $\mathrm{D}_{2}$ to exit, a case we consider next. 
Ex-ante Monopolization (exit by $\mathrm{D}_{2}$ ).

With $D_{2}$ exiting, $D_{1}$ receives $U_{1}$ 's supplies automatically (since they are merged) and negotiates to buy $U_{2}$ 's supplies too. An important difference between this case and previous ones is that if $\mathrm{D}_{1}$ declines to buy $U_{2}$ 's supplies, they disappear from the market. Hence the gains that $D_{1}$ can achieve from trading with $U_{2}$ are $P(\bar{Q}) \bar{Q}-P\left(\bar{q}_{1}\right) \bar{q}_{1}$, rather than $P(\bar{Q})\left(\bar{Q}-\bar{q}_{1}\right)=P(\bar{Q}) \bar{q}_{2}$ Given one-on-one bargaining, a proportion $\beta^{\prime}$ of these gains go to $D_{1}$ and a proportion $\left(1-\beta^{\prime}\right)$ to $\mathrm{U}_{2}$.

Proposition 19: Under integration by $\mathrm{U}_{1}-\mathrm{D}_{1}$ and exit by $\mathrm{D}_{2}, \mathrm{D}_{1}$ buys $\bar{q}_{1}$ from $\mathrm{u}_{1}$ and $\bar{q}_{2}$ from $\mathrm{U}_{2}$. Profits are:

$$
\begin{aligned}
& \left(U_{1}-D_{l}\right): V_{I}^{M}=P\left(\dot{q}_{l}\right) \dot{q}_{l}+\beta^{\prime}\left[P(\bar{Q}) \bar{Q}-P\left(\dot{q}_{I}\right) \dot{q}_{I}\right]-E, \\
& \mathrm{U}_{2}: \quad \mathrm{U}_{2}^{\mathrm{M} d}=\left(1-\beta^{\prime}\right)\left[\mathrm{P}(\overline{\mathrm{Q}}) \overline{\mathrm{Q}}-\mathrm{P}\left(\overline{\mathrm{q}}_{1}\right) \overline{\mathrm{q}}_{1}\right] \text {, } \\
& \mathrm{D}_{2} \text { : Zero. }
\end{aligned}
$$

As in Section 5, we suppose that $\left(U_{1}-D_{1}\right)^{\prime}$ s profits are higher under ex-ante monopolization than under nonintegration. That is:

$$
\mathrm{V}_{\mathrm{l}}^{\mathrm{M}}{ }^{\mathrm{d}}=\mathrm{P}\left(\overline{\mathrm{q}}_{1}\right) \overline{\mathrm{q}}_{1}+\beta^{\prime}\left[\mathrm{P}(\overline{\mathrm{Q}}) \overline{\mathrm{Q}}-\mathrm{P}\left(\overline{\mathrm{q}}_{1}\right) \overline{\mathrm{q}}_{\mathrm{l}}\right]-\mathrm{E}>(1-2 \beta) \mathrm{P}(\overline{\mathrm{Q}}) \overline{\mathrm{q}}_{1}+\beta \mathrm{P}(\overline{\mathrm{Q}}) \overline{\mathrm{Q}} .
$$

Note that the RHS is decreasing in $\beta$ (since $\bar{Q}<2 \bar{q}_{l}$ ) and so reaches a maximum $P(\bar{Q}) \bar{q}_{1}$ when $\beta=0$. Hence (6.2) certainly holds if $E$ is small enough. Note also that if (6.2) fails to hold, neither $U_{1}-D_{1}$ nor $U_{2}-D_{2}$ will ever have an incentive to integrate in the present model, i.e. nonintegration will be the outcome. 
The Investment Decision.

Let's reconsider our assumption that downstream firms invest. Under nonintegration, $\mathrm{D}_{1}$ and $\mathrm{D}_{2}$ cover their costs and invest as long as

$$
\beta P(\bar{Q}) \bar{Q}>J
$$

We assume (6.3) in what follows.

Under full integration, it is not difficult to show that it will never pay $D_{i}$ to exit for some $i$. (Obviously it would not pay $D_{1}$ and $D_{2}$ both to exit since then there would be no market.) In particular, $U_{i}-D_{i}$ would do better not to merge at all if merger leads to $\mathrm{D}_{i}^{\prime}$ 's exit. To see this, note that the result of $D_{i}$ 's exit would be that $U_{i}$ would sell $\bar{q}_{i}$ to $D_{j}$, receiving a fraction $\left(1-\beta^{\prime}\right)$ of the surplus. ( $\left.U_{i}-D_{i}\right)^{\prime}$ s total profits would be $\left(1-\beta^{\prime}\right)\left(P(\bar{Q}) \bar{Q}-P\left(\bar{q}_{j}\right) \bar{q}_{j}\right)-E$, as opposed to $P(\bar{Q}) \bar{q}_{i}-E-J$ if $D_{i}$ invests. Because $P\left(\bar{q}_{j}\right) \leq P(\bar{Q}), D_{i}^{\prime} s$ exit increases $\left(U_{i}-D_{i}\right)^{\prime} s$ profit only if $J>$ $\beta^{\prime} \mathrm{P}(\bar{Q}) \dot{\mathrm{q}}_{i}$. But in the latter case, $\mathrm{D}_{i}$ would exit if $\mathrm{U}_{i}-\mathrm{D}_{i}$ were not integrated, given that $\mathrm{U}_{j}-\mathrm{D}_{j}$ are integrated; and thus $\mathrm{U}_{i}$ would enjoy profit $\left(1-\beta^{\prime}\right)\left(P(\bar{Q}) \bar{Q}-P\left(\bar{q}_{j}\right) \bar{q}_{j}\right)>\left(1-\beta^{\prime}\right)\left(P(\bar{Q}) \bar{Q}-P\left(\bar{q}_{j}\right) \bar{q}_{j}\right)-E$ by not merging with $D_{i}$. Thus $U_{i}$ would be better off refusing to merge with $D_{i}$.

Consider finally partial integration - - in particular the case where $\mathrm{U}_{1}$ and $\mathrm{D}_{1}$ merge but $\mathrm{U}_{2}$ and $\mathrm{D}_{2}$ stay separate (the logic in the reverse case is the same). Under these conditions, as we have already noted, $\mathrm{D}_{2}$ may or may not invest. It is easily seen, however, that $D_{1}$ invests (if $U_{1}-D_{1}$ 's merger is worthwhile at all). In particular, note that, by the same argument as in the full integration case, if $D_{1}$ exits, $U_{1}-D_{1}^{\prime} s$ profit equals $\left(1-\beta^{\prime}\right)(p(\bar{Q}) \bar{Q}$ - $\left.p\left(\bar{q}_{2}\right) \bar{q}_{2}\right)$ - E. But this is smaller than $U_{1}^{\prime}$ 's profit in the worst possible 
scenario if $\mathrm{U}_{1}-\mathrm{D}_{1}$ do not integrate, $\left(1-\beta^{\prime}\right)\left(\mathrm{p}(\overline{\mathrm{Q}}) \overline{\mathrm{Q}}-\mathrm{p}\left(\overline{\mathrm{q}}_{2}\right) \overline{\mathrm{q}}_{2}\right)$ (which occurs if $\mathrm{U}_{2}-\mathrm{D}_{2}$ integrate and $\mathrm{D}_{1}$ exits).

\section{The Merger Game.}

As above, we suppose that a merger is irreversible and that if $U_{i}$ and $D_{i}$ merge, $U_{j}$ and $D_{j}$ can respond instantaneously by merging too.

As in Proposition 15, we begin by supposing that $U_{l}-D_{l}$ merge if any merger occurs at all, and investigate $U_{2}-D_{2}^{\prime}$ s incentive to respond. We then check that $\mathrm{U}_{2}-\mathrm{D}_{2}$ would not preempt $\mathrm{U}_{1}-\mathrm{D}_{1}$ and prevent $\mathrm{U}_{1}-\mathrm{D}_{1}$ from integrating. It is clear that the worst outcome for $U_{1}-D_{1}$ is if $U_{2}-D_{2}$ decide to merge too. The reason is that in this case $U_{2}$ 's supplies are denied to $\mathrm{D}_{1}$ but at the same time they are sold on the market and so depress output price. Hence if $\mathrm{U}_{1}-\mathrm{D}_{1}$ 's profits rise from merger even in this case, we know that $\mathrm{U}_{1}-\mathrm{D}_{1}$ will certainly merge: doing so is a dominant strategy. From Propositions 16-17, we conclude that if

(6.4) $\quad \beta P(\bar{Q})\left(\bar{q}_{1}-\bar{q}_{2}\right)>E$,

$\mathrm{U}_{1}-\mathrm{D}_{1}$ certainly mezge.

On the other hand, if

$(6.5)$

$$
\beta P(\bar{Q})\left(\bar{q}_{1}-\bar{q}_{2}\right)<E
$$

$\mathrm{U}_{1}$ - $\mathrm{D}_{1}$ 's decision to merge will depend on $\mathrm{U}_{2}-\mathrm{D}_{2}$ 's response. Proposition 20, which is proved in Appendix 8, provides a full characterization of the different cases. Let $A=P(\bar{Q}) \bar{q}_{2}-J-E, B=\left(1-\beta^{\prime}\right)\left[P(\bar{Q}) \bar{Q}-P\left(\bar{q}_{1}\right) \bar{q}_{1}\right]$. 
Proposition 20: Suppose $U_{1}-D_{1}$ decide first whether to merge, and if and only if they merge, $\mathrm{U}_{2}-\mathrm{D}_{2}$ can respond by merging too.

Then:

(A) If $\beta \mathrm{P}(\overline{\mathrm{Q}})\left(\overline{\mathrm{q}}_{1}-\overline{\mathrm{q}}_{2}\right)>\mathrm{E}$ and $\beta \mathrm{P}\left(\overline{\mathrm{Q}}_{\mathrm{q}} \overline{\mathrm{q}}_{2}>\mathrm{E}, \mathrm{U}_{1}-\mathrm{D}_{1}\right.$ will merge and

(1) $\mathrm{U}_{2}-\mathrm{D}_{2}$ will also merge if $\mathrm{A}>\mathrm{B}$ (reluctant bandwagon: $\mathrm{U}_{2}-\mathrm{D}_{2}$ prefer to merge than stay independent, given that $\mathrm{U}_{1}-\mathrm{D}_{1}$ merge, but $\mathrm{U}_{2}-\mathrm{D}_{2}$ is worse off than under nonintegration) $D_{2}$ will exit if $A<B$.

(B) If $\beta \mathrm{P}(\overline{\mathrm{Q}})\left(\overline{\mathrm{q}}_{1}-\overline{\mathrm{q}}_{2}\right)>\mathrm{E}$ and $\beta \mathrm{P}(\overline{\mathrm{Q}}) \overline{\mathrm{q}}_{2}<\mathrm{E}, \mathrm{U}_{1}-\mathrm{D}_{1}$ will merge and

(1) $\mathrm{U}_{2}, \mathrm{D}_{2}$ will stay independent with $\mathrm{D}_{2}$ investing if $\beta \mathrm{P}(\overline{\mathrm{Q}}) \overline{\mathrm{q}}_{2}>\mathrm{J}$.

(2) $\mathrm{D}_{2}$ will exit if $\beta \mathrm{P}(\overline{\mathrm{Q}}) \overline{\mathrm{q}}_{2}<\mathrm{J}$ and $\mathrm{A}<\mathrm{B}$

(3) $\mathrm{U}_{2}-\mathrm{D}_{2}$ will merge if $\beta \mathrm{P}(\overline{\mathrm{Q}}) \overline{\mathrm{q}}_{2}<\mathrm{J}$ and $\mathrm{A}>\mathrm{B}$ (forced bandwagon: $\mathrm{U}_{2}-\mathrm{D}_{2}$ would prefer to stay independent but cannot since $D_{2}$ would exit)

(C) If $\beta \mathrm{P}(\overline{\mathrm{Q}})\left(\overline{\mathrm{q}}_{1}-\overline{\mathrm{q}}_{2}\right)<\mathrm{E}$,

(1) $\mathrm{U}_{1}-\mathrm{D}_{1}$ will merge and $\mathrm{D}_{2}$ will exit if $\beta \mathrm{P}\left(\overline{\mathrm{Q}}_{)}\right) \overline{\mathrm{q}}_{2}<\mathrm{J}$ and $\mathrm{A}<\mathrm{B}$.

(2) $U_{1}-D_{1}$ will merge, $U_{2}$ and $D_{2}$ will stay separate and $D_{2}$ will not exit if $\beta \mathrm{P}(\overline{\mathrm{Q}}) \overline{\mathrm{q}}_{2}>\mathrm{J}, \quad \beta \mathrm{P}(\overline{\mathrm{Q}}) \overline{\mathrm{q}}_{2}<\mathrm{E}$ and $\beta \mathrm{P}(\overline{\mathrm{Q}}) \overline{\mathrm{q}}_{1}>\mathrm{E}$.

(3) No merger will occur if $\beta \mathrm{P}(\overline{\mathrm{Q}}) \overline{\mathrm{q}}_{2}<\mathrm{J}$ and $\mathrm{A}>\mathrm{B}$ or $\beta \mathrm{P}(\overline{\mathrm{Q}}) \overline{\mathrm{q}}_{2}>\mathrm{J}, \beta \mathrm{P}(\overline{\mathrm{Q}}) \overline{\mathrm{q}}_{2}>\mathrm{E}$ or $\beta \mathrm{P}(\overline{\mathrm{Q}}) \overline{\mathrm{q}}_{2}>\mathrm{J}, \beta \mathrm{P}(\overline{\mathrm{Q}}) \overline{\mathrm{q}}_{2}<\mathrm{E}$ and $\beta \mathrm{P}(\overline{\mathrm{Q}}) \overline{\mathrm{q}}_{1}<\mathrm{E}$.

Note that a merger by $\mathrm{U}_{1}-\mathrm{D}_{1}$ will certainly occur if $\overline{\mathrm{q}}_{1}$ is very large relative to $\overline{\mathrm{q}}_{2}$, i.e. $\overline{\mathrm{q}}_{1} \simeq \overline{\mathrm{Q}}, \overline{\mathrm{q}}_{2} \simeq 0$. This is because (6.2) implies that 
$\beta \mathrm{P}(\overline{\mathrm{Q}}) \overline{\mathrm{Q}}=\beta \mathrm{P}(\overline{\mathrm{Q}})\left(\overline{\mathrm{q}}_{1}-\overline{\mathrm{q}}_{2}\right)>\mathrm{E}$. However, a merger by $\mathrm{U}_{1}-\mathrm{D}_{1} \mathrm{can}$ also occur even if $\bar{q}_{1}$ and $\bar{q}_{2}$ are quite close, if the shift in surplus away from $D_{2}$ is just enough to cause $\mathrm{D}_{2}$ 's profits to fall below $\mathrm{J}$ and lead to $\mathrm{D}_{2}$ 's exit (e.g., consider Proposition $20 \mathrm{C}(1)$ and suppose $\beta \mathrm{P}(\bar{Q}) \bar{q}_{2} \simeq J, P(\bar{Q}) \simeq P\left(\bar{q}_{1}\right)$ and $\beta^{\prime}$ very small).

It is worth noting that eager bandwagon is never an outcome in this model. $\mathrm{U}_{2}-\mathrm{D}_{2}$ are never better off under full integration than nonintegration; this follows from the fact that (6.4) cannot hold where $\bar{q}_{1}$ and $\bar{q}_{2}$ are interchanged. However, reluctant bandwagon occurs in $A(1)$ and forced bandwagon in $B(3)$.

So far we have assumed that $U_{1}-D_{1}$ move first. Might $U_{2}-D_{2}$ want to pre-empt a merger by $\mathrm{U}_{1}-\mathrm{D}_{1}$ ? Clearly there is no advantage to pre-emption if $U_{1}-D_{1}$ decide to merge anyway $\left(U_{2}-D_{2}\right.$ would do better to let $U_{1}-D_{1}$ merge first and then select a best response). This means that pre-emption is useless in Cases A and B of Proposition 20 since merger by $U_{1}-D_{1}$ is a dominant strategy. In Case $C(3)$, pre-emption is unnecessary since no merger occurs anyway. This leaves $C(1)$ and $C(2)$. C (2) implies that $\beta P(\bar{Q}) \bar{q}_{I}>J$, i.e, $D_{1}$ doesn't exit if $U_{2}-D_{2}$ merge; moreover, together with $\beta P(\bar{Q}) \bar{q}_{1}>E$ (see $C(2)$ ), this tells us that $U_{1}-D_{1}$ will jump on the bandwagon. Hence pre-emption does not prevent merger here. This leaves $C(1)$. It is easy to check that in the continuous time preemption game described in Section $2, U_{1}$ - $D_{1}$ has more incentive to integrate, and preempts $U_{2}-D_{2}$, except possibly in the following subcase: if $\beta \mathrm{P}(\overline{\mathrm{Q}}) \overline{\mathrm{q}}_{1}<\mathrm{J}\left(\mathrm{D}_{1}\right.$ exits if $\mathrm{U}_{2}-\mathrm{D}_{2}$ merge and $\mathrm{U}_{1}$ does not rescue $\left.D_{1}\right)$ and $P(\bar{Q}) \bar{q}_{1}-J-E<\left(l-\beta^{\prime}\right)\left(P(\bar{Q}) \bar{Q}-P\left(\bar{q}_{1}\right) \bar{q}_{1}\right)\left(U_{1}\right.$ does not rescue $D_{1}$ ), the incentives for $U_{1}-D_{1}$ to preempt $U_{2}-D_{2}$ and for $U_{2}-D_{2}$ to preempt $U_{1}-D_{1}$ are equal. The idea is that whoever preempts the other, the 
nonintegrated downstream firm exits, and therefore the preemption game is a "zero-sum game" (what one gains, the other loses). In that case, precmption occurs at the date at which each is indifferent between preempting and not preempting. 26

Note finally that in contrast to Section 4 there are no "public good" aspects to mergers here (the nonmerging downstream firm suffers from lack of supplies and the nonmerging upstream firm may suffer from the exit of its downstream partner). Hence, neither $U_{1}-D_{1}$ nor $U_{2}-D_{2}$ ever wants the other to move first, i.e. there cannot be a war of attrition.

Remark 1. To keep the variant relatively simple, we have ignored upstream investments. An implication of this is that vertical mergers have no effect on consumers: in all the subcases of Proposition 20, $\bar{Q}$ units are supplied to consumers and price is $P(\bar{Q})$. Allowing upstream investments would not alter the "first-round" effects of a $U_{1}-D_{1}$ merger since such a merger has no effect on $\mathrm{U}_{2}$ 's profits. However, if $\mathrm{D}_{2}$ exits as a result of the merger, this will reduce $U_{2}$ 's profits and might cause $U_{2}$ to exit. In other words, a "sequence" of exits is a possible outcome when upstream and downstream firms both invest. Under these conditions, supplies will disappear from the market and consumer prices will rise.

${ }^{26} U_{1}-D_{1}$ and $U_{2}-D_{2}$ then have equal probabilities of preempting: see Fudenberg-Tirole (1985) for the formalization of the continuous-time preemption strategies. The date $(-\mathrm{T})$ at which preemption occurs is given by: $E=e^{-r T}\left[P\left(\bar{q}_{1}\right) \bar{q}_{1}+\beta^{\prime}\left(P(\bar{Q}) \bar{Q}-P\left(\bar{q}_{1}\right) \bar{q}_{1}\right)-\left(1-\beta^{\prime}\right)\left(P(\bar{Q}) \bar{Q}-P\left(\bar{q}_{2}\right) \bar{q}_{2}\right)\right]$, where E is now taken to be a stock rather than a flow. 
There is another new possibility that arises when upstream firms invest Whereas $U_{1}$ - $D_{1}$ always benefit from $D_{2}$ 's exit (this increases $D_{1}$ 's monopsony power), $U_{1}-D_{1}$ may suffer from $U_{2}$ 's exit since scarce supplies disappear from the market. Hence in some cases $\mathrm{U}_{1}-\mathrm{D}_{1}$ may refrain from merging in order to keep $\mathrm{U}_{2}$ alive. ${ }^{27}$

Welfare.

The welfare effects of a merger are straightforward in the scarce Supplies variant. Since, in the absence of upstream investments, total output is always $\bar{Q}$, consumers neither gain nor lose from mergers. Firms lose in the aggregate to the extent that merger costs are incurred, but gain to the extent that investment costs $\mathrm{J}$ are saved (e.g. if $\mathrm{U}_{1}-\mathrm{D}_{1}$ merge and $\mathrm{D}_{2}$ exits, the net gain is J - E). Since, under partial or full integration, merger costs are incurred without investment costs being saved, these cases are always dominated by nonintegration.

Once upstream investments are allowed, consumers will generally be affected by mergers. In particular, under the maintained hypothesis that all firms invest under nonintegration, a merger by $U_{1}-D_{1}$ that leads to $D_{2}$ and $U_{2}$ both exiting will cause a fall in total supply from $\bar{Q}$ to $\bar{q}_{1}$, and a

27 One case where $U_{1}-D_{1}$ will barely be hurt by $U_{2}$ 's exit and hence will not refrain from merging is when $P\left(\dot{q}_{1}\right) \bar{q}_{1}=P(\bar{Q}) \bar{Q}$. This is because even if $D_{2}$ and $\mathrm{U}_{2}$ exit, $\mathrm{U}_{1}-\mathrm{D}_{1}$ achieve $\mathrm{P}\left(\overline{\mathrm{q}}_{1}\right) \overline{\mathrm{q}}_{1}-\mathrm{E}$ and this is almost as much as they receive if only $D_{1}$ exits (i.e., $v^{M}$ ). Hence for this case the presence of upstream investments will not change the analysis at all. Moreover, if $\beta \mathrm{P}(\overline{\mathrm{Q}}) \overline{\mathrm{q}}_{2}<\mathrm{J}$ and $\left(1-\beta^{\prime}\right)\left[\mathrm{P}(\overline{\mathrm{Q}}) \overline{\mathrm{Q}}-\mathrm{P}\left(\overline{\mathrm{q}}_{1}\right) \overline{\mathrm{q}}_{1}\right]<\mathrm{I}$, i.e. $\mathrm{D}_{2}$ and $\mathrm{U}_{2}$ both exit, there will be a clear effect on consumers from $U_{1}-D_{1}$ 's merger: output will fall from $\bar{Q}$ to $\overline{\mathrm{q}}_{1}$ and price will rise from $\mathrm{P}(\overline{\mathrm{Q}})$ to $\mathrm{P}\left(\overline{\mathrm{q}}_{1}\right)$. 
corresponding price rise from $P(\bar{Q})$ to $P\left(\dot{q}_{l}\right)$.

\section{Applications.}

In this section, we discuss the application of our model to three industries. The discussion is only meant to suggest how one might analyze these industries using our framework; needless to say, the evidence on vertical integration in these industries was not collected with this kind of model in mind.

Case \#1: The Cement and Ready-Mixed Concrete Industries.

Background. The cement industry consists of kilns and mills which convert limestone, clay and gypsum into cement. The ready-mixed concrete industry combines cement, sand, aggregates and water in the correct proportions to make concrete. In the early 1960s, a large amount of vertical integration occurred between the cement industry and the ready-mixed industry. In particular, a large number of cement companies integrated forward by acquiring ready-mix concrete companies. This heightened merger activity attracted the attention of the Federal Trade Commission, and they conducted an inquiry into the merger wave, resulting in the Economic Report on Mergers and Vertical Integration in the Cement Industry [1966].

Characteristics of the Cement and Concrete Industries. Cement is a very homogeneous commodity. It is manufactured to strict specification. There are no problems of customer-specific investment, and any ready-mixed concrete manufacturer can easily turn to an alternative supplier of cement. 
Because of large minimum efficient scale, concentration in the cement industry was very high. Since cement is bulky and costly to transport, ninety percent of all cement was shipped 160 miles or less [FTC Report, p. 7]. And, even at the state level (which may be larger than actual market areas), in only six.percent of the states did the four largest suppliers account for less than fifty percent of cement shipments.

Concentration in the downstream industry (ready-mixed concrete) was apparently lower; however, the industry consisted of a few large firms handling large contracting jobs (i.e., highways and bridges) and many small firms handling smaller jobs. As a result, in seventeen of 22 metropolitan areas for which the FTC had data, the four leading ready-mixed companies accounted for 75 percent or more of ready-mixed sales [FTC Report, p. 13].

The period immediately after world War II saw a steady growth in demand for cement with no corresponding increase in capacity. As a result, by 1955, cement mills were operating at 948 of capacity. 28 In response, existing cement mills were expanded and new mills constructed so that by 1960 the capacity utilization rate was down to 748 .

The merger wave in the cement and concrete industry seems to have been triggered by significant excess capacity among cement mills. From 1955 to 1965, the cement industry expanded capacity by sixty percent - twice as fast as actual shipments of cement grew during that time period. 29 This burst in cement mill construction and expansion was a response to high capacity utilization levels in the early 1950s, which resulted in spot shortages of

\footnotetext{
${ }^{28}$ Federal Trade Commission, Economic Report on Nergers and Vertical Integration in the Cement Industry (henceforth referred to as FTC Report), P. 1.

${ }^{29}$ Wall Street Journal, March 29, 1965, p. 1.
} 
cement. Demand continued to grow throughout the 1960 s, but because so much new capacity was brought on Iine, cement manufacturers saw their excess capacity cut into industry profits. Eighty percent of the vertical acquisitions occurred when market conditions were weak. ${ }^{30} 37$ of 55 vertical integrations took place in markets with above-average excess capacity. 31 Another factor contributing to the overcapacity was technological change making newer cement mills cheaper to operate. New technology also made it feasible to build ever-larger plants. By modernizing to cut costs, cement makers contributed to the industry-wide overcapacity. Neither denand conditions nor innovations in the downstream (concrete) market seem to have played an important role in triggering mergers.

Pattern of Integration. The sixties witnessed a wave of acquisitions of concrete manufacturers by cement producers. The acquired ready-mixed companies made between nineteen percent and 45 percent of total ready-mixed sales in their respective market areas (see FTC Report, p. 13, p. 98).

It is generally agreed that each acquiring cement producer hoped to assure itself of guaranteed outlets (e.g., FTC Report, p. 14, A1len [1971], p. 254); efficiency reasons do not seem to have been an important factor (Allen [1971], p. 253, fn. 76], Wilk [1968, p. 633-636], FTC Report, p. 3).

Bandwagoning occurred in many markets. All the executives' comments (to the extent that they are "incentive compatible") point to the fact that bandwagoning companies had been driven to purchase their customers because

$30_{\text {FTC Report, p. } 98 .}$

${ }^{31}$ Allen [1971]. 
their competitors were doing likewise. For example, in its Anmal Report of 1963, the Alpha Portland Cement Company stated,

Vertical integration within our industry has been on the increase in recent years. Alpha is presently not inclined to integrate vertically. However, if our position in the industry is put in jeopardy as a result of such corporate arrangements, there will be no alternative but to make similar moves.

Wilk [1968] also cites evidence that many cement firms dropped out of a market after a large customer had been bought out by competing cement manufacturers.

Link with our Analysis. The pattern of integration in the cement industry suggests that the relevant variant is the Scarce Needs one (see in particular the extension of the Scarce Needs model in which downstream firms have limited capacity). Upstream firms were eager to assure a downstream outlet. The bottleneck seems to have been the downstream industry.

Also consistent with the Scarce Needs variant are the facts that the complaining firms were cement producers; and that the mergers affected the largest ready-mixed concrete firms.

One prediction of the Scarce Needs model is not borne out by the facts. While the acquired ready-mixed companies substantially increased the fraction of their supply obtained from the acquiring cement companies after the mergers, from 37 percent to 69 percent (as the theory would predict), they still purchased some of their supplies from other cement suppliers. In

${ }^{32}$ Quoted in FTC Report, p. 2. 
contrast, the Scarce Needs variant has all supplies produced by the internal manufacturer. This particular prediction, however, relies on constant returns to scale upstream; and while there was excess capacity in the cement industry, there may have been capacity constraints at the individual cement producer level. The theory of section 5 could be modified (by increasing the number of upstream firms, allowing for individual but not industry capacity constraints) so as to account for the possibility of outside supplies.

Based on the executives' interviews and annual reports (FTC Report, p. 2 and 3, Allen [1971, pp. 267-270]), the type of relevant bandwagoning behavior seems to have been reluctant bandwagon.

One may of course wonder why integration took place in the sixties, and not earlier. As we noted, a primary determinant of the merger activity was the excess capacity in the cement industry, which appeared in the sixties. It should be noted that before this wave of forward integration, there were some instances of backward integration into cement manufacture by concrete makers. Typically, a large concrete maker would build a modern cement mill from scratch and use most of the cement produced to meet its own needs. These backward moves were initiated during the late 1950s, when cement was very profitable because of the limited capacity in the industry. Concrete makers' profits were squeezed by the high price of cement and the highly competitive nature of the concrete business, which held concrete prices down. That is, the relevant model for the late fifties may have been the Scarce Supplies variant. However, the gains from foreclosure seem to have been smaller in the fifties than in the sixties.

Finally, it would be interesting to know whether the FTC and the various commentators, in dismissing efficiency reasons for mergers, had recognized the 
possibility of hold-up problems in the cement industry. That is, it is possible that at a time of excess capacity, a number of cement producers would no longer have been viable in the absence of integration; they would have exited if they could not have combined with a concrete firm. This would provide an efficiency motive for mergers, which might offset the foreclosure effects emphasized here. More information is required to tell whether this efficiency effect could have been large. As noted in the Introduction, however, the fact that the mergers involved large cement and concrete firms provides some support for the foreclosure effect being the relevant one.

\section{Case \#2 Computer Reservation Systems}

a) Background. Computer reservation systems (CRS) perform the electronic booking of airline seats. The CRS industry was vertically integrated with airlines from its inception. The two largest systems are Sabre, owned by American Airlines, and Apollo, controlled by United Airlines. TWA, Texas Air and Delta have competing CRS. Although CRS typically listed flights of most other airlines than their controlling airlines or "hosts", by 1984 there had been widespread complaints that the CRS were biased in favor of the host airlines, neutral vis a vis the airlines that did not compete with the host airlines and biased against the airlines competing with the host airlines. For example, it seems that a substantial fraction of Continental's market was diverted by CRS bias. The bias was partly monetary; in 1981-82, American charged Eastern Airlines \$0.24 per segment booked on Sabre. It charged Delta $\$ 1.32$ per booking, and New York Air paid $\$ 2.00$ per booking. Eastern was a large carrier that did not compete fiercely with American. It was charged a 
low rate to give Sabre wider coverage, making Sabre more attractive to travel agents. Delta competed with American at its Dallas hub, and there is evidence that American wanted to drive Delta out of Dallas/Fort Worth. New York Air was charged an even higher price, because it was a price cutter. Another important element of discrimination concerned the order of display of flights on the travel agent's screen. This order is crucial as travel agents have little time and willingness to screen through several displays. Being listed early provides a major competitive advantage for an airline.

In 1984, eleven airlines which were not integrated into the CRS industry filed an antitrust suit against American and United, charging them with monopolization of CRS. In November 1984, the Civils Aeronautics Board established regulations for the purpose of guaranteeing more equal access to CRS. We are primarily interested in the pre-November 1984 period.

b) Analysis. One way of looking at the industry is to regard the CRS as an upstream firm with, possibly, scarce supplies. The CRS supplies an input (flight booking) to downstream firms, the airlines, who set prices for flights to consumers. For simplicity, we will analyze the industry using the paradigm of an upstream monopolist (an "essential facility") serving several downstream competitors. Clearly there is competition in the CRS segment, but this competition is imperfect, and furthermore, a travel agent usually consults a single CRS when serving a customer. Thus insights can be gleaned from the essential facility paradigm.

What are the efficiency gains of vertical integration? We are not aware of convincing arguments that they are substantial, but they may exist 
and further research is needed to see whether this is the case. ${ }^{33}$ The integrated CRS and airline can derive three other types of benefits. First. the host airline may favor its own flights by biasing display in their favor and against rival flights. This gives rise to an ex-post monopolization effect, as we discuss shortly. Second, the host airline may acquire real time access to all prices and seat availability and thus get an edge over its competitors who get the information later. The implications of this effect are less clear than those of the first, but they relate to an ex-post competitive advantage as well. Third, the integrated CRS will give priority to the host airline and thus does not leave bargaining rents to other airlines.

How do the first and third gains fit in our model? To take an extreme example, suppose that there is a single CRS and two airlines. Assume first that i) there are two priority lines on the screen allowing the CRS to display two flights (other lines require another display for the travel agent and do not sell in this extreme case) and ii) priority is not contractible. A customer's preferred departing time to go from city A to city B is noon, and the two airlines each have such a flight. A nonintegrated CRS will list the two airlines' noon flights (it is actually indifferent between doing this and listing two flights of the same airline as it does not receive compensation for priority, but it is reasonable to assume that it displays the noon flights of the two airlines if it receives some small benefit from pleasing travel agents or helping both airlines stay alive). Knowing this,

\footnotetext{
${ }^{33}$ It is sometimes argued that computer interconnections between the CRS and the airlines can be improved through vertical integration; it is unclear, however, why the same coordination could not be achieved under nonintegration via a contract.
} 
the two airlines will compete fiercely in the price of their noon flight. In contrast, if the first airline and the CRS merge, the CRS will exhibit this airline's noon and 2 PM flights, and will relegate the other airline's noon flight to a lower, non-selling ranking. Facing less competition, the first airline can raise its price on the noon flight, and the customer as well as the rival airline are hurt.

The story we just told is one of ex-post monopolization. Take now another extreme case in which i) there is a single priority line on the screen (all other lines are not conspicuous enough to sell) and ii) priority can be contracted upon between an airline and the CRS. The issues described above of the unintegrated CRS being unable to commit to give priority to a single airline disappears. Here there is the "scarce supplies" issue raised in Section 6. An unintegrated CRS leaves some bargaining gains to each airline when selling the scarce supply, i.e. the single line on the screen, and one airline's gain can be recaptured by the CRS vertically integrating with the other airline.

The assumptions underlying the ex-post monopolization and scarce supplies effects here seem inconsistent. However, we suggest that reality is a mixture of the two situations. First, priority was partly contractible before 1984. The ordering of display was computed through a complex system of penalties; penalty for not being the host airline, penalty for differences with desired departure time of customer, penalty for stops and connecting flights, etc. Airlines could reduce the level of non-host penalty by becoming a "co-host". However they could not fully contract on priority as the CRS could often make minor adjustments to its algorithm to bias priority, e.g. decide which connections are listed, change the algorithm when 
introducing new flights, issue boarding passes only for the host airline,

shave schedule times, break ties in favor of airlines who have certain flight numbers ... We thus conclude that priority had both contractible and non-contractible elements. Second, whether the supply of screen space for relevant flights is scarce depends on the route, the time of day, the season, etc. Thus, we would expect space on the screen to be sometimes scarce (as in our one-line example) and sometimes not (as in our two-line example). 34

$\underline{\text { Case \#3: }}$ Terminal Railroad Case US vs. Terminal Railroad Association, 224, US $383(1912)$

Terminal Railroad is the quintessential example of an essential

facility:

"The Terminal Company controlled a bridge across the Mississippi River, and the approaches and terminal at St. Louis, a very significant junction point for competing railroads. That company had every incentive to serve equally all railroads entering or leaving $S t$. Louis, charging whatever the market or regulatory agencies would bear. However, once the Terminal Company was acquired by several of those railroads, the new owners might use their control over it to exclude or prejudice their rivals. Rather than order dissolution of the combination, with restoration of the Terminal Company's

${ }^{34}$ The contracting difficulties may also offer clues as to why the vertically integrated outcome could not have been achieved through an exclusive dealing contract between the CRS and the airline. After all, discriminatory rates and penalties resemble partial exclusive dealing. One issue with exclusive dealing is that ideally an independent CRS would have liked to give a low penalty level to an airline together with the commitment to impose high penalty levels to the rival airlines. Such an exclusionary practice, like other forms of exclusive dealing contracts, would probably have been frowned on by the courts. Another issue is that, as we mentioned, display bias is only partially contractible, so that some of the private gains to exclusionary behavior are best realized through vertical incegration. And indeed, only one, short-lived, attempt was made by a non-airline-owned CRS to compete, which suggests that integrated CRS yielded more profits. 
independence, the Supreme Court required the members to admit their railroad competitors to their consortium.

Although the Court did not use the word, we might

describe the Terminal Company's bridge, tracks, and

terminals as "essential facilities" that had to be shared

with competitors." (Areeda-Hoovenkamp [1987, I.736.1b]).

One can view the Terminal Company as an upstream monopolist and the competing railroads as downstream rivals. Note that strategic vertical integration by an upstream essential facility cannot be driven by scarce

needs downstream. Because there is a single supplier, integration of a $U$ and a D appropriates no bargaining surplus from other suppliers. Thus, absent efficiency gains, forward integration by an upstream monopolist may be driven either by the ex-post monopolization effect or by the scarce supplies effect.

Scarce supplies seemed to play no role in this case. According to Areeda and Hovenkamp, "[the Terminal Company's] minimum efficient scale could accommodate all the traffic". Although we have little evidence about this, efficiency considerations also seemed secondary. [Furthermore, if there had been efficiency gains from vertical integration, one would have to explain why these gains would not also have applied to the excluded railroads in which case joint ownership of the Terminal Company by all the railroads would have been optimal - - see, e.g., the discussion in Hart and Moore [1988], Section 4.4.] Thus a first look at the Terminal Railroad case suggests that the motive for integration was to monopolize the rail market around St. Louis.

\section{Review of the Literature}

In this section we compare our analysis to the literature on vertical integration and foreclosure - - in particular the contributions of Ordover, Saloner and Salop (OSS, 1990), Salinger (1988) and Bolton and Whinston 
(1989).

OSS's model is effectively a special case of our first variant in which $c_{1}=c_{2}$. In contrast to our analysis, they find that vertical integration can be profitable under these conditions. OSS argue that, under nonintegration, price competition in the intermediate and output markets leads to the standard Bertrand product market outcome. In contrast, if upstream firm $\mathrm{U}_{1}$ and downstream firm $D_{1}$ merge, OSS argue that $U_{2}$ can raise its input price to $D_{2}$ since $U_{1}$ will no longer be as anxious to supply the rival downstream firm $D_{2}$ as before. This disadvantages $\mathrm{D}_{2}$ as a competitor in the product market and allows $U_{1}-D_{1}$ to increase their market share and make positive profit. 35 In other words, vertical integration forecloses product market competition by (in the words of Salop-Scheffman [1983]) "raising rivals' costs."

The OSS analysis makes implicit assumptions about commitment and/or contracting possibilities which are questionable. OSS assume that when $U_{1}$ $D_{1}$ merge they can commit not to supply rival $D_{2}$ at a price below $\bar{p}$, where $\bar{p}$ is a choice variable for $U_{1}$ and $D_{1} \cdot U_{2}$ and $D_{2}$ then decide whether to merge. OSS show that $U_{1}$ and $D_{1}$ commit to a price $\bar{p}$ above marginal cost $c$. In equilibrium, $U_{2}$ slightly undercuts $\overline{\mathrm{p}}$ to $\overline{\mathrm{p}}-\epsilon$ and $\operatorname{supplies} \mathrm{D}_{2} \cdot \mathrm{U}_{1}-\mathrm{D}_{1}$ has thus succeeded in raising $\mathrm{D}_{2}$ 's marginal cost. $\dot{\mathrm{p}}$ cannot be too large however because the shrinking of $\mathrm{D}_{2}$ 's market share would induce $\mathrm{U}_{2}-\mathrm{D}_{2}$ to merge as we11.

There are two problems with this reasoning. First, if two part-tariffs are allowed (as in our analysis), $\mathrm{U}_{2}$ and $\mathrm{D}_{2}$ always have an incentive to

${ }^{35}$ In fact, because competition between $U_{1}$ and $U_{2}$ becomes less fierce, the nonintegrated upstream firm $\mathrm{U}_{2}$ also benefits from the merger (i.e., makes positive profit) in equilibrium. 
transfer the intermediate good at marginal cost and bargain over a fixed fee.

Thus in the presence of two part-tariffs, $U_{1}-D_{1}$ cannot affect $D_{2}$ 's marginal cost and hence market competition. Second, $U_{1}-D_{1}$ 's commitment is unlikely to be believable. Why wouldn't $\mathrm{U}_{1}-\mathrm{D}_{1}$ under-cut $\mathrm{U}_{2}$ by $\epsilon$ in turn? The effect on $D_{2}$ 's reaction curve is negligible (of the order of $\epsilon$ ), while $U_{1}$ $\mathrm{D}_{1}$ 's increased profit from supplying $\mathrm{D}_{2}$ is significant (it is approximately $(\bar{p}-c) q$, where $q$ is the quantity $U_{2}$ sells to $\left.D_{2}\right)$. Thus $U_{1}-D_{1}$ can gain from such a deviation ex-post, and any commitment ex-ante not to make such a deviation lacks credibility. This is in spite of the fact that competitive undercutting of this type leads inexorably to the Bertrand outcome and thus eliminates all the benefits from $U_{1}-D_{1}$ 's integrating.

Note that we are not suggesting that it is never feasible for an upstream firm to commit to charge high prices to a downstream firm. One way this could be achieved is via a form of exclusive dealing contract (see the Introduction and Appendix 3); another is through reputation. What is unclear from OSS, however, is (a) what the mechanism for enforcing commitments is; why $U_{1}-D_{1}$ need to merge to take advantage of this mechanism. That is, if exclusive dealing contracts, say, are feasible, why cannot $U_{1}$ write such a contract with $\mathrm{D}_{1}$ to restrict supplies to $\mathrm{D}_{2}$, while remaining independent? 36 OSS also obtain different conclusions from ours. Our model explains why firms sometimes respond to a merger by merging as well; how it can be profitable for an integrated upstream firm to sell to a rival downstream

\footnotetext{
${ }^{36}$ Several papers have in fact studied the use of exclusive dealing contracts to foreclose markets; see, e.g., Comanor and Frech [1985], Mathewson and Winter [1986] and Schwartz [1987] (these papers, however, put restrictions on the types of non-exclusive dealing contracts that can be offered). Also, see Krattennaker-Salop [1986] for a very good discussion of the law and economics of exclusive dealing.
} 
firm; and why an upstream firm and downstream firm may merge to drive a rival out of the market. In contrast, bandwagoning never occurs in the oss model (at most one pair of firms are integrated); integrated and nonintegrated firms never trade with each other; and, since a nonintegrated upstream firm benefits from integration by its rival, an upstream firm might refrain from integration in order to monopolize the market ex-ante (in the presence of investment costs). Finally our model yields predictions on which firms are more likely to integrate (those with lower marginal costs, lower investment costs, or higher capacities), whereas OSS are silent on this since they consider identical firms.

Salinger's [1988] model is similar to OSS's in several respects. Salinger makes the same technological assumptions as oss, but assumes that a large number of upstream and downstream firms interact in an anonymous market. The downstream firms take the intermediate good price as given in their input decisions, but act as Cournot oligopolists in the consumer good market. The upstream firms in turn act as Cournot oligopolists in the intermediate good market. Salinger argues that, if $U$ and $D$ merge, $U$ no longer supplies intermediate good to the anonymous market, preferring instead to channel it to D. Similarly, D no longer purchases input in the anonymous market preferring instead to be supplied by $U$. The consequence of this withdrawal is that the size and competitiveness of the anonymous sector falls and in equilibrium the intermediate good price rises. Competitors of the merging downstream firms are disadvantaged, while $D^{\prime} s$ willingness to supply in the output market increases since it now receives input at marginal cost. Under some conditions, the result is a fall in the total output supplied by merged and unmerged firms. 
A problem with Salinger's model is that his conclusion that if $U$ and D merge, $U$ supplies only $D$ is based on a particular conjecture that $U$ is assumed to make: if U reduces its supply to a rival downstream firm, other upstream firms will not make up the difference. We exploit a similar idea in our Scarce Supplies variant, but derive it under the assumption that upstream firms are capacity constrained. Salinger's model does not have this feature. A strategy that Salinger does not permit is for an integrated supplier to undercut its nonintegrated rivals slightly, so that nonintegrated purchasers buy the same total amount as before, but now from the integrated supplier. Yet a price-cutting strategy seems natural, particularly in the context of many trading relationships between upstream and downstream firms that are personalized rather than anonymous, and where price-setting, possibly in conjunction with quantity- setting, seems more plausible than pure quantity-setting.

Finally, we turn to a recent paper by Bolton-Whinston (BW, 1989), written independently of ours. BW also study the motives for vertical integration from an incomplete contracting perspective, but mainly in a situation where downstream firms operate in different product markets. Their basic model consists of two downstream firms $D_{1}, D_{2}$ and one upstream firm $U$. The downstream firms make (variable) investments specific to the upstream firm, but the upstream firm does not invest. Each downstream firm requires one unit of intermediate good from the upstream firms ex-post; the upstream firms can satisfy both downstream firms in some states of the world, but in others it has only one unit of intermediate good available. Long-term contracts cannot be written and ex-post bargaining is modelled as an extensive form game, where the ability of the upstream firm U to sell to $\mathrm{D}_{j}$ 
plays the role of an outside option in the bargaining between $U$ and $D_{i}$. In contrast to our model, investment costs are not shared under integration and, in addition, the returns to investment are completely appropriated by a firm's owner.

In the case where the upstream firm has only one unit of intermediate good available, the $\mathrm{BW}$ model is close to our Scarce Supplies variant. The motive for integration in their model is different, however. If $D_{1}$ buys $U$, this has no direct effect on $\mathrm{D}_{2}$ 's investment decision since, (assuming the outside option binds), if $\mathrm{D}_{2}$ values the intermediate good more than $\mathrm{D}_{1}, \mathrm{D}_{2}$ will continue to buy it at a price equal to $\mathrm{D}_{1}$ 's willingness to pay.

However, there is an indirect effect due to the fact that $D_{1}$ now appropriates all the returns from U's bargaining with $D_{2}$ and so has an incentive to invest more in order to increase these returns: this in turn causes $D_{2}$ to invest less. 37

Given that the motive for integration is different in their model, it is not surprising that BW also reach different conclusions. BW find that, when outside options are binding in the bargaining process, nonintegration is socially optimal. The reason is that, given that each downstream firm pays an input price determined by the other downstream firm's willingness to pay, it receives at the margin the full increase in the marginal product of its investment. (In contrast, in Section 6, we find that either nonintegration or vertical integration and exit can be socially optimal.) However, when outside options are binding, nonintegration is not privately optimal in BW's

\footnotetext{
${ }^{37} \mathrm{BW}$ also consider a form of bandwagoning, whereby a merger of $U$ and $D_{1}$ causes $\mathrm{D}_{2}$ to build upstream capacity so as to supply its internal needs.
} 
model: by integrating, $U$ and one of the downstream firms can make themselves better off at the expense of the other downstream firm. In fact, BW find that the only privately optimal arrangements involve vertical integration by $\mathrm{U}$ and one of the $\mathrm{D}^{\prime} \mathrm{s}$, or complete integration of $\mathrm{U}, \mathrm{D}_{1}$ and $\mathrm{D}_{2} \cdot$ (In contrast, we do not allow complete integration, and find that, when $\bar{q}_{2}=0$ (i.e., there is only one upstream firm), either nonintegration, or integration between $U$ and $D_{i}$, with or without exit of $D_{j}$, can be privately optimal.)

A final difference between the two models is that, in $\mathrm{BW}^{\prime} \mathrm{s}$ consumer: surplus is independent of ownership structure (for example, if downstream firns make take it or leave it offers to consumers, consumer surplus equals zero). In contrast, in our Scarce Supplies variant, exit by a downstream firm can lead to exit by an upstream firm, and thereby to a fall in total supplies and a decrease in consumer surplus (see Remark 1 of Section 6).

\section{Concluding Remarks}

We conclude with two brief, possible extensions of the model.

1. Our analysis is couched in terms of integration between a supplier and a buyer. However, it seems likely to extend to integration between two manufacturers of complementary products $A$ and $B$. Suppose manufacturer $A_{1}$ merges with $\mathrm{B}_{1}$. By doing this, $\mathrm{A}_{1}$ makes it credible that it will give information about developments of its products only to $B_{1}$, thus allowing $B_{1}$ an early start in the design of compatible complements. [In contrast, a nonintegrated firm will have an incentive to give all B manufacturers this information in order to create more competition in the market for the complement.] Vertical integration may help $\mathrm{A}_{1}-\mathrm{B}_{1}$ through two channels. First, if the goods are not pure complements, as in the case when some 
consuners buy product $B$ only or when $B$ is consumed in variable proportions, $\mathrm{A}_{1}$ 's limiting its "supplies of information" to $\mathrm{B}_{1}$ increases $\mathrm{B}_{1}$ 's market powcr (for instance by forcing its rivals to exit). Second, whether goods $A$ and $B$ are pure complements or not, $A_{1}-B_{1}$ 's merging, may force other $B$ manufacturers to exit. A may then be able to monopolize the A market by tying products A and $B_{1}$ or, equivalently, by making $B_{1}$ 's product incompatible with other $A$ manufacturers' products. Very tentative applications (tentative because we haven't studied the industries in detail) are IBM's limiting early announcements of its developments in computer technology to its disk drive subsidiary, or airlines offering complementary flights gaining market power by facilitating exclusive coordination of schedules at hubs.

2. We have assumed that the upstream firms were subject to either constant returns to scale (first two variants) or decreasing returns to scale (third variant). An interesting extension of our model would allow for upstream increasing returns to scale over some range (as in the case of a U-shaped cost curve). A (possibly hypothetical) illustration is the following: the Japanese owners of supercomputers by buying supercomputers exclusively from Japanese manufacturers (e.g., as a result of vertical integration) reduce the size of the market for US supercomputer manufacturers, whose unit production costs therefore rise. As a consequence, the US consumers of supercomputers forego some use of them and hence are at a disadvantage relative to their Japanese competitors in the product market. This story is quite similar to our ex-post monopolization variant, except that vertical integration not only enables the most efficient supplier (which is ex-post the Japanese manufacturers of supercomputers) to commit to restrict supplies (to US consumers of supercomputers), but also creates the upstream cost differential 
that was assumed exogenous in Sections 3 and 4. Note that the story also

possesses some features of our Scarce Needs variant (in that variant a merger between an upstream and downstream firm could disadvantage the rival downstream firm by causing exit of the rival upstream firm - this is an extreme example of the upstream firm's unit production costs rising). 


\section{Proof of Proposition 1}

The strategies are: $U_{1}$ offers to sell $q^{*}$ units at $t^{*}$ to each $D_{j}$ (formally: $t_{1 j}\left(q_{1 j}\right)=t^{*}$ if $q_{1 j}=q^{*}$, = + if $q_{i j} \neq q^{*}$ ). $U_{2}$ offers to supply each $D_{j}$ at marginal cost (that is, $t_{2 j}\left(q_{2 j}\right)=c_{2} q_{2 j}$ for $j=1,2$ ). Each downstream firm accepts $\left(t^{*}, q^{*^{*}}\right)$ in equilibrium. If one of the upstream firms offers another contract to $\mathrm{D}$, this $\mathrm{D}$ continues to anticipate output $\mathrm{q}^{*}$ by its rival and maximizes its profit (that is, it maximizes $r\left(q_{1 j}+q_{2 j}, q^{*}\right)-t_{1 j}\left(q_{1 j}, \hat{Q}_{1 j}\right)-t_{2 j}\left(q_{2 j}, \hat{Q}_{2 j}\right)$ subject to $\left.q_{1 j}+q_{2 j} \geq \max \left(\hat{Q}_{1 j}, \hat{Q}_{2 j}\right)\right)$.

The downstream firms' behavior is obviously optimal given the offers it faces and given that it expects its rival to purchase $q^{*}$.

Can $\mathrm{U}_{2}$ deviate and make a positive profit? For instance, can it sell $\mathrm{q}_{22}$ at price $t_{22}>c_{2} q_{22}$ to $D_{2}$ ? Note that $D_{2}$ can guarantee itself $D^{N I}\left(c_{1}, c_{2}\right)=$ $r\left(R_{2}\left(q^{*}\right), q^{*}\right)-c_{2} R_{2}\left(q^{*}\right)$ by refusing $U_{2}^{\prime}$ s offer and purchasing $q^{*}$ at price $t^{*}$. Because $R_{2}\left(q^{*}\right)$ is the best response to $q^{*}$ for marginal cost $c_{2}$, $D_{2}$ would get strictly less than $D^{N I}\left(c_{1}, c_{2}\right)$ by buying $q_{22}$ at price $t_{22}>c_{2} q_{22}$ and rejecting $\operatorname{offer}\left(q^{*}, t^{*}\right.$ ) from $U_{1}$. Similarly, because $R_{2}\left(q^{*}\right) \leq q^{*}$ (as $\left.c_{2} \geq c_{1}\right), q_{22}=0$ maximizes $r\left(q^{*}+q_{22}, q^{*}\right)-c_{2} q_{22}$, and thus $D_{2}$ makes strictly less than $D^{N I}\left(c_{1}, c_{2}\right)$ if it buys from $U_{1}$ and furthermore buys $q_{22}$ at price $t_{22}>c_{2} q_{22}$ from $U_{2}$.

Last, can $U_{1}$ increase its profit? ro, because it is already maximizing $\tau_{1 j}-c_{1} q_{1 j}$ subject to the constraint $r\left(q_{1 j}, q^{\star x}\right)-t_{1 j} \geq r\left(R_{2}\left(q^{*}\right), q^{*}\right)-c_{2} R_{2}\left(q^{*}\right)$ over pairs $\left(q_{1 j}, t_{1 j}\right)$. Thus, it extracts the maximum feasible surplus from each $D_{j}$ given that the latter can buy at marginal cost $c_{2}$ and expects its rival to buy $q^{x^{*}}$.

Q.E.D. 


\section{Proof of Proposition 2}

The strategies are: $U_{1}$ offers $q_{2}^{*}$ at price $t_{2}^{*}$ to $D_{2}$. $U_{2}$ offers to supply at marginal cost $\left(t_{2 j}\left(q_{2 j}\right)=c_{2} q_{2 j}\right.$ for all $j$ and $\left.q_{2 j}\right)$. In equilibrium, $D_{2}$ buys $\mathrm{q}_{2}^{*}$ from $\mathrm{U}_{1}$ and 0 from $\mathrm{U}_{2}$.

Again, it is clear that $\mathrm{D}_{2}$ acts optimally given the contract offers and the anticipation that $\mathrm{D}_{1}$ procures $\mathrm{q}_{1}^{*}$ internally.

Can $\mathrm{U}_{2}$ make a strictly positive profit? Suppose that $\mathrm{U}_{2}$ makes a different offer and $\mathrm{D}_{2}$ buys $\mathrm{q}_{22}$ at price $t_{22}>\mathrm{c}_{2} \mathrm{q}_{22}$ from $\mathrm{U}_{2}$. Then $\mathrm{D}_{2}$ 's profit is $\max \left(r\left(q_{2}^{*}+q_{22}, q_{1}^{*}\right)-c_{2} q_{2}^{*}-t_{22}, r\left(q_{22}, q_{1}^{*}\right)-t_{22}\right)$. Because $q_{2}^{*}=R_{2}\left(q_{1}^{*}\right)$ and $t_{22}>c_{2} q_{22}$, this profit is strictly lower than $D^{P I}\left(c_{1}, c_{2}\right)$ and $D_{2}$ is better off rejecting $\mathrm{U}_{2}$ 's contract after all.

Can $\left(\mathrm{U}_{1}-\mathrm{D}_{1}\right)$ make more than $\mathrm{V}^{\mathrm{PI}}\left(\mathrm{c}_{1}, \mathrm{c}_{2}\right)$ ? Suppose that $\mathrm{U}_{1}$ offers a different contract to $D_{2}$. Let $\left(Q_{1}, Q_{2}\right)$ denote the resulting outputs for $D_{1}$ and $\mathrm{D}_{2}$, wich we for the moment assume deterministic. First, note that $\mathrm{Q}_{1}=$ $\mathrm{R}_{1}\left(\mathrm{Q}_{2}\right)$, as $\left(\mathrm{U}_{1}-\mathrm{D}_{1}\right)$ can procure internally at marginal cost $\mathrm{c}_{1}$ and externally at marginal cost $c_{2}$. Furthermore, $Q_{2} \geq R_{2}\left(Q_{1}\right)$ as $D_{2}$ can buy any amount from $\mathrm{U}_{2}$ at marginal cost $\mathrm{c}_{2}$. We thus have $\mathrm{Q}_{1} \leq \mathrm{q}_{1}^{*}, \mathrm{Q}_{2} \geq \mathrm{q}_{2}^{*}$ and $\mathrm{Q}_{1}+\mathrm{Q}_{2} \geq \mathrm{q}_{1}^{*}+\mathrm{q}_{2}^{*}$ from $\left|\frac{\mathrm{dR}_{1}}{\mathrm{dq}_{2}}\right|<1$ (see Figure 1). Thus industry profits are lower than in our presumed equilibrium. Yet $\mathrm{D}_{2}$ can guarantee itself $\mathrm{D}^{\mathrm{PI}}\left(\mathrm{c}_{1}, \mathrm{c}_{2}\right)$ because by turning down $\mathrm{U}_{1}^{\prime}$ 's offer it obtains $\max \left(\mathrm{r}\left(\mathrm{q}_{22}, \mathrm{Q}_{1}\right)-\mathrm{c}_{2} \mathrm{q}_{22}\right) \geq \max \left(\mathrm{r}\left(\mathrm{q}_{22}, \mathrm{q}_{1}^{*}\right)-\mathrm{c}_{2} \mathrm{q}_{22}\right\}$

$$
\mathrm{q}_{22} \quad \mathrm{q}_{22}
$$

$=D^{P I}\left(c_{1}, c_{2}\right)$. Hence industry profits have fallen, while $U_{2}$ and $D_{2}$ are at least as well off. Hence $\left(U_{1}-D_{1}\right)$ cannot increase its profit. This reasoning extends straightforwardly to random outcomes $\left(\bar{Q}_{1}, \bar{Q}_{2}\right)$. First note that $\bar{Q}_{1}$ is necessarily deterministic (equal to some $Q_{1}$ ) as it maximizes the strictly 
concave function $\mathcal{E}\left(r\left(\mathrm{Q}_{1}, \overline{\mathrm{Q}}_{2}\right)-\mathrm{c}_{1} \mathrm{Q}_{1}\right)$, where $\mathcal{E}$ denotes the expectation operator. $\overline{\mathrm{Q}}_{2}$

Furthermore any realization $Q_{2}$ of $\tilde{Q}_{2}$ exceeds $R_{2}\left(Q_{1}\right)$. Let $Q_{2}$ be the infimum in the support of $\tilde{Q}_{2} \cdot \underline{Q}_{2} \geq R_{2}\left(Q_{1}\right)$ and $Q_{1} \leq R_{1}\left(Q_{2}\right)$ (recall that reaction curves are downward sloping). This implies that $Q_{2} \geq q_{2}^{*}$ and $Q_{1} \leq q_{1}^{*}$ (see Figure 1). Hence, $D_{2}$ can guarantee itself $D^{P I}\left(c_{1}, c_{2}\right)$. Let $Q_{2}^{e}=E \bar{Q}_{2} \geq Q_{2} \geq q_{2}^{*}$ denote the expectation of $\widetilde{Q}_{2}$. Our assumption that a firm's marginal revenue is convex in the other firm's output and the fact that marginal revenue is decreasing in $Q_{1}$ imply that $Q_{1} \geq R_{1}\left(Q_{2}^{e}\right)$. This inequality, together with $Q_{2}^{e} \geq R_{2}\left(Q_{1}\right)$, implies that $Q_{1}+Q_{2}^{e} \geq q_{1}^{*}+q_{2}^{*}$ (see Figure 1). Last, because the industry profit function is concave in total output, the upper bound on industry profit (which presumes production efficiency) satisfies $\mathcal{E}\left(\mathrm{P}\left(\mathrm{Q}_{1}+\widetilde{\mathrm{Q}}_{2}\right)\left(\mathrm{Q}_{1}+\tilde{\mathrm{Q}}_{2}\right)-\mathrm{C}_{1}\left(\mathrm{Q}_{1}+\widetilde{\mathrm{Q}}_{2}\right)\right) \leq$ $P\left(Q_{1}+Q_{2}^{e}\right)\left(Q_{1}+Q_{2}^{e}\right)-C_{1}\left(Q_{1}+Q_{2}^{e}\right) \leq P\left(q_{1}^{*}+q_{2}^{*}\right)\left(q_{1}^{*}+q_{2}^{*}\right)-C_{1}\left(q_{1}^{*}+q_{2}^{*}\right)$. Hence, industry profit is smaller, and so is the profit of $\left(U_{1}-D_{1}\right)$.

\section{Proof of Proposition 3}

In equilibrium, $U_{1}$ produces internally $q_{1}^{*}$ and offers to supply $q_{2}^{*}$ to $D_{2}$ at price $t_{2}^{\ddot{n}}=c_{2} q_{2}^{\ddot{x}}$. $U_{2}$ does not supply. The proof is essentially that of Proposition 2. The only possible point of departure comes from the fact that $\mathrm{U}_{2}$ "supplies" $\mathrm{D}_{2}$ internally instead of externally. But this makes no difference for the proof that $\left(U_{1}-D_{1}\right)$ cannot raise its profit as $D_{2}$ can already buy at marginal cost $\mathrm{c}_{2}$ from $\mathrm{U}_{2}$ under $\mathrm{PI}_{1}$. We only have to check that $\left(\mathrm{U}_{2}-\mathrm{D}_{2}\right)$ cannot raise its profit by making an alternative offer to $\mathrm{D}_{1}$. Suppose it does so. Because $D_{1}$ and $D_{2}$ can purchase internally at marginal cost, we have $Q_{1} \geq R_{1}\left(Q_{2}\right)$ and $Q_{2} \geq R_{2}\left(Q_{1}\right)$ (the case of random $\bar{Q}_{1}$ and $\bar{Q}_{2}$ is solved as in Proposition 2). Thus industry profit can only be lower than the one 
obtained in Proposition 3. It thus suffices to check that even if $U_{2}$ changes its contract offer to $\mathrm{D}_{1}$ (which was to supply at marginal cost $\left.\mathrm{c}_{2}\right),\left(U_{1}-\mathrm{D}_{1}\right.$ ) can guarantee itself $v^{F I}\left(c_{1}, c_{2}\right)$ (gross of the efficiency loss). To see this, note that if $Q_{2}>R_{2}\left(Q_{1}\right)$, it is unprofitable for $U_{2}$ to supply $D_{2}$ any positive amount internally, and so $\mathrm{Q}_{2}=\mathrm{q}_{2}^{*}$; but then $\left(\mathrm{U}_{1}-\mathrm{D}_{1}\right)$ can get $\mathrm{v}^{\mathrm{FI}}\left(\mathrm{c}_{1}, \mathrm{c}_{2}\right)$ by not buying from $\mathrm{U}_{2}$ and producing $\mathrm{q}_{1}^{*}$ internally. On the other hand, if $\mathrm{Q}_{2}=$ $\mathrm{R}_{2}\left(\mathrm{Q}_{1}\right), \mathrm{Q}_{2} \leq \mathrm{q}_{2}^{*}$ as $\mathrm{Q}_{1} \geq \mathrm{R}_{1}\left(\mathrm{Q}_{2}\right)$ (see Figure 1 ) and again $\left(\mathrm{U}_{1}-\mathrm{D}_{1}\right.$ ) can get $\mathrm{V}^{\mathrm{FI}}\left(\mathrm{c}_{1}, \mathrm{c}_{2}\right)$. Hence, $\left(\mathrm{U}_{2}-\mathrm{D}_{2}\right)$ cannot gain by offering a different contract to $\mathrm{D}_{1}$

$$
\text { Q.E.D. }
$$

\section{Proof of Proposition 4}

Consider the following strategies: $\mathrm{U}_{2}$ offers to sell at marginal $\operatorname{cost} \mathrm{c}_{2}$ to $D_{1}$ up to $q^{*}\left(t_{21}\left(q_{21}\right)=c_{2} q_{21}\right.$ for $q_{21} \leq q^{*}$, $=+\infty$ for $\left.q_{21}>q^{*}\right)$. $U_{1}$ offers to sell $\mathrm{q}^{*}$ at price $t^{*}$ to $\mathrm{D}_{2}$ (where $\mathrm{q}^{*}$ and $t^{*}$ are as in Proposition 1 ). $\mathrm{U}_{1}$ offers to sell either $\mathrm{q}^{*}$ at price $t^{*}$ or $\mathrm{q}_{11}$ at price $\tau_{11}\left(\mathrm{q}_{11}, \mathrm{q}^{*}\right)=$ $r\left(q^{*}, q^{*}\right)-r\left(q^{*}-q_{11}, q^{*}\right)$ to $D_{1}$ if $D_{1}$ can exhibit total output $\hat{Q}_{1} \geq q^{*}$. In equilibrium $\mathrm{D}_{1}$ buys $\mathrm{q}^{*}$ at price $t^{*}$ from $\mathrm{U}_{1}$.

Note that $U_{1}$ simply offers to make up the difference to $q^{*}$ if $D_{1}$ does not buy $\mathrm{q}^{*}$ from $\mathrm{U}_{2}$. First, we show that $\mathrm{D}_{1}$ cannot increase its profit. From the definition of $t_{11}$, if it buys $q_{21} \leq q^{*}$ from $U_{2}, D_{1}$ has the same profit whether it buys the complement to $\mathrm{q}^{*}$ from $\mathrm{U}_{1}$ or not. Its profit is thus $r\left(q_{21}, q^{*}\right)-c_{2} q_{21} \leq r\left(R_{2}\left(q^{*}\right), q^{*}\right)-c_{2} q^{*}=D^{N I}\left(c_{1}, c_{2}\right)$ (by definition of $\left.R_{2}\right)$.

Second, the proof that $U_{1}$ cannot make more than $U^{N I}\left(c_{1}, c_{2}\right)$ is the same as that in Proposition 1: $U_{2}$ and $D_{2}$ are now integrated, but $U_{2}$ continues to supply $D_{2}$ at marginal cost $c_{2}$. 
The third and more difficult part of the proof consists of showing that $\left(U_{2}-D_{2}\right)$ cannot make more than $D^{N I}\left(c_{1}, c_{2}\right)$. Suppose that $U_{2}$ makes a different contract offer to $D_{1}$. Suppose first that there exists no $\left(q_{21}, t_{21}\right)$ in the new contract such that $r\left(q_{21}, q^{*}\right)-t_{21}>D^{N I}\left(c_{1}, c_{2}\right)$; then specify that $D_{1}$ turns down $\mathrm{U}_{2}$ 's contract offer, buys $\mathrm{q}^{*}$ from $\mathrm{U}_{1}$ and that $\mathrm{D}_{2}$ buys $\mathrm{q}^{*}$ from $\mathrm{U}_{1}$ as well and does not produce internally. This is clearly a continuation equilibrium and it gives the same profit to $\left(U_{2}-D_{2}\right)$ as before. Thus assume that there exists $\left(q_{21}, \tau_{21}\right)$ such that $r\left(q_{21}, q^{*}\right)-\tau_{21}>D^{N I}\left(c_{1}, c_{2}\right)$. The definition of $D^{N I}\left(c_{1}, c_{2}\right)$ implies that $\left(U_{2}-D_{2}\right)$ does not make money on the trade as $t_{21} \leq c_{2} q_{21}$. Either $q_{21} \leq q^{*}$ and then specify that $D_{1}$ buys $q_{21}$ at price $\tau_{21}$ from $U_{2}, q^{*}-q_{21}$ at price $t_{11}\left(q^{*}-q_{21}, q^{*}\right)$ from $U_{1}$ and that $D_{2}$ buys $q^{*}$ at price $t^{*}$ from $U_{1}$ and does not produce internally. Again, this continuation equilibrium yields at most $D^{N I}\left(c_{1}, c_{2}\right)$ to $\left(U_{2}-D_{2}\right)$. Or $q_{21}>q^{*}$, and suppose that in equilibrium $D_{1}$ buys $\mathrm{q}_{21}$ from $\mathrm{U}_{2}$ (the case of a random strategy for $\mathrm{D}_{1}$ is treated as in Proposition 2). Then, $\mathrm{D}_{1}$ 's total output $\mathrm{Q}_{1} \geq \mathrm{q}_{21}$ and the profit of $\left(\mathrm{U}_{2}-\mathrm{D}_{2}\right)$ is at most $\max \left(r\left(Q_{2}, q_{21}\right)-c_{2} Q_{2}\right) \leq r\left(R_{2}\left(q^{*}\right), q^{*}\right)-c_{2} R_{2}\left(q^{*}\right)=D^{N I}\left(c_{1}, c_{2}\right)$ (buying
$Q_{2}$ $\mathrm{q}^{*}$ from $\mathrm{U}_{1}$ is not a best response to $\mathrm{Q}_{1}$ as it yields $r\left(\mathrm{q}^{*}, \mathrm{Q}_{1}\right)-t^{*}=$ $r\left(q^{*}, Q_{1}\right)-r\left(q^{*}, q^{*}\right)+D^{N I}\left(c_{1}, c_{2}\right)<D^{N I}\left(c_{1}, c_{2}\right)$. We thus conclude that $\left(U_{2}-D_{2}\right)$ cannot increase its profit beyond $D^{N I}\left(c_{1}, c_{2}\right)$.

Q.E.D.

Appendix 2 :

Uniqueness. We look at (perfect Bayesian) equilibria in the following class:

1. The equilibrium is in pure strategies.

2. (Market by market bargaining). When a downstream firm $\mathrm{D}_{\mathrm{k}}$ receives an 
out-of-equilibrium offer from an unintegrated upstream firm $U_{i}$, it does not change its beliefs about $\mathrm{U}_{i}$ 's offer to $\mathrm{D}_{\ell}(\ell \neq k)$.

3. (No money-losing offers): An unintegrated firm does not make an offer at price below marginal cost (that is, that would lose money if accepted); $t_{i j}\left(q_{i j}, \hat{Q}_{i j}\right) \geq c_{i} q_{i j}$ for $a l l i, j, q_{i j}, \hat{Q}_{i j}$.

Let us comment on restrictions 2 and 3. Restriction 2, although not implied by perfect Bayesian equilibrium, is a natural one. An unintegrated U makes secret and independent offers to two downstream firms and tries to extract the best deal from each of them. Because there is no "informational leakage" from one customer to the other, the unintegrated $U$ has no incentive to change the offer to $D_{l}$ when it changes its offer to $D_{k}$ (and indeed equilibrium behavior requires that it does not do so if its offer to $D_{\ell}$ is uniquely optimal). Note that no such restriction can be imposed for an integrated $U$. When it changes its offer to its subsidiary's rival, it also wants to change its supply to its subsidiary, with whom it shares profit.

Given restriction 2 , restriction 3 is in the spirit of trembling-hand perfection (Selten [1975]) of not allowing a player to play a weakly dominated strategy. An offer that contains a money-losing pair is worse for $U$ than the same offer without it if there is a small probability that the downstream firm chooses this money-losing pair. 38

Note that the equilibria described in Section 3 satisfy restrictions 1 through 3 .

\footnotetext{
${ }^{38}$ One might think that including the money-losing pair could act as a "sunspot" and induce the downstream firm to choose among the non-money-losing pairs the one that $\mathrm{U}$ prefers. However, this selection can also be made directly by $U$ by offering a single best pair to the downstream firm.
} 
Proposition $A$ : (i) Under NI, FI, $P_{I}, M_{u}, M_{d}$ and $M_{u d}$, there exists a single perfect Bayesian equilibrium satisfying restrictions 1 though 3.

(ii) Under $\mathrm{PI}_{2}$, the equilibrium described in Proposition 4 is undominated in the set of perfect Bayesian equilibria satisfying 1 through 3 . Furthermore, any other equilibrium satisfying 1 through 3 , if one exists, has $U_{2}$ supply at a loss to $\mathrm{D}_{1}, \mathrm{D}_{1}$ produce more than $\mathrm{q}^{x^{2}}$, and the integrated firm $\mathrm{U}_{2}-\mathrm{D}_{2}$ make less profit than in the equilibrium of Proposition 4.

We have been unable to prove or disprove uniqueness in the class considered under $\mathrm{PI}_{2}$. But if other equilibria exist, there are somewhat pathological: $\mathrm{U}_{2}$ supplies at a loss its subsidiary's rival; such a behavior might be plausible if $D_{1}$ bought from $U_{2}$ a quantity less than $q^{*}$ and nothing from $U_{1}$. However, $D_{1}$ ends up buying more than $q^{*}$, the amount it buys (from $\mathrm{U}_{1}$ ) in the equilibrium of Proposition 4.

Let $q_{1}$ and $q_{2}$ denote $D_{1}$ and $D_{2}$ 's final outputs, and $q_{i j}$ be $U_{i}$ 's supply to $D_{j}\left(q_{j} \equiv q_{1 j}+q_{2 k}\right)$.

Nonintegration. Under market by market bargaining (restriction 2), ${ }_{1}$ and $\mathrm{U}_{2}$ are competing à la Bertrand for each $\mathrm{D}_{j}$ separately. For instance, $\mathrm{D}_{1}$ 's beliefs about $\mathrm{q}_{2}$ are fixed in a given equilibrium and do not depend on $\mathrm{U}_{1}$ and $\mathrm{U}_{2}$ 's offers to $\mathrm{D}_{1}$. $\mathrm{U}_{1}$ 's best offer is then trivially the best reaction $R_{1}\left(q_{2}\right)$ to $\mathrm{q}_{2}$ at the highest price such that $\mathrm{D}_{1}$ does not want to buy from $\mathrm{U}_{2}$. And symmetrically for $D_{2}$. Hence the equilibrium outputs are $q_{1}=q_{2}=q^{*}$ and the 
transfers to $U_{1}$ equal $t^{*}$, where $\mathrm{q}^{*}$ and $t^{*}$ are given in Proposition 1.

Full integration. Because integrated $D^{\prime}$ s can procure internally at marginal cost, $q_{i} \geq R_{i}\left(q_{j}\right)$. Hence aggregate profit, gross of integration $\operatorname{cost}, \pi_{1}+\pi_{2}$, satisfies $\pi_{1}+\pi_{2} \leq r\left(q_{1}^{*}, q_{2}^{*}\right)+r\left(q_{2}^{*}, q_{1}^{*}\right)-c_{1}\left(q_{1}^{*}+q_{2}^{*}\right)$, with equality if and only if $\mathrm{q}_{1}=\mathrm{q}_{1}^{*}$ and $\mathrm{q}_{2}=\mathrm{q}_{2}^{*}$ (i.e., if and only if $\mathrm{q}_{1}=\mathrm{R}_{1}\left(\mathrm{q}_{2}\right.$ ) and $\mathrm{q}_{2}=$ $R_{2}\left(q_{1}\right)$ ). It thus suffices to show that $U_{1}-D_{1}$ can guarantee itself $\pi_{1}^{*} \equiv$ $r\left(q_{1}^{*}, q_{2}^{*}\right)-c_{1} q_{1}^{*}+\left(c_{2}-c_{1}\right) q_{2}^{*}$, and that $U_{2}-D_{2}$ can guarantee itself $\pi_{2}^{*} \equiv$ $r\left(q_{2}^{*}, q_{1}^{*}\right)-c_{2} q_{2}^{*}$. If this is so, the equilibrium outputs and profits are as in Proposition 4.

Suppose that firm 1 offers to supply $D_{2}$ up to $q_{2}^{*}$ at price $t_{12}^{n}\left(q_{12}\right)$ where $t_{12}^{n}\left(q_{2}^{*}\right)=c_{2} q_{2}^{*}, t_{12}^{n}\left(q_{12}\right)<c_{2} q_{12}$ and $\lim _{n \rightarrow \infty} t_{12}^{n}\left(q_{12}\right)=c_{2} q_{12}$ for $0<q_{12}<$ $\mathrm{q}_{2}^{*}$. That is, $\mathrm{U}_{1}$ offers to undercut $\mathrm{U}_{2}$ slightly up to $\mathrm{q}_{2}^{*}$. Figure 2 exhibits $\mathrm{D}_{2}$ 's reaction curve $\mathrm{R}_{2}^{\mathrm{n}}\left(\mathrm{q}_{2}\right)$ coming from the maximization of $r\left(q_{2}, q_{1}\right)-c_{2} q_{22}$ $t_{12}^{\mathrm{n}}\left(\mathrm{q}_{12}\right.$ ) subject to $\mathrm{q}_{12}+\mathrm{q}_{22}=\mathrm{q}_{2}$. $\mathrm{R}_{2}^{\mathrm{n}}$ coincides with $\mathrm{R}_{2}$ for $\mathrm{q}_{1} \leq \mathrm{q}_{1}^{*}$, and, for $n$ sufficiently large, is close to $R_{2}$ for $q_{1} \geq q_{1}^{*}$. Note that $t_{12}^{n}(\cdot)$ can be chosen so that $R_{2}^{n}$ is continuous, which we will assume.

Because $U_{2}$ may make an offer to $D_{1}, D_{1}^{\prime}$ s reaction curve $\tilde{R}_{1}\left(q_{2}\right)$ is obtained by solving

$$
\begin{aligned}
& \operatorname{Max}\left\{r\left(\mathrm{q}_{1}, \mathrm{q}_{2}\right)-\mathrm{c}_{1} \mathrm{q}_{11}-\mathrm{t}_{21}\left(\mathrm{q}_{21}, \hat{\mathrm{Q}}_{21}\right)\right\} \\
& \text { subject to }\left\{\begin{array}{l}
\mathrm{q}_{11}+\hat{\mathrm{q}}_{21}=\mathrm{q}_{1}, \\
\mathrm{q}_{1} \geq \hat{\mathrm{Q}}_{21}
\end{array}\right.
\end{aligned}
$$

where we adopt the convention that $t_{21}(0, \cdot)=0 . \quad \hat{Q}_{21}$ denotes the quantity exhibited to $U_{2}$ by $D_{1}$.] By the standard revealed preference argument, $\tilde{R}_{1}\left(q_{2}\right)$ 
(which need not be single valued) is monotonic (non-increasing). Furthermore $\tilde{R}_{1}\left(q_{2}\right) \geq R_{1}\left(q_{2}\right)$ (because $D_{1}$ can always refrain from buying from $U_{2}$ ). The crucial feature of $\bar{R}_{1}$ is that it admits only horizontal jumps. Therefore $\bar{R}_{1}$ and $R_{2}^{n}$ intersect for some $q_{2} \leq q_{2}^{*}$ (there may exist several such intersections, but they all share this property). See Figure 2. This implies that by buying $\mathrm{q}_{21}=0, \mathrm{U}_{1}-\mathrm{D}_{1}$ can guarantee itself at least $\pi_{1}^{*}$ by offering the above contract to $\mathrm{D}_{2}$. The reasoning for why $\mathrm{U}_{2}-\mathrm{D}_{2}$ can guarantee itself $\pi_{2}^{*}$ is symmetrical. It suffices that $U_{2}$ offer no contract to $\mathrm{D}_{1}$.

\section{Figure $2 \underline{\text { Here }}$}

Partial Integration $\mathrm{PI}_{1}$. First note that the no-money-losing-offer assumption implies that in equilibrium $q_{1}=R_{1}\left(q_{2}\right)$ : because the unintegrated $\mathrm{U}_{2}$ does not supply under marginal cost $\mathrm{C}_{2}$ and $\mathrm{D}_{1}$ can procure internally at marginal cost $c_{1}<c_{2}, D_{1}$ only purchases internally and has reaction curve $R_{1}$. Next we claim that $q_{2} \geq R_{2}\left(q_{1}\right)$. For, suppose that $q_{2}<R_{2}\left(q_{1}\right)$. Then $U_{2}$ could increase its profit by offering to put $\mathrm{D}_{2}$ on its reaction curve. More precisely, if $q_{12}, q_{22}, \hat{Q}_{12}$ and $\hat{Q}_{22}$ maximize $r\left(q_{2}, q_{1}\right)-\tau_{12}\left(q_{12}, \hat{Q}_{12}\right)$ $t_{22}\left(q_{22}, \hat{Q}_{22}\right)$ such that $q_{12}+q_{22}=q_{2}$ and $q_{2} \geq \hat{Q}_{12}, \hat{Q}_{22}$, then the contract $" R_{2}\left(q_{1}\right)-q_{12}$ at price $t_{22}\left(q_{22}, \hat{Q}_{2}\right)+r\left(R_{2}\left(q_{1}\right), q_{1}\right)-r\left(q_{2}, q_{1}\right)-\epsilon$ " offered by $\mathrm{U}_{2}$, where $\epsilon$ is positive and small, is strictly preferred by $\mathrm{D}_{2}$ to rejecting the contract and buying from $U_{1}$ only, and yields a strictly higher profit to $\mathrm{U}_{2}$, as is easily checked.

Because $q_{1}=R_{1}\left(q_{2}\right)$ and $q_{2} \geq R_{2}\left(q_{1}\right), q_{1} \leq q_{1}^{*}$ and $q_{2} \geq q_{2}^{*}$ and $\pi_{1} \leq \pi_{1}^{*}$ with equalities if and only if $\pi_{1}=\pi_{1}^{*}$. To show that $U_{1}-D_{1}$ can guarantee 


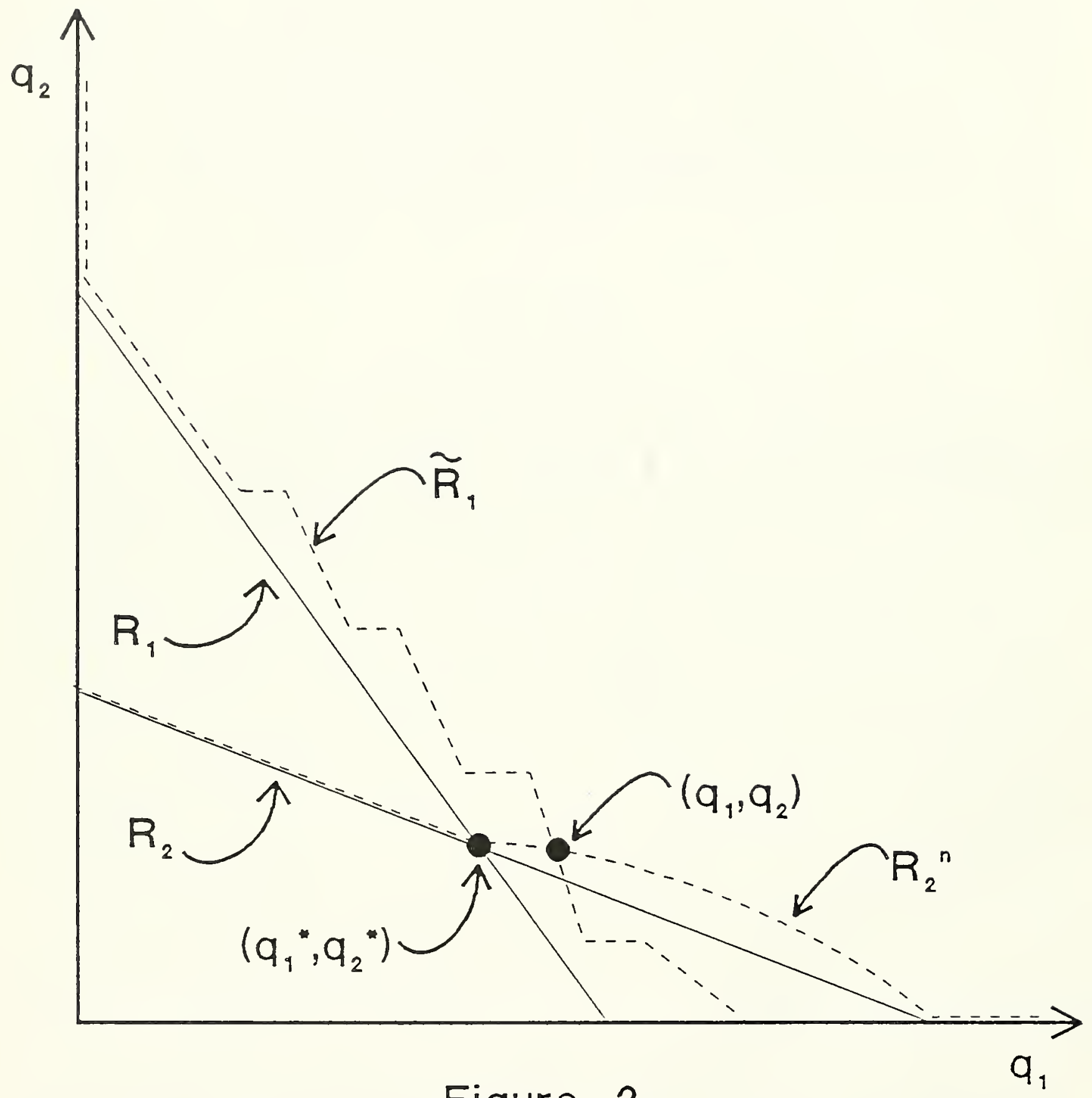

Figure 2 
itself $\pi_{1}^{*}$, note that if it offers the schedule $\tau_{12}^{\epsilon}\left(q_{12}\right)=\left(c_{2}-\epsilon\right) q_{12}$ for all $\mathrm{q}_{12}$ to $\mathrm{D}_{2}$, where $\epsilon$ is small, $\mathrm{D}_{2}$ will never buy from $U_{2}$ (who makes no money-losing offer) and has reaction curve $R_{2}^{\epsilon}(\cdot)$ converging uniformly to $R_{2}(\cdot)$ when $\epsilon$ tends to 0 . Thus, as $\epsilon$ tends to 0 , the Nash equilibrium when $t_{12}^{\epsilon}(\cdot)$ is offered to $D_{2}$ by $U_{1}$ converges to $\left(q_{1}^{*}, q_{2}^{*}\right)$. We thus conclude that the unique equilibrium satisfying our restrictions is the one exhibited in Proposition 2.

Partial integration $\mathrm{PI}_{2}$. Note first that market-by-market bargaining (for $\mathrm{U}_{1}$ ) implies that $\mathrm{U}_{1}$ sells $\mathrm{q}_{2}=\mathrm{R}_{1}\left(\mathrm{q}_{1}\right)$, at price $\mathrm{c}_{2} \mathrm{q}_{2}$ to $\mathrm{D}_{2}$. Second, we claim that $\mathrm{q}_{1} \geq \mathrm{R}_{1}\left(\mathrm{q}_{2}\right)$. Otherwise, $\mathrm{U}_{1}$ would put $\mathrm{D}_{1}$ on its reaction curve $\mathrm{R}_{1}\left(\mathrm{q}_{2}\right)$ (again, we invoke market-by-market bargaining). Furthermore $q_{1}=R_{1}\left(q_{2}\right)$ if $q_{21}=0$. We thus conclude that either $q_{1}=q_{2}=q^{*}$ and $U_{1}$ supplies $q^{*}$ at price $\mathrm{c}_{2} \mathrm{q}^{*}$ to both $\mathrm{D}_{1}$ and $\mathrm{D}_{2}$, or $\mathrm{q}_{1}>\mathrm{q}^{*}>\mathrm{q}_{2}$ and $\mathrm{q}_{21}>0$. Uniqueness under $\mathrm{M}_{\mathrm{u}}, \mathrm{M}_{\mathrm{d}}$ and $\mathrm{M}_{\mathrm{ud}}$ is straightforward.

Q.E.D.

\section{Appendix 3: Exclusive Dealing}

We analyze exclusive dealing in the context of the model of Section 3. We solve the ex-ante stage with deterministic costs under exclusive dealing (ED) in order to point to the essential difference between ED and vertical integration as means of foreclosing markers. In our model, ED allows an upstream firm $\left(U_{1}\right.$, say) to commit not to supply $D_{2}$.

In a nutshe11, ED has two drawbacks and one advantage relative to vertical integration. It dominates vertical integration in that it allows firms to remain independent and avoids the incentive loss E. The first drawback, which we will not study but could be represented by a constant loss 
$\mathrm{K}$ given our constant returns-to-scale-assumption, is associated with the loss of gains from trade between the upstream firm $U_{1}$ and third parties (firms outside the industry). Such a loss occurs if either shipments by $\mathrm{U}_{1}$ cannot be monitored by $D_{1}$ or if arbitrage between third parties and $D_{2}$ cannot be prevented; then the only credible way for $U_{1}$ to cease trading with $D_{2}$ is if $\mathrm{U}_{1}$ promises not to trade with anybody but $\mathrm{D}_{1}$. Second, and more importantly from the point of view of our model, ED implies production inefficiency. Precisely when $U_{1}-D_{1}$ gain by foreclosing the market $\left(c_{1}<c_{2}\right)$, ED forces $D_{2}$ to buy from the high-cost supplier. Hence, under ED, $\left(\mathrm{U}_{1}-\mathrm{D}_{1}\right)$ loses the profit $\left(c_{2}-c_{1}\right) q_{2}^{*}$ obtained by selling $q_{2}^{*}$ to $D_{2}$. Thus, ignoring the cost $k$ of not trading with third parties (for example, there exists no third party), the total profit of $U_{1}$ plus $D_{1}$ when $c_{1} \leq c_{2}$ is:

$$
V^{E D}\left(c_{1}, c_{2}\right)=r\left(q_{1}^{*}, q_{2}^{*}\right)-c_{1} q_{1}^{*} \quad \text { under ED }
$$

and

$$
V^{P I}\left(c_{1}, c_{2}\right)-E=V^{F I}\left(c_{1}, c_{2}\right)-E=r\left(q_{1}^{*}, q_{2}^{*}\right)-c_{1} q_{1}^{*}+\left(c_{2}-c_{1}\right) q_{2}^{*}-E \quad \begin{aligned}
& \text { under vertical } \\
& \text { integration. }
\end{aligned}
$$

Now, suppose that costs are deterministic and that $c_{1} \leq c_{2}$. Propositions 3 and 4 imply that $\left(U_{2}-D_{2}\right)$ have no incentive to integrate whether $U_{1}$ and $D_{1}$ are integrated or not. It is easy to see that $U_{2}$ and $D_{2}$ have no incentive to sign an ED contract either. Assuming no exit occurs, the only possible industry structures are $N I, \mathrm{PI}_{1}$, and $\mathrm{ED}_{1}$ ( $\mathrm{ED}$ contract between $\mathrm{U}_{1}$ and $\mathrm{D}_{1}$ ). The optimal choice for $\left(\mathrm{U}_{1}-\mathrm{D}_{1}\right)$ between these three structures is given by:

Proposition B: Consider the deterministic case in which there are no investments and thus exit does not occur. Assuming $c_{1}<c_{2}$, 
either of the three possible industry structures NI, PI and $E D_{1}$ may be optimal for $\left(U_{1}-D_{1}\right)$, and thus arise. In particular: If $c_{2}$ is close to $c_{1}$, NI is preferred to $E D_{1}$ by $\left(\mathrm{U}_{1}-\mathrm{D}_{1}\right)$ if the demand function is linear.

(ii) If $c_{2}$ is much larger than $c_{1}, E D_{1}$ is preferred to NI.

(iii) If $\mathrm{E}$ is small, $\mathrm{PI}_{1}$ dominates both $\mathrm{NI}$ and $\mathrm{ED}_{1}$.

(iv) If $E$ is large, $P I_{1}$ is dominated by both $N I$ and $E D_{1}$.

Proof: (i) Note that $V^{E D}\left(c_{1}, c_{1}\right)=U^{N I}\left(c_{1}, c_{1}\right)+D^{N I}\left(c_{1}, c_{1}\right)$, so $\left(U_{1}-D_{1}\right)$ is indifferent between NI and $E D_{1}$ in the symetric case. Raising $c_{2}$ above $C_{1}$, we obtain from the envelope theorem:

$$
\frac{\partial v^{E D}}{\partial c_{2}}=\frac{\partial r}{\partial q_{2}} \frac{\partial q_{2}^{*}}{\partial c_{2}}=P^{\prime}\left(q_{1}^{*}+q_{2}^{*}\right) q_{1}^{*} \frac{\partial q_{2}^{*}}{\partial c_{2}}
$$

while

$$
\frac{\partial\left(U^{N I}+D^{N I}\right)}{\partial c_{2}}=R_{2}\left(q^{*}\left(c_{1}\right)\right) .
$$

Because at $c_{2}=c_{1}, q^{*}\left(c_{1}\right)=R_{1}\left(q_{2}^{*}\right)=R_{2}\left(q^{*}\left(c_{1}\right)\right)$, for linear demand one has

$$
\left.\frac{\partial v^{E D}}{\partial c_{2}}\right|_{c_{2}=c_{1}}<\left.\frac{\partial\left(U^{N I}+D^{N I}\right)}{\partial c_{2}}\right|_{c_{2}=c_{1}}
$$

(ii) Fixing $c_{1}$, define $\bar{c}_{2}$ as the lowest value of $c_{2}$ such that $q_{2}^{\ddot{*}}\left(c_{2}, c_{1}\right)=0$. For $c_{2} \geq \bar{c}_{2}$, ED 1 allows $U_{1}-D_{1}$ to obtain the monopoly profit $\pi^{m}\left(c_{2}\right)$, while $\left(U^{N I}\left(c_{1}, c_{2}\right)+D^{N I}\left(c_{1}, c_{2}\right)\right)$ is bounded away from this monopoly profit (see Proposition 1). 
(iii) It suffices to show that $\left(U_{1}-D_{1}\right)$ strictly prefers vertical integration for $E=0$ (by continuity, this will also hold for E smal1). That PI strictly dominates $N I$ for $\left(U_{1}-D_{1}\right)$ when $E=0$ results from Proposition 2. And $V^{P I}\left(c_{1}, c_{2}\right)=V^{E D}\left(c_{1}, c_{2}\right)+\left(c_{2}-c_{1}\right) q_{2}^{*}$ implies that $P_{1}$ dominates $E D_{1}$ when $E=0$ (for $c_{2}<\bar{c}_{2}$; for $c_{2} \geq \bar{c}_{2}, E D_{1}$ and $P I_{1}$ are equivalent if $E=0$ ).

(iv) Trivial ( $E$ is incurred only under vertical integration).

Q.E.D.

\section{Appendix 4 :}

\section{Proof of Proposition $\underline{5}$}

(ii): Proposition 5 is trivial in case (ii). From Propositions 1

through 4, the gain from integration occurs when $c_{i}=c$ and $c_{j}=+\infty$, which has a higher probability for $i=1$ than for $i=2$.

(i): To prove the Proposition for small uncertainty, we first show that $g\left(c_{i}, c_{j}\right)$ is decreasing in $c_{i}$ and increasing in $c_{j}$. Using the definition of $g\left(c_{i}, c_{j}\right)$ and the envelope theorem, we have (for $\left.c_{i}<c_{j}\right)$ :

$$
\frac{\partial g\left(c_{i}, c_{j}\right)}{\partial c_{j}}=P^{\prime}\left(q_{i}^{*}+q_{j}^{*}\right) q_{i}^{*} \frac{\partial q_{j}^{*}}{\partial c_{j}}+q_{j}^{*}+\left(c_{j}-c_{i}\right) \frac{\partial q_{j}^{*}}{\partial c_{j}}-R_{j}\left(q^{-2}\left(c_{i}\right)\right) .
$$

In particular, because $q_{j}^{\ddot{n}}(c, c)=R_{j}\left(q^{\not{k}}(c)\right)$,

$$
\frac{\partial g\left(c_{i}, c_{j}\right)}{\partial c_{j}} \mid c_{j}=c_{i}=P^{\prime}\left(2 q^{*}\left(c_{i}\right)\right) q^{*}\left(c_{i}\right) \frac{\partial q_{j}^{*}}{\partial c_{j}}>0
$$


Hence, $g\left(c_{i}, c_{j}\right)$ is increasing in $c_{j}$ for small uncertainty. Next, we have

$$
\begin{aligned}
\frac{\partial g\left(c_{i}, c_{j}\right)}{\partial c_{i}} & =-q_{i}^{*}-q_{j}^{*}+\left[p^{\prime}\left(q_{i}^{*}+q_{j}^{*}\right) q_{i}^{*}+\left(c_{j}-c_{i}\right)\right] \frac{\partial q_{j}^{*}}{\partial c_{i}} \\
& =\left[2 P^{\prime}\left(2 q^{*}\left(c_{i}\right)\right) q^{*}\left(c_{i}\right) \frac{d q^{*}}{d c_{i}}-2 q^{*}\left(c_{i}\right)-P^{\prime}\left(q^{*}\left(c_{i}\right)+R_{2}\left(q^{*}\left(c_{i}\right)\right)\right) R_{2}\left(q^{*}\right) \frac{d q^{*}}{d c_{i}}\right] .
\end{aligned}
$$

In particular,

$$
\frac{\partial g\left(c_{i}, c_{j}\right)}{\partial c_{i}} \mid c_{i}=c_{j}=p^{\prime}\left(2 q^{*}\left(c_{i}\right)\right) q^{*}\left(c_{i}\right)\left(\frac{\partial q_{j}^{*}}{\partial c_{i}}-\frac{d q^{*}\left(c_{i}\right)}{d c_{i}}\right)<0,
$$

$\operatorname{as} \frac{\partial \mathrm{q}_{j}^{*}}{\partial c_{i}}-\frac{d q^{*}\left(c_{i}\right)}{d c_{i}}>0$

Last, we note that if $\frac{\partial g}{\partial c_{i}}<0$ and $\frac{\partial g}{\partial c_{j}}>0$, then $G\left(F_{i}, F_{j}\right)>G\left(F_{j}, F_{i}\right)$ if $F_{i}$ first-order stochastically dominates $F_{j}$. Because $\frac{\partial g}{\partial c_{j}}>0, G\left(F_{i}, F_{j}\right)>$ $G\left(F_{i}, F_{i}\right)$. And because $\frac{\partial g}{\partial c_{i}}<0, G\left(F_{i}, F_{i}\right)>G\left(F_{j}, F_{i}\right)$.

\section{Appendix 5 :}

\section{Proof of $\underline{\text { Proposition }} \underline{6}$}

The inequality in Proposition 6 is an equality in the large uncertainty case. $U_{i}$ and $D_{i}$ might suffer from integration by $U_{j}$ and $D_{j}$ only if $c_{i}=+\infty$ and $c_{j}=c$ (see Propositions 1 through 4). But in this $\operatorname{case~} D_{i}^{N I}(+\infty, c)=0$ anyway. 
Consider next small uncertainty: As in Proposition 5, our strategy is to show that $\ell\left(c_{i}, c_{j}\right)$ is decreasing in $c_{j}$ and increasing in $c_{i}$ for $c_{i}>c_{j}$ We have

$$
\frac{\partial \ell\left(c_{i}, c_{j}\right)}{\partial c_{j}}=P^{\prime}\left(R_{i}\left(q^{*}\left(c_{j}\right)\right)+q^{*}\left(c_{j}\right)\right) R_{i}\left(q^{*}\left(c_{j}\right)\right) \frac{d^{*}\left(c_{j}\right)}{d c_{j}}-P^{\prime}\left(q_{i}^{*}+q_{j}^{*}\right) q_{i}^{*} \frac{\partial q_{j}^{*}}{\partial c_{j}} .
$$

At $c_{j}=c_{i}:$

$$
\left.\frac{\partial \ell\left(c_{i}, c_{j}\right)}{\partial c_{j}}\right|_{c_{i}=c_{j}}=p^{\prime}\left(2 q^{*}\left(c_{j}\right)\right) q^{*}\left(c_{j}\right)\left(\frac{d q^{*}\left(c_{j}\right)}{d c_{j}}-\frac{\partial q_{j}^{*}}{\partial c_{j}}\right)<0,
$$

as $\frac{d q^{2}}{d c}-\frac{\partial q_{j}^{x_{j}}}{\partial c_{j}}>0$ (as is easily seen on a diagram). Hence, in the small uncertainty case, $\ell\left(c_{i}, c_{j}\right)$ is decreasing in $c_{j}$. Next,

$$
\left.\frac{\partial \ell\left(c_{i}, c_{j}\right)}{\partial c_{i}}\right|_{c_{i}=c_{j}}=-R_{i}\left(q^{*}\left(c_{j}\right)\right)+q_{i}^{*}-p^{\prime}\left(q_{i}^{*}+q_{j}^{*}\right) q_{i}^{*} \frac{\partial q_{j}^{*}}{\partial c_{i}} .
$$

In particular:

$$
\left.\frac{\partial \ell\left(c_{i}, c_{j}\right)}{\partial c_{i}}\right|_{c_{i}=c_{j}}=-p^{\prime}\left(2 q^{*}\left(c_{j}\right)\right) q^{*}\left(c_{j}\right) \frac{\partial q_{j}^{*}}{\partial c_{i}}>0 .
$$

Hence, $\ell\left(c_{i}, c_{j}\right)$ is increasing in $c_{i}$ in the case of small uncertainty. Last, if $\frac{\partial \ell}{\partial c_{j}}<0, I\left(F_{1}, F_{2}\right)<L\left(F_{1}, F_{1}\right)$. And because $\frac{\partial \ell}{\partial c_{i}}>0, L\left(F_{1}, F_{1}\right)<$ $L\left(F_{2}, F_{1}\right)$. 


\section{Proof of Proposition 9}

(i) In the case of large uncertainty:

$$
u_{j}^{M}=\alpha_{j}\left(1-\alpha_{i}\right) \pi^{m}(c)>u_{j}^{P I}=\alpha_{j}\left(1-\alpha_{i}\right)\left(2 \pi^{d}(c)\right),
$$

where $\pi^{d}(c) \equiv r\left(q^{*}(c), q^{*}(c)\right)-c q^{*}(c)$ and $\pi^{m}(c) \equiv \max \{r(q, 0)-c q\}$.

(ii) Suppose that $c_{j} \leq c_{i}$. Then

$$
\begin{aligned}
& U^{P I}\left(c_{j}, c_{i}\right)-U^{M} d\left(c_{j}, c_{i}\right)= \\
& 2\left[r\left(q^{*}\left(c_{j}\right), q^{*}\left(c_{j}\right)\right)-c_{j} q^{*}\left(c_{j}\right)\right]-2\left[r\left(R_{i}\left(q^{*}\left(c_{j}\right)\right), q^{*}\left(c_{j}\right)\right)\right. \\
& \left.-c_{i} R_{i}\left(q^{*}\left(c_{j}\right)\right)\right]-\left[\pi^{m}\left(c_{j}\right)-\pi^{m}\left(c_{i}\right)\right] .
\end{aligned}
$$

Keeping ${ }^{c}{ }_{j}$ constant, let us take the derivative of this expression with respect to $c_{i}$ at $c_{i}=c_{j}:$

$$
\left.\frac{\partial\left(U^{P I}\left(c_{j}, c_{i}\right)-U^{M} d\left(c_{j}, c_{i}\right)\right)}{\partial c_{i}}\right|_{c_{i}=c_{j}}=2 q^{*}\left(c_{j}\right)-q^{m}\left(c_{j}\right)>0,
$$

(where we use the fact that in a symmetric Cournot equilibrium, total output exceeds the monopoly output). But $U^{P I}\left(c_{j}, c_{i}\right)=u^{M}{ }^{M}\left(c_{j}, c_{i}\right)=0$ for $c_{j} \geq c_{i}$. Hence, $U^{P I}\left(c_{j}, c_{i}\right)>U^{M}\left(c_{j}, c_{i}\right)$ for $c_{j}<c_{i}$ and $\left(c_{i}-c_{j}\right)$ small, which proves the result in the case of small uncertainty. 
War of Attrition and Preemption in the Merger Game in the Ex-Post Monopolization Variant.

We assume large downstream investments $\left(D_{2}^{\mathrm{PI}}<\mathrm{J}\right.$ ) (and small upstream investments so as to focus on downstream monopolization) and show that two polar cases of merger dynamics, war of attrition and preemption, may arise. The point is that if uncertainty is large, a low-cost upstream firm is a monopolist when its rival's cost is high. The low-cost firm's problem is then to commit not to supply both downstream firms. One possibility for commitment is that the low-cost supplier is integrated. Another is that one of the downstream firms has exited. The upstream firm then benefits from downstream monopolization and does not want to rescue a failing downstream firm (Proposition 9). In this respect ex-ante monopolization by vertical integration resembles a public good. Both upstream firms benefit from it, and each firm prefers the other to trigger downstream exit and incur the integration cost. This suggests the possibility of a war of attrition between the upstream firms. There is a second consideration, however. When both upstream firms costs are low the remaining buyer following ex-ante monopolization enjoys a monopoly profit on the product market. Obviously, each downstream firm would like to be the one that enjoys this monopoly profit, which suggests that the merger game might resemble a game of preemption. We show by means of symmetric examples that there is indeed a conflict between these two effects. In the relevant range for the integration cost, firms will wage a war of attrition if the integration cost 
is high, and will try to preempt each other if the integration cost is low, resulting in late and early vertical integration respectively.

\section{The Case of Symmetric, large uncertainty}

Consider, in the ex-post monopolization variant, a slight modification of the symmetric, large uncertainty case. Let $c_{i}=c$ with probability $\alpha$ and $c^{\prime}$ with probability $(1-\alpha)$. Before, we assumed that $c^{\prime}=+\infty$. Let us assume that $c^{\prime}$ is slightly smaller than $\bar{c}$ where $\bar{c}$ is the smallest marginal cost such that the Cournot output of a firm with cost $\bar{c}$ facing a firm with cost $c$ is equal to zero. The purpose of having $c^{\prime}$ lower than $\bar{c}^{-}$or $+\infty$ is to allow downstream firms to suffer from integration. Let $q^{*}(c)$ denote the Cournot output when both firms have cost $c, \pi^{d}(c) \equiv r\left(q^{2^{2}}(c), q^{\dot{x}^{2}}(c)\right)-c q^{*}(c)$ denote the Cournot profit, and $\pi^{m}(c) \equiv \max \{r(q, 0)-c q\}$ denote the monopoly profit. In

this symmetric example, we drop the subscripts under the expected profit functions. The reader will easily check that the expected profits are:

NI: $\quad U^{N I}=\alpha(I-\alpha) 2\left(\pi^{d}(c)-D^{N I}\left(c, c^{\prime}\right)\right)$

$$
\mathcal{D}^{N I}=\alpha^{2} \pi^{\mathrm{d}}(\mathrm{c})+(1-\alpha)^{2} \pi^{\mathrm{d}}\left(\mathrm{c}^{\prime}\right)+2 \alpha(1-\alpha) D^{N I}\left(c, c^{\prime}\right)
$$

$M_{d}: v^{M}=\alpha \pi^{m}(c)+(1-\alpha) \pi^{m}\left(c^{\prime}\right)$

$$
u^{M} d=\alpha(1-\alpha)\left(\pi^{m}(c)-\pi^{m}\left(c^{\prime}\right)\right)<v^{M} d .
$$

[Partial integration is not feasible if, as we will assume, $J$ is sufficiently big. Also, full integration will not occur if $c^{\prime}$ is close to $\bar{c}$ from Propositions 9 and 10.] Because $D^{P I}\left(c, c^{\prime}\right)<D^{N I}\left(c, c^{\prime}\right)$ (from Proposition 2), for any $\alpha$, there exists $\mathrm{J}$ such that $\mathcal{D}^{\mathrm{NI}}>\mathrm{J}>\mathcal{D}^{\mathrm{PI}}=$ $\alpha^{2} \pi^{d}(c)+(1-\alpha)^{2} \pi^{d}\left(c^{\prime}\right)+\alpha(1-\alpha) D^{N I}\left(c, c^{\prime}\right)+\alpha(1-\alpha) D^{P I}\left(c, c^{\prime}\right)$. Furthermore, a merger 
implies exit of the unnerged downstream firm. Knowing that $v^{\mathrm{M} d}>u^{\mathrm{NI}}+D^{\mathrm{NI}}$, lot us choose E such that

$$
v^{\mathrm{M}} \mathrm{d}-\mathrm{E}>u^{\mathrm{NI}}+\mathcal{D}^{\mathrm{NI}}
$$

so that non integration cannot be an equilibrium of the merger game. We must further distinguish two cases:

Case 1: $\underline{v}^{{ }^{\mathrm{d}} \mathrm{d}-\mathrm{E}-\mathrm{J}}<\mathrm{u}^{\mathrm{M} \mathrm{d}}$. In this case, everybody likes ex-ante monopolization, but each would like the other to merge because the integration cost is high. Ex-ante monopolization is a "public good." While our reduced form for the merger game yields two pure strategy equilibria (" $\mathrm{U}_{1}-\mathrm{D}_{1}$ merge" and "U $\mathrm{U}_{2}-\mathrm{D}_{2}$ merge"), we argue that in this case the reduced form representation of the game is inadequate. In real time, we would expect a war of attrition. To be more precise, suppose that all payoffs are flow payoffs (as discussed in the description of the merger game), and let e denote the flow equivalent of the integration cost at rate $r: e=r E$. Case 1 can then be described by $V^{M} d-e-J$ $<u^{\mathrm{M}} \mathrm{d}$.

In the symmetric equilibrium of the war of attrition, each $\left(U_{i}-D_{i}\right)$ randomizes between integrating and not integrating at each instant conditionally on no one having merged yet. That is, if the game takes place on $[0,+\infty)$, the probability of integration by $\left(U_{i}-D_{i}\right)$ between $t$ and $(t+d t)$ conditional on no merger having yet occurred is $x d t$, where $x$ is given by

$$
x\left[\frac{u^{M} d-\left(v^{M} d-e-J\right)}{r}\right]=\left(v^{M}-e\right)-\left(u^{N I}+D^{N I}\right) .
$$

The left-hand side represents the benefits of not integrating times the per-unit of time probability that the rival integrates, and the right-hand 
side denotes the gain from monopolizing the industry. The war of attrition is shorter ( $x$ is larger) when the integration cost is larger.

Case 2: $\underline{v^{M_{d}}-E_{-J}}>u^{M_{d}}$. In this case, each firm prefers to be the one that triggers ex-ante monopolization. Again, the reduced-form representation of the merger game is not adequate. In real time, the game would resemble a preemption game and rent dissipation would occur. To see this, suppose that the game is played in continuous time, with the payoffs standing for flow payoffs (thus case 2 corresponds to $\left.\left(V^{M} d-J-U^{M} d\right) / r>E\right)$. Assume that the market "opens" at date 0 , but mergers can occur before date 0 . We claim that some $\left(U_{i}-D_{i}\right.$ ) merges at date - T (triggering $D_{j}^{\prime} s$ exit), where $T$ is such that $\left(U_{j}-D_{j}\right)$ is indifferent between preempting $\left(U_{i}-D_{i}\right)$ by merging at $-(T+\epsilon)$ and letting $\left(U_{i}-D_{i}\right)$ preempt:

$$
-E+e^{-r T}\left(\frac{v^{M} d-J-u^{M} d}{r}\right)=0.39
$$

In equilibrium, the firms' profits from ex-ante monopolization are dissipated through wasteful early integration.

${ }^{39}$ See Fudenberg-Tirole [1985] for a similar treatment in the context of the adoption of a new technology and for a full description of the equilibrium strategies. 


\section{Proof of Proposition 20}

We argued in the text that, if $\beta p(\bar{Q})\left(\bar{q}_{1}-\bar{q}_{2}\right)>E$, it is a dominant strategy for $U_{1}-D_{1}$ to merge. What is $U_{2}-D_{2}^{\prime}$ 's response? If $\beta P(\bar{Q}) \bar{q}_{2}>E$, then Propositions 16, 18 tell us that, given that $\mathrm{D}_{2}$ invests, $\mathrm{U}_{2}-\mathrm{D}_{2}$ will prefer to merge than not to merge. Hence either $U_{2}-D_{2}$ will integrate or $D_{2}$ will exit, depending on whether $P\left(\bar{Q}^{\prime}\right) \bar{q}_{2}-J-E \gtrless\left(1-\beta^{\prime}\right)\left[P(\bar{Q}) \bar{Q}-P\left(\bar{q}_{1}\right) \bar{q}_{1}\right]$ (the left-hand side of this inequality represents $U_{2}-D_{2}$ 's profits if they merge, while the right-hand side represents $\mathrm{U}_{2}$ 's profits if $\mathrm{D}_{2}$ exits; it is easy to see that if the LHS $<$ RHS, $D_{2}$ will choose to exit).

On the other hand, if $\beta \mathrm{P}(\overline{\mathrm{Q}}) \overline{\mathrm{q}}_{2}<\mathrm{E}$, then if partial integration is viable, i.e., $\beta P(\bar{Q}) \bar{q}_{2}>\mathrm{J}, \mathrm{U}_{2}-\mathrm{D}_{2}$ will not merge. However, if $\beta \mathrm{P}(\overline{\mathrm{Q}}) \overline{\mathrm{q}}_{2}<\mathrm{J}$, $\mathrm{U}_{2}$ can either let $D_{2}$ exit and make profit $\left(1-\beta^{\prime}\right)\left[P(\bar{Q}) \bar{Q}-P\left(\bar{q}_{1}\right) \bar{q}_{1}\right]$ or rescue $D_{2}$ by a merger and make profit $\mathrm{P}(\overline{\mathrm{Q}}) \overline{\mathrm{q}}_{2}-\mathrm{J}-\mathrm{E} . \mathrm{U}_{2}$ will choose whichever strategy is more profitable.

Consider next the case $\beta P(\bar{Q})\left(\bar{q}_{1}-\bar{q}_{2}\right)<E$. Now $U_{1}-D_{1}$ 's decision to merge will depend on $U_{2}-D_{2}^{\prime}$ s response. A comparison of $V_{1}^{F I}$ and $\left(U_{1}^{N I}+D_{1}^{N I}\right)$ shows that, given $(6.5), U_{1}-D_{1}$ will only merge if $U_{2}$ and $D_{2}$ remain separate, with $\mathrm{D}_{2}$ possibly exiting. In fact we know from (6.2) that $\mathrm{D}_{2}$ 's exiting is a sufficient condition for $U_{1}-D_{1}$ to merge. On the other hand, if $\mathrm{D}_{2}$ remains independent and continues to invest, $U_{1}-D_{1}$ will merge if and only if $\beta \mathrm{P}(\overline{\mathrm{Q}}) \overline{\mathrm{q}}_{1}>\mathrm{E}$, since this guarantees that $\left(\mathrm{U}_{1}-\mathrm{D}_{1}\right)$ 's profits are higher under partial integration than under nonintegration. This yields Case (C). Q.E.D. 
Allen, B. [1971] "Vertical Integration and Market Foreclosure: The Case of Cement and Concrete," Journal of Law and Economics, 14, 251-274.

Areeda, P. and H. Hovenkamp [1987] Antitrust Law, supplement, Boston: Little Brown and Co.

Bork, R. [1978] The Antitrust Paradox, New York: Basic Books.

Comanor, W. and H. Frech [1985] "The Competitive Effects of Vertical Agreements," American Economic Review, 75, 539-46.

Federal Trade Commission [1966] Economic Report on Mergers and Vertical Integration in the Cement Industry, Washington, DC: Federal Trade Commission.

Fershtman, C. and K. Judd [1987] "Strategic Incentive Manipulation and the Principal-Agent Problem," Mimeo, Northwestern University.

Fudenberg, D. and J. Tirole [1985] "Preemption and Rent Equalization in the Adoption of New Technology," Revien of Economic Studies, 52: 383-401.

Grossman, S. and O. Hart [1986] "The Costs and Benefits of Ownership: A Theory of Vertical and Lateral Integration," Journal of Political Economy, 94: 691-719.

Hart, 0. [1989] "An Economist's Perspective on the Theory of the Firm," Columbia Law Review, Vol.89(7):1757-1774.

Hart, O. and J. Moore [1988] "Property Rights and the Nature of the Firm," Journal of Political Economy, forthcoming.

Holmström, B. and J. Tirole [1989a] "The Theory of the Firm," in The Handbook of Industrial Organization, R. Schmalensee and R. Willig, eds., North-Holland.

Holmström, B. and J. Tirole [1989b] "Corporate Control and the Monitoring Role of the Stock Market," Mimeo, Yale University.

Katz, M. [1987] "Game-Playing Agents: Contracts as Precomitments," Mimeo, U.C. Berkeley.

Klein, B., R. Crawford, and A. Alchian [1978] "Vertical Integration Appropriable Rents and the Competitive Contracting Process," Journal of Law and Economics, 21: 297-326.

Mathewson, F. and R. Winter [1986] "Is Exclusive Dealing Anticompetitive?", Mimeo, University of Toronto.

Ordover, J., G. Saloner, and S. Salop [1990] "Equilibrium Vertical Foreclosure," American Economic Review, 80:127-142. 
Peck, M. and J. McGowan [1967] "Vertical Integration in Cement: A Critical Examination of the FTC Staff Report," Antitrust Bulletin, 12, 505-531.

Posner, R. and F. Easterbrook [1981] Antitrust: Cases, Economic Notes and Other Materials, West Publishing Co.

Riordan, M. [1989] "Ownership without Control: Towards a Theory of Backward Integration," Mimeo, Boston University.

Salinger, M. [1988] "Vertical Mergers and Market Foreclosure," Quarterly Journal of Economics, 103: 345-356.

Salop, S. and D. Scheffman [1983] "Raising Rivals' Costs," American Economic Review, Papers and Proceedings, 73: 267-271.

Selten, R. [1975] "Reexamination of the Perfectness Concept for equilibrium Points in Extensive Games", International Journal of Game Theory, 4, $25-55$.

Schwartz, M. [1987] "The Competitive Effects of Vertical Agreements: Comment," American Economic Review, Vol. 77(5).

Tirole, J. [1988] The Theory of Industrial Organization, Cambridge: MIT Press.

Williamson, 0. [1975] Markets and Hierarchies: Analysis and Antitrust Implications, New York Free Press.

Williamson, 0. [1985] The Economic Institutions of Capitalism, New York: Free Press.

Wilk, D. [1968] "Vertical Integration in Cement Revisited: A Comment on Peck and McGowan," Antitrust Bulletin, 13, 619-647. 




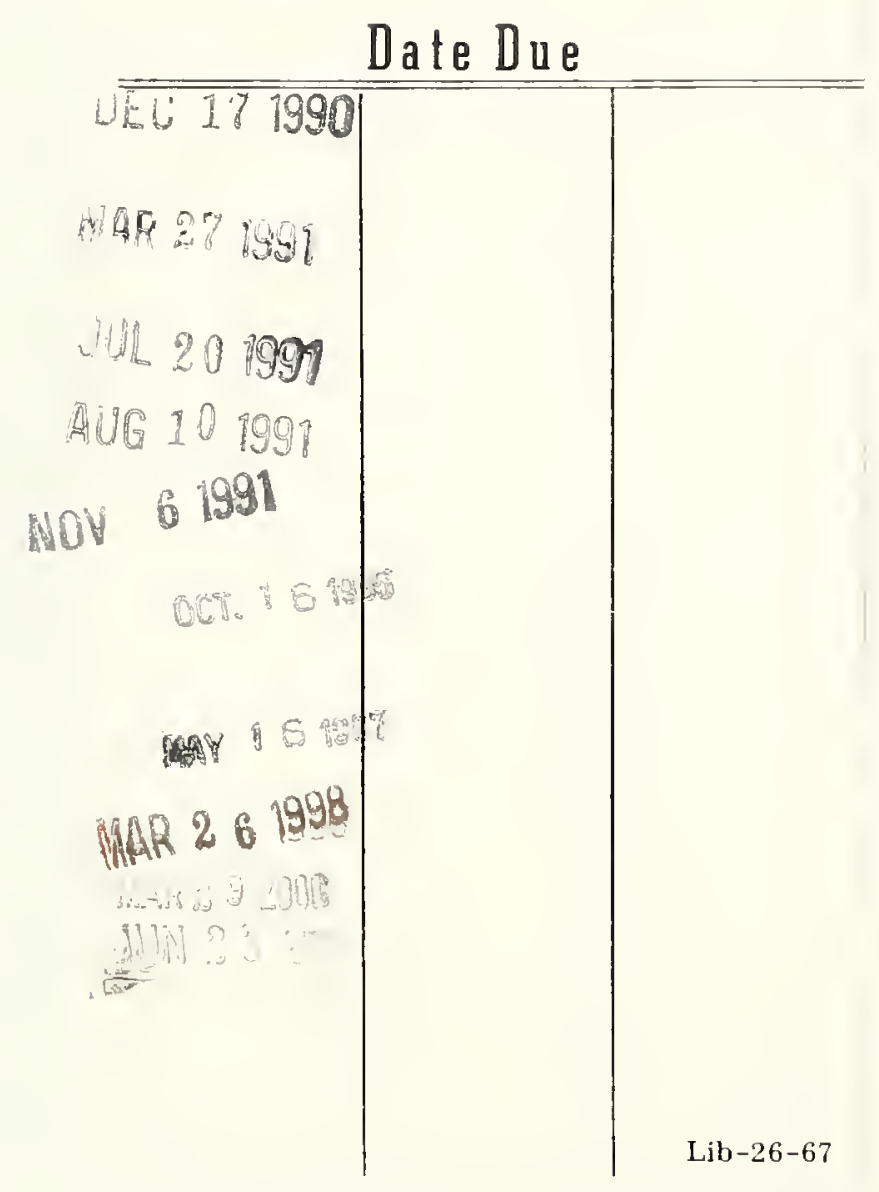




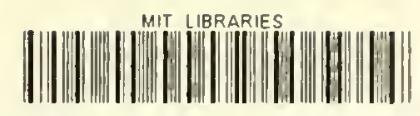

З 9080006583758 
